STUDIES

in

6. 81

AFRICAN LINGUISTIGS 
Published by the Department of Linguisties

and the African Studies Center

The Untversity or Callfornis, Ios Angeles

Editorial Board

Karen Courtenay

Baruch Blimelech

Victorla Fromkin

Peter Ladefoged

Carol Lord

Ian Maddieson

Alos1 Molo1

Thomas Penchoen

Paul Schachter

Beng1 Wald

Wililan Welmers

Joint Baitors

Talmy Givón

Thomas J. Hinnebusch
Associate Editors

Charles B1rd, Indiana

John Eulenberg, M1chigan State

Jeanette Harr1es, Wisconsin

Robert Hetzron, UCSB

Larry Hyman, Berkeley

Williem R. Leben, Stanford

A. E. Meeussen, Leiden

Russell Schuh, Kano

Herbert Stahlke, Illinois

Erhard Voeltz, Indiana

Kay Willlamson, Tbadan

Editorigl Assistance

Claudia Kessler

Alice McGaughey

Linda Sparkman

Subscription: U.S. and Canads: $\$ 7.00$ per volume (three issue)

Overseas:

$\$ 8.00$ per volume (air mail rates

available on request)

Single issue: $\$ 3.00$

Supplenent: $\quad \$ 5.00$ (if ordered separately or in beck order)

Make checks payable to: African Studies Center

Studies in African Linguistics is published three times a year. Supplements are independently financed and are sent free of charge with current subscriptions. Authors receive 50 free offprints of published articles.

For subscriptions and editorial informstion please write:

The Editors, Studies in African Lineustics

c/o Department of Lingulstics

University of California

Los Angeles, California 90024

Volume 5, Number 1, March 1974

Copyright 1974

By the Regents of the UnIversity of Callfornia 


\author{
STUDILS IN AFRICAN LINGUISTICS \\ Volume 5, Number 1 \\ March, 1974
}

TABLE OF CONTENTS

\title{
Art1cles
}

J1lal1 SeIb, GBMINATION AND SPIRANTIZATION IN BERBER:

DIACHRONY AND SYHCHRONY ................ 1

Fritz Ponel1s, ON THE DYNAMICS OF VELARIZATION AND

LABIALIZATION: SOME BANTU EVIDENCE . . . . . . . . 27

David Dwyer, THE HISTORICAL DEVELOPMENT OF SOUTHWESTERN

MANDE CONSONANTS ............... 59

A. E. Meeussen, A NOTE ON GLOBAL RULES IN BANGUBANGU 'TONE. . . 95

Gayle Partmann, DHRTVATIOH AND SIMPLIFICAIION IYY ADOLESCENT DIOULA SPEAKERS ............ 101

Telmy Givón, SYNTACTIC ClLANGE IN LAkE-BANTU: A REJOINDER . . . . . $\mathrm{l} 7$

\section{Conference Reports}

COLLOQUIUM ON SUPRA-SEGMENTAL PHONOLOGY, LLEIDEN UNIVERSITY . . . . 141

FIFI'H ANNUAL CONFERENCE ON AFRICAN LINGUISTICS, STANFORD

UNIVBRSITY . . . . . . . . . . . . . . 143 



\section{GEMINATION AND SPIRANTIZATION IN BERBER: \\ DIACHRONY AND SYNCHRONY 1

\author{
Jilali Sa1b \\ Department of Linguistics \\ University of Calffornia, Los Angeles
}

\section{Introduction}

Generative phonologists have become increasingly interested in questions relating to the psychological reality of granmars. It is clear that many different grammars can account for the data (1.e. be observationally adequate) but what is being sought is the unique grammar (if there is one) which will also represent a speaker's competence (i.e. is descriptively adequate). Various constraints have been proposed to accomplish this including the strong and weak alternation conditions (cf. Kipersky [1968]), constraints on rule ordering (cf. Koutsoudss et alia [1971]; Vennemann [1973]; Hooper [1973]), markedness conventions (cf. Chomsky and Halle [1968]; Schane [1968]), etc. Th1s paper is concerned with some aspects of this question as it relates to the representation of lexical formatives in Berber granmar.

The specific questions to be considered are those raised by the morphophonemic alternation between single and geminate consonants within the Berber languages of North Africa, and the occurrence of non-strident spirants, e.g. $\theta$ and $\zeta$, which alternate with geminate stops in the Northern and Central dialects of Morocco (e.g. Tirifiyt and Tamaziyt). ${ }^{2}$

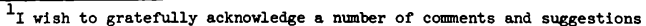
on earlier drafts of this paper (December 1971 and March 1973) by Professors Anttila, Bedell and Schuh. Speciel thanks are due to Professors Hyman, Vennemann, and most of all, to Professor Fromkin whose critical colments and insightful suggestions led me to undertake a number of revisions both in content and in style.

An abridged version of this paper was presented at the IVth Annual Conference on African Linguistics, Queens College, New York (April 1973). I wh to thank Professor Jeanette Harries, the Berberist at the University of Wisconsin, for her helpful comments and encouragements. Thanks are also due to another Berberlat, Professor $T$. Penchoen, for being so helpful in discussing some of the data.

Any errors or omissions are my sole responsibility, however.

${ }^{2}$ other Northern dialects such as Kabyle and Shawla are not included in this discussion. 
The Southern dislects (e.g. Tachelhiyt and Trareg) lack this series of non-strident spirants and exhibit instead simple stops in cognate alternating forms.

2. The Data

The simple consonant/geminate consonant alternations are 1llustrated by the following: ${ }^{3}$

(1) Tamaziyt

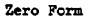

$\begin{array}{ll}\text { eçmez } & \text { cemmez } \\ \text { eymes } & \text { yemmes } \\ \text { eJnu } & \text { Jennu } \\ \text { oßnu } & \text { pennu } \\ \text { efley } & \text { felley } \\ \text { emrey } & \text { merrey } \\ \text { erżem } & \text { rezzzem } \\ \text { ens } & \text { nessa }\end{array}$

(2)

Tachelbiyt

$\begin{array}{ll}\text { bez } & \text { ebbez } \\ \text { eftel } & \text { fettel } \\ \text { ebdu } & \text { beddu } \\ \text { enzu } & \text { nezza } \\ \text { enker } & \text { nekker }\end{array}$

Glos:

$$
\begin{aligned}
& \text { 'to scratch' } \\
& \text { 'to cover' } \\
& \text { 'to sew' } \\
& \text { 'to bulld' } \\
& \text { 'to tear' } \\
& \text { 'to rub' } \\
& \text { 'to open' } \\
& \text { 'to wear' }
\end{aligned}
$$

'to peel"

'to roll couscous'

'to start'

'to be sold'

'to get up'

The examples under (1) and (2) are merely 1llustrative of the fact that this alternation is pervasive throughout the dialects. Other examples could be cited to show that all consonants (except for the rolceless bilabial stop $p ; c f$. below) are affected. The 'zero forms' (hereafter z.F.) in the above examples represent the shape of the verb that is used in the imperative (2nd person singular). It is the simplest form in that it is the most morphologieally unmarked. The 'intensive form' (hereafter I.F.) is the imperfect (or continuous and habitual) aspect, and as Been in the examples, is a morphologically 'marked' form.

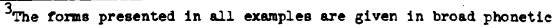
transcriptions. It should be noted that $J$ represents a volced palatal fricative, the volced counterpart of $\zeta$, and $a$ represents a schva. A dot under a consonant indicates that the consonant is pharymgealized.
} 
In the Southern dialects (Tachelpiyt and Twareg) the only apparent exceptions to the alternations between simple consonants and 1dentical geminates are the alternations $d: t t$ and $\gamma:$ q as show in $(3):{ }^{4}$

Tachelpiyt

Z.F.
ebḍu
ekd़u
nex
rey

I.F.

Gloss

rex

$$
\begin{aligned}
& \text { betfu } \\
& \text { kettu } \\
& \text { negga } \\
& \text { regga }
\end{aligned}
$$

$$
\begin{aligned}
& \text { 'to divide' } \\
& \text { 'to smell' } \\
& \text { 'to kill' } \\
& \text { 'to be varm' }
\end{aligned}
$$

These cases are actually the result of a very general rule applying to simple and geminate pharyngealized consonants; the simple pharyngeals are voiced and the geminates always volceless. The consonants symbolized as $\gamma$ and $q$ are pharyngealized velars (or uvulars). The rule is simple (assume for now that the underlying segment is non-geminate, an assumption which will be justified below):

$$
\left[\begin{array}{l}
\text { tconsonantal } \\
\text { +pharyngealized }
\end{array}\right] \rightarrow \text { [+voiced]/ } \mathrm{X} \text { : where } \mathrm{x} \neq \text { identical } \mathrm{C}
$$

Using Bach's neighborhood convention (cf. Bach [1968]), this rule states that a pharyngealized consonant is voiced when the preceding or following segment is not identical to it.

One problem, then, to be accounted for in synchrontc grammars of Berber dialects is this occurrence of $\mathrm{C} / \mathrm{CC}$ alternations. A second problem arises when the Central and Northern Berber dialects of Morocco are examined. These dialects have, instead of all of the above alternations, a series of non-strident apirants alternating with geminate stops. That 1s, Instead of the $t: t t$ alternation, we find $\theta: t t$. This may be 1llustrated by examples from the Nit Ndhir dialect of Tamaziyt where spirantization is particularly widespread.

\footnotetext{
"Though this paper deals with underlying representation, I will not concern myself with the question as to whether ney 'to kill', for instance, 1s underlying ney or eny or ny. Rather, I will give all the examples in their brosd phonetic transcription (cf. footnote 3 above).
} 
(5)

\begin{tabular}{|c|c|c|c|c|}
\hline \multirow[b]{2}{*}{$t: t f$} & \multicolumn{2}{|l|}{ Z.F. } & \multirow{2}{*}{$\begin{array}{c}\text { I.F. } \\
\text { neffeŏ }\end{array}$} & \multirow{3}{*}{$\begin{array}{l}\text { Gloss } \\
\text { 'to throb' } \\
\text { 'to dip' }\end{array}$} \\
\hline & enfeọ̆ & $:$ & & \\
\hline & erfes & : & reffeş & \\
\hline$\beta: b b$ & en $\beta e^{x}$ & : & nebbes & 'to be nosy' \\
\hline & erpel & : & rebbel & 'to ramble' \\
\hline \multirow[t]{2}{*}{$\theta: t t$} & efteel & : & fettel & 'to roll couscous' \\
\hline & entel & : & nettel & 'to hide' \\
\hline \multirow[t]{2}{*}{$\delta: d d$} & eß̧̆u & & Beddu & 'to start' \\
\hline & enŏu & & neddu & 'to become buttermilk' \\
\hline \multirow[t]{2}{*}{$\Phi: t t$} & erơ̆el & : & reftel & 'to loan' \\
\hline & eßర̣u & : & Bettu & 'to divide' \\
\hline \multirow[t]{2}{*}{$j: g g$} & jen & : & eggan & 'to sleep' \\
\hline & erjem & : & reggem & 'to insult' \\
\hline \multirow[t]{2}{*}{$r: q q$} & ner & $:$ & neqqa & 'to kill' \\
\hline & rey & : & reqqa & 'to be varn' \\
\hline
\end{tabular}

Some additional facts should be noted prior to a discussion of the historical processes which gave rise to these alternations and dialect differences and to the discussion of how best to account for these facts in Berber synchronic grammars. Of particular interest is the fact that in no dialect do we find $a$ P or PP (an exception is the baby talk word pappa 'bread'). This non-occurrence of the voiceless bilabial stop is also found in other languages in the area (Arabic, Hausa, Somali etc.) where only a two-way labial obstruent contrast is found, usually between $b$ and $f$; nelther $P$ nor $v$ occurs. In addition, as noted above, the non-geminate pharyngealized consonants are automatically voiced. Furthermore, they are epirantized in Northern dialects as shown in (6):

(6) Tamaziyt (NIt Nahir)

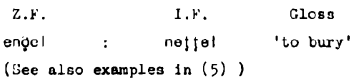


Finally, the spirant alternants of the geminates $k k$ and $g g$ are the palatals $\&$ and $j$ respectively in the spirantizing dialects, as seen in (7) (however, see (13), (14), (15b) below and Append1x I):

(7) Tamaziyt (Near Demnate)

$\begin{array}{ccc}\text { Z.F. } & \text { I.F. } & \text { Gloss } \\ \text { erçel } & \text { rekkel } & \text { 'to kick' } \\ \text { erçem } & \text { rekkem } & \text { 'to boll' } \\ \text { erjem } & \text { reggem } & \text { 'to insult' } \\ \text { emjer } & \text { megger } & \text { 'to harvest' }\end{array}$

This fronting may be due to the need for 'maximal differentiation' between velars and uvulars.

The question of the systematic phonemic representation of the verbs in the Ait Ndhir dialect will be considered here. Specifically the paper w1ll attempt to resolve the problem of whether underlying forms have geminates, simple stops, or spirants. The solution to the problem has direct bearing on phonological theory. An historical account of the development of these dialect differences is relevant to the discussion and will hopefully also contribute to our understanding of historlcal change 1n general.

3. Diachronic account

It is generally accepted that historically the Berber spirants derived from atops (cf. Leoust [1918] and [1939]; Loubignac [1924]; Ren1sio [1932]; Basset [1952]). This process 1llustrates the historical 'veakening' found in many languages. In the dialect under discussion, there appears to have been no conditioning factor other than that the stop that undergoes spirantization is non-geminate. Ait Nahir shows the most complete process; other dialects show varying degrees of spirantization. Thus, for example, whlle the Ait Izdeg dialect of Tamaziyt exh1bits a number of instances of $*_{k} \rightarrow \&$ (and even $*_{k} \rightarrow \xi$ ), and " $\mathrm{g} \rightarrow \mathrm{J}$, it exhibits only a few instances of $t \rightarrow \theta$ and $d \rightarrow \partial$. This is 1llustrated in (8) (cr. Mercier's lexicon [1937]): 
(8)

Tamaziyt (Ait Izdeg)

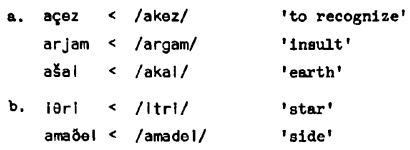

Unfortunately, the published description of many of the dialects (see references above) are so sketchy that the reader is unable to determine what sound changes are posited for which dialect. Thus, it is not possible at this time to illustrate or analyze all the inter-dependencles as, say, Foley [1969] has proposed. What is clear is that all dialects have spirantized $* p$ to $f .^{5}$

The relationship between the $p \rightarrow f$ spirantization and the other cases of spirantization is not clear-cut. This $p \rightarrow f$ change charscterizes most of the vast Afro-Asiatic family, including Arabic, Heuse, Somall and also Berber. (A similar change characterizes Jepanese, though the resultant $f$ is further modified to $h$ [Ulten 1970] .) This change may have triggered the chain of subsequent spirantizations that characterize many Berber dialects. But, it is clear that this change is separated Prom the other spirantizations by a considerable period of time. ${ }^{6}$

Also, it should be noted that the other Afro-Aslatic languages do not spirantize as does Berber. Furthermore, in Berber, the " $p \rightarrow f$ change is unlike the other changes in that it affects the geminates as well as the non-geminates; there is no Berber dialect where single $f$ alternates with pt which might be assumed as an intermediate step. Thus, all Berber dialects reflect the historical context-free rule (9):

${ }^{5}$ Th1s is assuming that Proto-Berber 1ndeed had a *p.

6 Borrowings with $p$ from Latin are rendered with $f$, even in Tachelhiyt, a non-spirantizing dialect. E.g. Latin pullus > Tachelipiyt afullus 'chicken'. Yet, just as in native Tachelpiyt morphemes, other stops remain unchanged in loan-words from Letin, e.g. Latin hortus > Tachelhiyt urtu 'garden'. The Romans ostablished their direct rule over Eastern North Africa shortly after the third Punle War. Parts of Moroceo were colonized by the Romans from around 42 A.D. until the Arabic invasions (end of the seventh century, A.D.). 
(9) $p>f$

Moreover, the spirantizine dialects reflect additional historical rules resulting in the alternations: $c_{f}^{1}: c_{g}^{2}$ (where $c_{f}^{1}=a$ single spirant and $\mathrm{C}_{s}^{2}=a$ geminate stop).

Other than the voiceless lablal spirantization, the only spirantization attested in all the Berber dialects I have investigated concerns the uvulars: all dialects appear to have a simple $y$ which alternates with qq.$^{7}$ Dialects such as Tachelniyt and Twareg, then, have only two cases of spirantization: $f: f f$ and $y: q 9,{ }^{8}$ as shown in (10).

\section{Tachelhiyt}

$$
\begin{array}{cl}
\text { Z.F. } & \text { I.F. } \\
\text { ney : neqqa } \\
\text { rey : reqqa } \\
\text { esfed : seffed }
\end{array}
$$

Twareg 9

$$
\begin{array}{ll}
\text { Z.F. } & \text { I.F. Gloss } \\
\text { eny : negg (naqq) } & \text { 'to kill' } \\
\text { ery : reqq (raqq) } & \text { 'to be warm' } \\
\text { sfed : seffed } & \text { 'to wipe' }
\end{array}
$$

Since the * $p$ was presumably lost at an earlier period, possibly when this occurred in other Afro-Asiatic languages, and since at one stage speakers would hear only $f$ and $f f$, this spirantization does not provide a viable model for stop/spirant alternations. We can hypothesize that the first spirantization in the later chain of historical development is an uvular pair. It is this pair, then, which may have triggered the rest, if triggering did indeed occur. It is, of course, possible

\footnotetext{
There are few instances of $Y Y$ however, e.g. ayyu 'buttermilk', taypatt 'goat', etc.

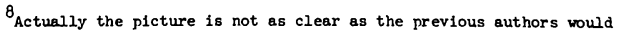
like us to believe. Spirantization is slowly spreading southwards. In 1971 I personally observed the spirantization of ${ }^{*} k \rightarrow q$ and $* g \rightarrow$ $j$ in the speech of a Berber from around Demnate. Doyle llatt (personal communication) found this to be true of speakers of Tachelhiyt, and Russell Schuh (personal communication) observed the same trends in the speech of some Twaregs. However, until a thorough investigation of this apread is done, I will assume only the two cases of spirantization illustrated in (10) for Tachelhiyt and Twareg.

9The Twareg data, taken from Basset [1929], are reproduced here in their original transcription ( $r$. also footnote 4 ).
} 
that each spirantization took place independently of the others when it was 'due' on the strength scale (Vennemann, personal communication).

Another indication that the labial change had little influence on subsequent spirantization is the relatively rare occurrence of $\beta$ in Berber. There are some dielects that show an alternation between $\beta$ and bb, but in many dialects the picture is one of general spirantization of single stops except for the labial bo. Thus, in addition to the spirantization problem, there is a labial problem. That is, whereas other places of articulation permit a four way contrast (e.g. alveolar obstruents $t, d, s$ and $z$ ) the lebial position seems to permit only a two-way obstruent contrast between $f$ and $b$. There appears to be some force in the langugge that strives to maintain this pattern.

A final case of historical change to be consicered here is that of the fronting of the velars $k$ and $g$. The spirantized realizations of these segments pose seversl questions. First of all, the expected spirants are $\&$ and $j$, which are, in fact, widely attested in present day Berber dielects. However, some dielects have further modified these to $\xi$ and $\xi$ wile in other verbs the alternations are between $\xi \xi \xi$, $\xi \xi$ and $\xi$, respectively as show in the following examples.

(11) Tamszipt (Aït Ndhir) 10

\begin{tabular}{|c|c|c|c|}
\hline \multirow[b]{2}{*}{$\mathbf{z}: \mathbf{z} \mathbf{z}$} & Z.F. & I.F. & Gloss \\
\hline & mseọ̆ & mešร̌ క̌ & 'to comb' \\
\hline & enšef & nešset & 'to scratch' \\
\hline$z:\{z z$ & eržem & režžm & 'to lapidate' \\
\hline & enžer & nežžer & 'to saw' \\
\hline
\end{tabular}

The further change from $k$ and $j$ to $\xi$ and $z$, respectively, 1 not surprising. It has often been noted that [-back, -coronal] lingual continuents often become [+strident, +coronal] (cf. German lch which

10 At first glance these forms would seem to pose a problem for the synchronic solution suggested below. However, these four verbs, borrowed from Arabic, are to my knowledge the only alternations between $\xi / \xi \xi$ and $\xi / Z z$, and are therefore outaide the main pattern. 
dialectically becomes if ). Chomaky and Ilalle [1968], claiming that $\xi$ and $z$ are less marked than $c$ and $J$, posit 'IInking rules' to account for this 'natural process'.

In Berber, however, both $\zeta$ and $\zeta$ and $J$ and $\xi$ occur in single dialects without any apparent conditioning factor. In (12) forms from Tachelpiyt and Tamaziyt are compared, in which it is seen that Tachelpiyt $k$ corresponds to Tamaziyt \& .

\begin{tabular}{|c|c|c|c|}
\hline \multirow[t]{10}{*}{ (12) } & Tachelhiyt & Temaziyt & Gloss \\
\hline & akssum & açsum & 'meat' \\
\hline & akssar & açsar & 'slope' \\
\hline & azukenni & azuçenn I & 'thyme' \\
\hline & aknuz & açuz & 'weevil' \\
\hline & akzz & $\overline{a c ̧ z z}$ & 'to remember' \\
\hline & aseksu & aseçsu & 'couscous strainer' \\
\hline & asekgsa & aseçsa & 'chick' \\
\hline & uska & usça & 'hound' \\
\hline & akgurdu & açurơu & 'kind of bug' \\
\hline
\end{tabular}

In (13), however, Tachelḥiyt $k$ corresponds with Tamazlyt š :

\begin{tabular}{|c|c|c|c|}
\hline (13) & $\begin{array}{l}\text { Tachelhiyt } \\
\text { akal }\end{array}$ & $\begin{array}{l}\text { Tamaziyt } \\
\text { așal }\end{array}$ & $\begin{array}{l}\text { Gloss } \\
\text { 'earth' }\end{array}$ \\
\hline & aknabar & ašaßar & 'caravan' \\
\hline & aknan If & ašanif & 'grill' \\
\hline & tarikgt & $\theta a r I \underline{s} \theta$ & 'saddle' \\
\hline & tanekrra & 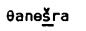 & 'awakening' \\
\hline & tiskkert & $\theta i క \underline{s} \in \operatorname{er} \theta$ & 'garlic' \\
\hline
\end{tabular}

We can see that it is not simply the case that in some dialects *k and $g$ have become $\&$ and $J$, respectively, but that in others the process is extended further to yleld $\xi$ and $z$. These dialects appear to represent "language change in progress" [Labov 1972].

In addition we also find the modification of " $g$ to the slide $Y$. The seven different realizations of Proto-Berber *agsum 'neat' as given In (14), show the changes which have occurred. These changes are all 
attested in different dialects.

$$
\begin{aligned}
& \text { agsum (Proto-Berber) } \\
& \text { a. agsum (no change) } \\
& \text { b. aksum (devoicing) } \\
& \text { c. açsum (devolcing and spirantization) } \\
& \text { d. ašsum (devolc., spir., palataliz.) } \\
& \text { e. ajsum (spirantization) } \\
& \text { f. aysum (spirantiz., glide-creation) } \\
& \text { b. ažsum (spirantiz., palatalization) }
\end{aligned}
$$

Not only do we find inconsistent historical reflexes in a single dialect, but, in addition, we find the seme inconsistencles in borrowings from Arabic, where Arabic $k$ is sometimes realized as $\&$ and sometimes as $\xi$, gain with apparently no statable conditioning factor(s):

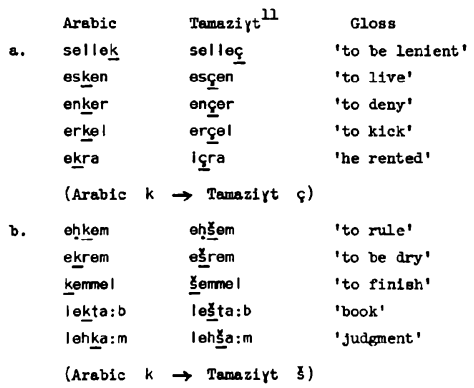

There are some borrowings from Arable which, to further complicate the problem, show phonetic $k$ :

II The Tamaziyt forms in (15a) would be representative of the tranoitionary dialects spoken near Demnate (cf. footnote 7 above). 


$\begin{array}{lll}\text { Arabic } & \text { Berber } & \text { Gloss } \\ \text { lekktatbil } & \text { akktatbi } & \text { 'secretary' } \\ \text { elhakgem } & \text { alhakem } & \text { 'Judge' }\end{array}$

We can now summarlze the historical changes which have occurred.

$$
\begin{aligned}
& \text { a. } P \rightarrow f \\
& \text { b. } q \rightarrow \gamma \\
& \text { c. } k \rightarrow \xi \rightarrow \xi \\
& \text { d. } t \rightarrow \theta \\
& d \rightarrow \delta \\
& \text { e. } t \rightarrow \text { o } \\
& \text { f. } b \rightarrow \beta
\end{aligned}
$$

4. Synchronic account

While the sumbary of the historical changes reveals the differences observed in Berber dialects and explains the alternations that now occur, the problem of how to account for the present situation is not necesserily resolved by the diachronic account.

The two major questions discussed here which must be resolved concern the representation of the sipple/geminate consonant alternations, and the stop/spirant alternations.

The examples given above (cf. (1), (2), (3) and (5) ) show the alternations between simple and geminate consonants in the Zero and Intensive Forms of the verb, respectively. Clearly, if this is a predictable regularity it can best be accounted for by positing a single phonological representation of the stems and a rule (or rules) for the alternant phonetic forms. This possibility has been denied by previous uriters like B1sson [1940] who stated: "Il faut connaftre la forme d'habitude (1.e. Intensive Form) de chaque verbe, car 11 est 1mpossible de la construire so1-mene de façon certaine (emphasis mine, J.S.)." Despite this claim,. such rules exist and can be stated so as to reveal the generalizations. For convenience sake examples of the alternations are given in (18) (cf. also (1), (2), (3) and (5) above). 
(18) Tamaziyt (Ait Ndhir)

\begin{tabular}{|c|c|c|c|}
\hline & Z.F. & I.F. & Gloss \\
\hline a. & effeel & fettel & 'to roll couscous' \\
\hline & erz̨em & rezzżem & 'to open' \\
\hline b. & ney & negga & 'to $\mathrm{kIll}$ ' \\
\hline & ons & nessa & 'to spend the night' \\
\hline c. & sey & ssay & 'to buy' \\
\hline & yer & ggar & 'to call' \\
\hline d. & ebốu & beddu & 'to start' \\
\hline & erzzu & rezzu & 'to look for' \\
\hline e. & negger & ttnegqar & 'to shake off' \\
\hline & ferrey & tt ferray & 'to pour' \\
\hline
\end{tabular}

The data in (18) show that Berber verbs behave differently with respect to the process of gemination (or lengthening) which takes place in the formation of the I.F. One pattern which emerges (from looking at the data) is that the selection of the consonant to be geminated (or lengthened) is dependent on the number of consonants in the stem of the $\mathrm{Z} . \mathrm{F}$. which is assumed here as the underlying stem. However, this leaves us with the problem of explaining the different behavior of the verbs in (18c). These verbs geminate (or lengthen) the first stem consonant instead of the second ( $f f .(18 a, b, a)) .12$ This points to a difficulty of the Berber verb system, a difficulty which may be resolved by the establishment of verb classes and the utilization of a discritic festure $\left[-G_{2}\right]$ (where $\mathrm{G}_{2}=$ gemination of second consonant) on the verbs in ( $18 \mathrm{c}$ ). This diacritic feature would prevent the gemination of the second consonant and permit gemination of $C_{1}$.

The data in (18) are handled by a set of rules which stipulates that a simple $C$ of the Z.F. becomes CC in the I.F., as well as other internal changes, such as vowel alternation, that sometimes occur. This

I2 In Twareg, which is regarded by Berberists as the most conservative Berber dialect, the tensing of the first consonant is not the exception but the norm for verbs with two consonants. 
18 assuming that the direction of the derivation 18: Z.F. $\rightarrow$ I.F. (1. the Z.F. is the underlying form).

Concelvably, one might want to take another position. On the basis of the data given in (18) one could argue that it is just as reasonable to derive the Z.F. from the I.F.: all that is taking place, according to this alternative analysis, is the loss of gemination (or length) and scme vowel alternations and deletion. There are other considerations, however, which make the derivation Z.F. $\rightarrow$ I.F. not only more motivated or more economical, but intuitively more satisfying.

A certain number of arguments--two of which I present here-can be brought forth against this alternative analysis (and hence, for the Z.P. to I.F. analysis). This is in addition to the fact that the Z.F. is the citation form, as well as the least morphologically marked one. First, the predicating power of the I.F. to Z.F. analysis is not as great as that of the Z.F. to I.F. analysis. This is 1llustrated in (19) which shows that the Past and the Z.F. have the same consonant structure.

(19) Tameziyt (Ait Nahir)

\begin{tabular}{|c|c|c|c|}
\hline Z.F. & Pest & I.F. & Gloss \\
\hline ef $\theta e l$ & $-\theta f \theta \theta l-$ & fettel & 'to roll couscous' \\
\hline ney & - ney- & neqqa & 'to kill' \\
\hline ebdgu & -ebḍ- & bettu & 'to divide' \\
\hline
\end{tabular}

Notice that if one starts with the I.F., then one is compelled to derive the Past from the Z.F., following the diagram given in (20):

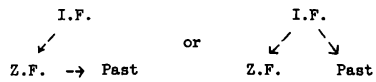

This obviously points to the fact that a linguiatically significant generalization $1 \mathrm{~s}$ beling lost, as other languages do not seem to operate in this way. Furthermore, it means that degemination rules must be written for both Z.F. and the Past. Also, the I.F. to Z.F, analysis would be at a loss to explain the alternations given in (2l): 
(21) Tamazlyt (Aït Nahlr)

\begin{tabular}{|c|c|c|c|}
\hline Z.F. & I.F. ${ }^{13}$ & Past & Closs \\
\hline ggall & ttgalla & -ggull- & 'to swear' \\
\hline gganney & ttgannay & -ggunney- & 'to wa1t' \\
\hline qqim & ttyima & $-q q / m-$ & 'to sit' \\
\hline qqar & ttyara & -qqur- & 'to be ary' \\
\hline Jiwen & ttgawan & -jiwen- & 'to be full' \\
\hline elc & ttetta & $-e^{x}-$ & 'to eat' \\
\hline
\end{tabular}

If we start from the I.F., then we would have to say that what is taking place here is degemination of a stem consonant. Moreover, we would have to mark a great many verbs with lexical geminate with a [-Rule $X$ ] in the lexicon so as to insure that they do not undergo the degemination rule. Finally, the forms Jiwen 'to be full' and ec' 'to eat', would be very hard to derive from /tt-gawan/ and /tt-tta/, respectively. Thus, we can see that the I.F. to Z.F. analysis makes the wrong predictions, leads to further complications, and proves to be very costly. No such complications result if the Z.F. to I.F. analysis is chosen. 14

Another alternative solution would be to regard each case of elternation between a simple consonent and a geminate consonant as suppletive (not unlike English go : went) in which case we would be forced to recognize both $\mathrm{C}$ and $\mathrm{CC}$ for each morphene. This does not exclude the posaibility that where there are no alternating forms, surface CC's derive from underlying geminates. This is 1llustrated in (22) (cf. also (18e) above).

13 The prefixation of a $t$ t 18 another means of forming the I.F. It is selected by verbs with lexical geninates and verbs with underlying plain rowels.

14 Moreover, data from Kabyle-At Megellat (cf. Dallet [1953]) indicate that what is taking place 18 otrengthening and not weakening, e.g. Z.F. efsu : I.F. feşu 'to untangle' (where $\$$ ats), Z.F. erzu : I.F. rezzu 'to violt' (where $z=d z$ ) (cf. also data from Tamaziyt (Bou Hsousen) [Loubignac 1924]: Z.F. exS1 : I.F. xeşi 'to be ext1nguished', Z.F. exzen : I.F. xezzen 'to h1de'.) 
(22) Tanazipt (Aït Ndhir)

\begin{tabular}{|c|c|c|c|}
\hline Z.F. & & I. F. & Glов8 \\
\hline effoy & : & tteffey & 'to go out' \\
\hline ekkes & $:$ & ttekkes & 'to take off' \\
\hline eqqen & : & t teqqen & 'to lock' \\
\hline
\end{tabular}

In these instances, to posit simple C's would strongly violate the naturalness condition. Such a solution would in actuality be a case of absolute neutralization where the morphemes would have to be marked by some diacritic to permit them to be operated on by a context-free $\mathrm{C} \rightarrow$ CC rule, since all single C's in these morphemes would have to become geminate. Moreover, the contrast between simple and geminate consonants is a very basic one in Berber, as seen in (23).

(23) Tanaziyt (Aït Ndhir)

$\begin{array}{llll}\text { ass } & \text { 'to tie' } & \text { as } & \text { 'to fit' } \\ \text { aff } & \text { 'to be rull' } & \text { af } & \text { 'to rind' } \\ \text { suddem } & \text { 'to drip } & \text { s-udem } & \text { 'to the face' } \\ \text { uzzal } & \text { 'iron } & \text { uzal } & \text { 'hot period of the day'15 }\end{array}$

The conclusion then is to represent the alternating $\mathrm{C} / \mathrm{CC}$ forms with a simple $C$ and to represent non-alternating $C C$ as derived from $C C$.

'The second problem to be solved concerns those dialects like my own, in which simple stops have become spirants ( $\mathrm{c} f$. examples given in ( 5 ) for instance). Since these spirants alternate with geminate stops it is necessary to decide in some principled way as to whether the underlying, segment is a stop or a spirant. This problen does not apply to dialects such as 'Tachelhiyt and Twareg where spirantization has had little effect and where the only alternation of this kind is that between $\gamma$ and qq, which, as stated above, is handled by a different rule.

(24) $\left[\begin{array}{l}+ \text { pharymgealized } \\ + \text { back }\end{array}\right] \rightarrow\left[\begin{array}{l}+ \text { voiced } \\ + \text { cont. }\end{array}\right] / \mathrm{x}:$ where $\mathrm{x} \neq$ identical $\mathrm{C}$

${ }^{15}$ uzal is in the 'construct state'. The noun is in this state when it is the subject of a verb or the complement of a preposition. In the 'free state' the noun is azal. sudem 'to the face' is from s + udem where $s=$ 'to'. 
The alternation between $f: f f$ presents no problem in this regard except for those phonologists who vould totally violate the naturalness condition (cf. Postal [1968]) and posit an underlying $p$ for the reason that a language with an $f$ and no $p$ would be considered 'unnatural'. This solution would require an absolute neutralization rule such that in all cases $P \rightarrow f$ and seems so umnotirated that one cannot really consider it seriously (cf. Kiparsky [1968] et alis).

There are also cases, though sporadic, in which $b$ alternates with $f$ as is show by the followins examples: ${ }^{16}$

(25) Tirifiyt (cr. Renisio [1932])

\begin{tabular}{|c|c|c|c|}
\hline Senhaja & & Oašebbatd & 'flute' \\
\hline & pl. & $\theta i s e b b a b$ in & \\
\hline Touzine & $\begin{array}{l}\text { se. } \\
\text { pl. }\end{array}$ & $\begin{array}{l}\theta a \text { jarbut } \\
\text { जjasbab }\end{array}$ & 'ccrer, case' \\
\hline
\end{tabular}

This presents no problem if ve posit an underlying $b$ which undergoes the regular volcing assimilation rule found generally in Berber and which in some cases is optional.

(26) Tamaziyt (Aitt Nahir)

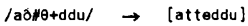

$$
\begin{aligned}
& \text { Fut.-she-go 'she will go' }
\end{aligned}
$$

Since in these dialects $\beta$ does not occur, clearly the underlying segment must be the stop $b$, which when non-geminate and devolced becomes the only permitted volceless labial $f$.

It may be noted that voicing assimilation is general throughout the Berber dialects, and that the spirantization of $b$ to $f$ occurs even in dialects where manner assimilation does not occur. In Tachelhiyt, for example, we find the sequence it in ifta 'he left'. The rule should, therefore, not include volcing and spirantization assinilation as one

${ }^{16}$ In Tamaziyt (Ait Ndhir) some Arebic loan words with $b$ are rendered with $f$ in the speech of country people: Arabic elbettix 'melon' Tamaziyt afettix; Arabic lebșel 'onion' Tamaziyt Żefșež, etc. In this speech, I $\rightarrow \xi$, or something very close to $z$. 
process. Since there is no dialect in which a $P$ occurs, a sepment structure condition for labials would be included. This constraint vould reapply whenever applicable (cf. Stanley [1967]; K1sseberth [1970]; Shibatan1 (1973]). To include a segnent structure condition in the grammar of Berber such as

$$
\begin{array}{cl}
\text { IF : } & {\left[\begin{array}{l}
+ \text { anterior } \\
- \text { coronel } \\
- \text { volced }
\end{array}\right]} \\
\text { THEN : } \quad[+ \text { continuant }]
\end{array}
$$

would reveal the historical spirantization of * $p$ to $f$ which hes special status in the history of Berber. This is so because the "p to $f$ spirantization has the following characteristics:

(i) It is also found in non-Berber Afro-Asiatic langueges.

(ii) It has occurred in all Berber dialects.

(iii) It is true of the geminates as well as the single consonants. (In the I.F. of the verbs, for instance, $f f$ occurs rather then $P P$ which is not the case for other $\mathrm{C} / \mathrm{CC}$ alternations.)

The representation of the labial consonants is thus straight-forward; we posit underlying $b$ and $f$.

Let us now return to a dialect such as my own (the Aït îdhir dialect of Tamazi yt) where, as shown in (12) and (13), ell simple stops are spirantized. Moreover, in the verb paradign, Instead of an alternation of simple/identical geminate stops, as in Tachelpiyt (cf. (2) and ( 3 )), the alternation exhibited by this dialect is one between non-strident spirants and geminate stops (cf. (5) above). Forms with lexical geminate stops like the ones given in $(18 \mathrm{e})$ and (22) do not alternate and are not affected by spirantization.

Since we have already concluded that the geminates in alternating forms should be derived from non-geminate consonants, the problem, then, Is to decide whether the underlying segments should be spirants or stops. If stops are posited as the underlying segrents, the grammar must include a spirantization rule that would be identical to the diachronic 
rule. That 1s, it may be concluded that the diachronic rule 1s still operative, 1.e. has been incorporated Into the synchronic grammar of Ait Nanir. With this rule in the grammar, one would clain that certain Arabic Joan words are phonemically represented in Berber unchanged with the Arabic stops occurring in the lexical forms as shown in (28):

(28) Arabic Tameziyt (Aït Nahir)

Gloss

letnayn

/letnayn/ $\rightarrow$ [leonayn]

'Monday'

lekta:b

/lekta:b/ 'book'

(vis the rule: [- cont.] $\rightarrow[+$ cont.] $/ \mathrm{x}$ :

where $X \neq$ geninate)

Since the rule would not apply to underlying geminates, Arabic loan words with such geminstes would not be affected, as shown in (29):

(29) Arebic Tamaziyt (Ait Nahir)

\begin{tabular}{|c|c|c|c|}
\hline ttaman & $\begin{array}{l}\text { /ottaman/ } \\
\text { /aSekkwaz/ }\end{array}$ & $\rightarrow$ & $\begin{array}{l}\text { [ettaman] } \\
\text { [afekkHa:z] }\end{array}$ \\
\hline
\end{tabular}

Th1s solution is observationally adequate and is also supported by concepts of markedness and implicational universals.

The proposed theory of markedness [Chomsky \& Halle 1968] suggests that the non-strident spirants are more complex than the corresponding stops. Thus, $\theta$ is more complex then $s$ which is more complex than $t$; s must occur phonemically because of such alternations as in (30): (30) Tamaziүt (Aït Nahir)

$\begin{array}{lll}\text { Z.F. } & \text { I.F. } & \text { Gloss } \\ \text { efser } & \text { fesser } & \text { 'to spread' } \\ \text { efsey } & \text { fessey } & \text { 'to melt' } \\ \text { exsey } & \text { xessey } & \text { 'to be extinguished' }\end{array}$

The proposed solution then would be to have as systematic phonemes / $t$ / as well as $/ \mathrm{s} /$ which vould be a more 'natural system' then one in which $/ s /$ and $/ \theta /$ occur to the exclusion of $/ t /$.

Further support for this solution may be dram from the proposed 1mplicational unfversals of Jakobson [1941, 1968] . Jakobson states: 
The acquisition of fricatives presupposes the acquisition of stops in child lanpuare; and in the linfuistic system of the world the former cannot exist unless the latter ex1sts as well. [ $1968: 51]$

Thus, the Ait Ndhir dialect, where spirantization is general, would be an obvious exception to this apparently well-established universal unless underlying stops are assumed for certain spirants. The fact that in non-alternating forms underlying geminates would occur phonemically would not help 'restore' a natural system since a language with geninates and no simple stops would also violate implicational universals.

There appears, then, to be strong evidence for positing underlying single stops and deriving the non-strident spirants (and geminates) from these segments. There is, however, counter-evidence which must be considered.

Since on the phonetic level no simple stops occur in this dialect, the solution posited above is a strong violation of the naturalness condition, and absolute neutralization results to some extent. That is, although some context is stated for the change from stop to spirant (i.e. the stop in question must be non-geminate), the stop will 'surface' as a spirant in all cases.

Furthermore, the spirents occur in the morphologically least marked category, the Z.F.; whereas phonetic stops, existing only as geminates, are found in the marked category, the I.F. One could argue that the spirants must be basic to the synchronic gramur, which is interesting in that such a solution would represent a further case of rule inversion [Vennemann 1972]. That is, at one stage in the history of the language a rule existed whereby the spirants were derived from stops; at present the rule would derive the stops from spirants.

Native speakers of this dialect never hear simple stops, except in Arabic and French loan words. Nor do they have access to the history of the language, nor to the comparative evidence which might lead to the positing of simple underlying stops. To argue for underlying simple stops because of markedness and implicational universals would be forcing the language to fit the theory rather than using, language data to test 
theoretical hypotheses. It should be noted, in addition, that other solutions attempting to arrive at a unique gramar using markedness conventions to determine the underlying representation of segrents have been questioned. (See, for example, Schane's discussion of the underlying representations for French vendre 'to sell', and for German und 'and', which have been rightly criticized by Hyman [1970].)

The argument in favor of underlying non-strident spirants is not basically one of simplicity: although the spirantization rule would not be necessary, a rule which changes these spirants, when geminates, would have to be included:

$$
\begin{aligned}
& \text { SD: } \quad[- \text { strident, + cont. }]_{1} \text { (H) }[\text { - strident, + cont. }]_{2} \\
& \text { sc: }[- \text { cont. }]_{1} \\
& {[\text { - cont. }]_{2}}
\end{aligned}
$$

(where $1=2$ )

(For Justification of transformational rules in phonology, see Chomsky \& Halle [1968].) The parenthesized word boundary is required since two sequential spirants agreeing in point of articulation become geminate stops across morpheme and word boundaries as illustrated in (32):

(32) Tamazipt (Aït Ndhir)

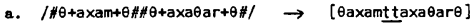

'tent' 'big'

'the big tent'

$(\theta \# \# \theta=\mathrm{tt})$

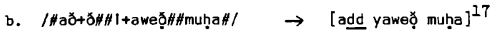

fut.dir, errive Muha

'Muha will arrive over here.'

Moreover, the examples given in (16) above, lllustrating the fact that some Arabic loen words occur with phonetic non-geminate stops, indicates that the spirantization rule, if posited, is no longer an obligatory rule. If words with a phonetic spirant are represented with a stop, one would no longer have to treat these loan words as exceptions

17 Dir = directional particle. It is used with verbs of motion to indicate the direction of the movenent. It could be translated as 'over here' or 'towards here'. 
or marked as [t forelgn] or [t late loans]. If these words are marked as [+ foreign] and the other Arablc loans are not so marked the diacritic would merely be another way of stating [- rule $X$ ] and would falsely differentiate between the loans in the language. If instead the $\mathrm{l}+$ late loan] feature were used as the diacritic, this would also be a false representation since there is no justification for determining the relative dating of such loans, given that there are no written documents to support such a classification. Furthermore, speakers learning the language would certainly not have access to such knowledge. What they do have access to is the phonetic pronunclation of these forms. The solution with underlying spirants, then, permits us to account for the loan words which do not undergo spirantization in a simple way; whenever a word in the lexicon includes a simple stop in its matrix it must be a loan word from Arabic or French.

The solution whereby non-strident geminates occur phonemically in non-alternating forms also sugbests a possible direction for changes which may occur in the language. There is already a trend in some dialects to reduce the gerinates. Thus, the stressed form of the third person pronoun netta 'he', which has a geminate stop, is more and more being pronounced as enta. This is also observed in the feminine nouns ending with geminate $t t$, for exemple, tahanutt vs. Oahanut 'shop' and Gaxbutt vs. Gaxbut 'little hole'. One may hypothesize that the next step for Berber is to simplify geminates into simple stops. Thus, Instead of a surface contrast between $\partial$ and $t t$, which in some cases would both be derived from $/ \theta /$, the new contrast between $\theta$ and $t$ would simplify the alternation rules and, possibly in the future, lead to a rephonenticization whereby there would be a contrast between $/ \theta /$ and $/ \mathrm{t} /$.

One might speculate further that an inverse rule inversion will take place whereby the spirants are once more derived from the simple stops. Using Vennemann's notion of rule inversion [Vennemann 1972] we can describe the Berber situation as in (33), where $t$ is taken to represent stops. 
(33)

$\begin{array}{ll}\text { Stage I } & / t / / t t / \\ & (\text { no rule) }\end{array}$

Stage II

$/ \mathrm{t} / \mathrm{L} / \mathrm{t} /$

(rule: $/ t$ /

Stage III : $/ \theta / / \mathrm{tt} /$

(rule: $/ \theta / \rightarrow[t t]$ in the I.F.)

Stage IV / / / / / $/$

(no rule)

Between Stage III and the predicated Stage IV there is likely to be a stage where the rule is $\theta \rightarrow$ [t] In Intensives, etc., due to degentnation. So the rule $108 s$ would actually affect this rule, rather than the original inverge rule. 18

Similer conversions of contrast have been observed in numerous languages; they are the historical basis of 'consonant gradation' (as in Finnish) and have been called 'drag chains' [Martinet 1955; King 1970] We are therefore justified in expecting such a conversion of contrast in Berber, 1.e. In predicting degenination and rephonenicization.

\section{Conclusion}

The standard theory of generative phonolgy [Chomsky and Halle 1968] does not provide the bssis for a choice between the two solutions outlined above. The evaluation metric, even if we knew how to apply it in all cases (e.g. in choosing between rewrite and transformational rules), would not necessarily choose the solution with stops over that with spirants, although the second solution would be to some extent simpler, in that loan words would not have to be marked as exceptions to a spirantization rule. Dependence on the theory of markedness or putative implication universals should only be resorted to when the solution so based is more predictive and more in keepling with the language data. The more

\footnotetext{
18 The rule in Stage III 1 s what Vennemann would call a 'partial imverse rule'. Indeed 1t 1s the 'partial inverse rule' of the rule given in Stege II. This mechanism of gremmar change, for which Vennemann colned the term 'rule inversion', has been shown convincingly to obtain in Chadic in an article by Russell Schuh [1972].
} 
concrete solution (such as would be required by constraints similar to those proposed by Vennemann (1972] and [1973]) seems to meet the cr1teria of descriptive adequacy better than does the solution positing underlying single stops. It seems clear that the theory must be strengthened (made more explanatory) by weakening 1t, 1.e. by including constraints which force us to 'hug the phonetic ground' when a choice is to be made between 'non-unique' solutions.

\section{REFERENCES}

Bach, Emmon. 1968. "Two proposals concerning the simplicity metric in phonology", Glossa 2:128-149.

Basset, André. 1929. La langue berbère, morphologie, le verbe. Paris: Leroux.

Basset, André. 1952. La langue berbère. Oxford: International African Institute.

Bisson, Paul. 1940. Leçons de berbère tamazight. Rabat: Moncho.

Chomsky, N. and M. Halle. 1968. The Sound Pattern of English. New York: Harper and Row.

Dallet, J. M. 1953. Le verbe kabyle: parler des At-Mangellat. Alger: Fort National.

Foley, James. 1969. "Phonological distinctive features", Folia Linguistice $4: 87-92$.

Hooper, Joan. 1973. Aspects of Natural Generative Phonology. Unpublished doctoral dissertation, University of California, Los Angeles.

Hymen, Larry. 1970. "The role of borrowing in the justification of phonological grammars", Studies in Africen Linguistics 1:1-48.

Jakobson, Roman. 1968. Child Languege, Aphesia and Phonological Universals. The Hegue: Mouton.

King, Robert D. 1969. "Push chains and drag chains", Glossa 3.3-21.

Kipersky, Paul. 1968. "llow abstrect is phonolory?" Bloomington: Indiana University Linguistics Club.

Kisseberth, Charles. 1970. "On the functional unity of phonological rules", Linguistic Inquiry 1.3:291-306.

Koutsoudas, Andreas, et alia. 1971. "The application of phonological rules", (to appear in Language).

Labov, W1lliam. 19\%2. Sociolinguistic Patterns. Philadelphia: University of Pennisylvania Press. 
Laoust, Bnile. 1918, Etude sur le dlalecte des Ntifa. Paris: Leroux.

Laoust, Fmile. 1939. Cours de berbère marocain: dialecte du Maroc Central. Paris: Paul Geuthner.

Loubignac, Victorien. 1924. Etude sur le dialecte berbère des Zaian et Alt Sgougou. Paris: Leroux.

Martinet, André. 1955. L'économie des chengements phonétiques. Berne: Francke.

Mercler, Henr1. 1937. Vocabula1res et textes berberes. Rabat: cḱré.

Penchoen, Thomes G. 1973. Tamaziyt of the Ayt Nahir. In Afroasiatic Dialects, Vol. 1 , Berber, edited by W. Leslau and T. G. Penchoen. Los Angeles: Undena Publications.

Postal, Paul. 1968. Aspects of Phonological Theory. New York: Harper and Row.

Renisio, A. 1932. Etude sur les dialectes berbère des Beni Iznassen, du Rifet des Senhala de Srair. Paris: Leroux.

Schane, Sanford. 1968. "On the non-uniqueress of phonological representations", Language 44:709-716.

Schuh, Russell. 1972. "Rule inversion in Chadic", Studies in African Linguistics 3:379-397.

Shibatant, Masayosh1. 1973. "The role of surface phonetic constraints", Language 49:87-106.

Stanley, Richard. 1967. "Redundancy rules in phonology", Languege 43: $393-436$.

Ultan, Russell. 1970. "Some sources of consonant gradation", Working Papers on Language Universals 2, Stanford University.

Vennemann, Theo. 1972. "Rule Inversion", Lingua 29:209-242.

Vennemann, Theo. 1973. "Phonological concreteness in natural generative Bramar". Ms. 


\section{APPENDIX I}

Regarding the varlation in the spirantization of underlying $k$ 's in spirantizing dialects ( $\mathrm{f}$. Sec. 3 above), Tom Penchoen (personal communication), upon returning from a field trip, offers the following observation concerning possible conditioning, factors for the changes $k \rightarrow \uparrow$ and $k \rightarrow \xi$ in Tamaziyt: $k$ goes to $c(1)$ when followed by an $u$ (e.g. takurt $\rightarrow$ taçure 'ball'); 2) in words containing $s, z, \xi$, 2 whether adjecent to $k$ or not (e.g. aksum $\rightarrow$ açsum 'meat'; cf. however my proto-Berber form for 'meat' In (14); ekrez $\rightarrow$ eçrez 'to plough'); 3) in verbs preceded by the causative prefix ss (e.g. kned 'to burn' [+ intrans.] $\rightarrow$ sseçneọ 'to burn' [+ trans.]). Apart from these cases, $k \rightarrow \xi$. It should be emphasized that this observation, if it obtains, would apply only to Tamaziyt, because Tirifiyt, for instance, has weakened $k$ 's into $\xi^{\prime} s$ in words containing $\xi$ (e.g. ašsum 'meat', cf. (14) above). And even within Tamaziyt the weakening of $k^{\prime} s$ in some dialects (AYYt Izdeg and Zaian, for instance) is not governed by the conditioning factors mentioned above. Aitt Izdeg (cf. Mercier [1937]), a dislect in transition (i.e. not totally spirantizing), exhibits the following facts: 1) Some $k^{\prime} s$ do not go to $q^{\prime} s$ when followed by an U (e.s. afešku 'utensil', not *afesçu; akuz 'weevil', not *açuz). 2) Some $k^{\prime} s$ go to $c^{\prime} s$ before (or after) any other vowel (e.g. açabar 'caravan' < akabar ; açniw 'twin' < akniw; içfer 'turtle' < ikfer). 3) k's go to ç's in words containing consonants other than $s, z, \xi$, $\Sigma$ (e.g. açtay 'remembrance' < aktay ; imçra 'tenants' < imkra ; eçti 'to remember' < ekti). 4) Aït Izdeg has alternative pronunciations for some morphenes (e.g. tafuçt and tafušt 'sun'; areçtu and arestu 'dough') as well as instances of just $\xi<k$ (e.g. ašal 'earth' < akal; ašer 'to steal' < aker; Šrạ̣ 'three' < krad). These are but a few facts which indicate that the weakening of $k$ to $\zeta$ and to $\xi$ does not seem to be conditioned in Tamaziyt (AYt Izdeg). Th1s 1в particularly interesting in that, if there is conditioning, one would expect to $\mathrm{find}$ it to be operative in a dialect in transition such Alt Izdeg and not in the most advanced spirantizing dialect (AIt Ndhir) 
on which Tom Penchoen's observation was apparently based. And even the Ait rdair dielect exhibits some instances of $k \rightarrow \xi$ before $u$ (e.g. adasu 'shoe' $<$ adaku) and $k \rightarrow \xi$ in words containing $\xi$ for instance (e.g. ašrlš 'assoclate' < asrlk).

Space not permitting, I w11l not go into the Zalan alalect of Tamaziyt, a more advanced spirantizing dialect than Alt Izdeg, but a look at the data (cf. Loubignac [1924]) will also indicate that there are no statable conditioning factors for the different weakenings of k's. Moreover, a solution to this problem would be incomplete unless the other velar, $g$, is included. For, if the veakening of $k$ is conditioned, one vould expect a similar conditioning to obtain for $g$ as well, since $g$ scmetimes veskens to $j$, other times to $z$, and still other times into $y$. As for the other stops there is, so far as I know, no conditioning factor for their spirantization other than the one repeatedly mentioned in the main body of the paper, namely, that they must be non-geminate.

Tom Penchoen's observation has since been included in his newly published grammatical sketch on Tamaziyt [1973:26], though the observation is restricted there to the AIt Nahir dialect only. 
Studies in African Lingulstics

Volume 5, Number 1, March 1974

ON THE DYNAMICS OF VELARIZATION AND LABIALIZATIOH:

SOME BAITU EVIDENCE 1

Fritz Ponelis

University of South Africa

1. Introduction

In the literature the term 'secondary articulation' is used in two senses:

(i) It frequently serves as a descriptive, classificatory tag, denoting the structure of segments such as $k^{w}$ and $p^{\gamma}$; cf. Abercrombie [1967:61]: "...there are occasions when it is necessary to draw attention to aspects of the vocel tract other than place and manner of the stricture, and when this is so, we do it in terms of secondary articulations... We have here...another dimension of classification for segments..." Compare also Ladefoged [1971:59]: "Sounds can also be modified by secondary articulations which occur at the same time as the primary articulations."

(ii) Chansky and ialle [1968:307 ff.] account for sense (i) but point out that ( $i$ ) is the result of a PROCESS, viz. regressive assimilation (cf. for instance [1968:308]). We shall be attending primarily to sense (11) in respect to labialization and velarization.

The strict sense of velarization (labialization) is: regressive assimilation of a consonant to the velarity (labiality) of the following sonorant. The regressive assimilation triggers a whole train of processes, and velarization (labialization) will frequently be used in this sense: a whole set of processes resulting from velarization proper (labialization proper). The main factors of velarization and

\footnotetext{
${ }^{1}$ Professor E.B. van Wyk has read and commented on an earlier draft. I have benefited greatly from numerous suggestions by Professors Larry Ilyman and Thomas Hinnebusch. My thanks to each of these gentlemen; the responsibility remains my orm, naturally.
} 
labialization viewed as functionally unified sets of different processes are regressive assimilation (velarization and labialization proper) and narrowing (also called hardening):

(1)

Velarization

P

$P^{\text {II }} \quad$ Velarization proper

pt Narrowing (Fricativization)

Labialization

k

kw Labialization proper

kp Narrowing (Closure)

In terms of tongue body participation the secondary articulations may be classified as follows:

(2)

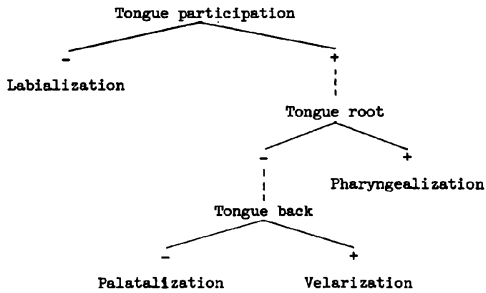

This classification is formally reflected as follows [Chomsky and Halle 1968:306, 310]:
Labialization:
[+ round]
1.e. $\left[k^{*}\right]$
Pharyngeal1zation:

$$
\text { 1.e. }\left[p^{D}\right]
$$$$
\left[\begin{array}{l}
+ \text { low } \\
+ \text { beck }
\end{array}\right]
$$
Velarization:

$$
\left[\begin{array}{l}
+ \text { high } \\
+ \text { besk }
\end{array}\right] \text { 1.e. [p [m] }
$$
Palatalization:

$$
\left[\begin{array}{l}
+ \text { h1gh } \\
- \text { back }
\end{array}\right] \text { 1.e. }\left[p^{\gamma}\right]
$$


Such a classification 18 not an adequate reflexion of the similarity and complementarity of lablalization and velarization:

(4) (1) Both are [+ grave] superimpositions.

(11) Labialization is initiated with velars and velarization with labials.

(iii) Labialization may result in velar segments and velarization in labials.

The ambivalence of [+ round] seems to be part of the problen. This feature is characteristic of vowels and is related to [+ anterior, - coronal], i.e. [+ labial] in consonants. The problem is explored in Vennemann and Ladefoged [1972] and in Reighard [1972].

A secondary articulation is a type of regressive assimilation. This has been substantiated for labialization, velarization and palatalization, but not, as far as I know, for pharyngealization. Palatalization and pharyngealization are excluded from further consideration.

I shall try to account for the following main features of labielization and velarizetion:

(5) Labialization: gwa > gba > Ba ( $g \circ a)$

Velarization: bwa > bga > ga

Labialization is initiated with velars and velarization with labials. In both processes the secondary articulation is hardened, i.e. develops (maximally) into a closure. Finally, the processes may result in single segments, velars in the case of velarization and lablals (Implosives and, rather peripherally, clicks) under labialization.

\section{Shona Velarization}

2.1. Velarization as regressive assimilation. Velarization is a process of regressive assimilation under which a consonant takes on the velarity of a following [+ grave] sonorant. The process progresses dimensionally along the axes of place and manner of articulation: (1) labials are affected before linguals, (11) glides are converted to obstruent glides, then to fricatives and finally to stops. 
My data are dravn almost exclusively from Doke [1931], the extensive pioneering study of the process. In Bantu velarization manifests itself most clearly in Shona, especially the Zezuru dialect of Central Shona, but is attested also in Venda, Rund1, Nyiha, Tumbuka and Mang'anja. Its occurrence in Sotho and Nguni is subject to debate, but cf. Ponelis [1973].

The fact that velarization is phonologically a process of regressive assimilation is obscured in much of the literature, since on the one hand the $W$ causing velarizetion is considered extraneous and on the other hand Doke's statement of the process seens to be at variance vith its regressive assimilatory nature.

2.1.1. The status of $W$. Chomsky and Halle [1968:310] state that "Labialization combines quite commonly with velarization...." Trubetzkoy [1969:137-8] distinguishes between the correlation of full gutturalization (i.e. extreme velarization) and the correlation of labiovelarization. Trubetzkoy and Chomsky and Halle obviously follow Doke [1931:109 ff.], who distinguished between 'plain velarization', and 'velarization with semi-vowel', as in (6) below. The latter process is viewed by Trubetzkoy and Chomsky and Halle to be a product of velarization combined with labialization.

(6)

$\begin{array}{llll}\text { a. } \frac{\text { Plain }}{2} & & & \\ \text { pkere } & \text { 'child' } & \text { rambłe } & \text { 'buffalo' } \\ \text { pkisa } & \text { 'absorb' } & \text { sempa } & \text { 'be hated' } \\ \text { kupkera } & \text { 'to suckle' } & \text { mpene } & \text { 'owner' } \\ \text { błana } & \text { 'crush' } & \text { mjara } & \text { 'flint' } \\ \text { rušambga } & \text { 'accident' } & & \end{array}$

2These are all zezuru forms. * is a volced palatal fricative. Other graphs used elsewhere in the text are $q$, a voiceless palatal fricative (the congener of $\psi$ ); $\widehat{w}, \hat{\gamma}$ and $\tilde{w}$ are used to indicate extremely narrow glides, respectively volced, voiceless and nasalized. The term 'obstruent glide' will be used to characterize this set of segments collectively. 
(6) b. With sem1-vowel

$\begin{array}{llll}\text { tkwana } & \text { 'little children' } & \text { tanijwa } & \text { 'be picked' } \\ \text { utkwu } & \text { 'these' } & \text { rywa } & \text { 'fight' } \\ \text { tkwaenda } & \text { 'they travelled' } & \text { rłwadza } & \text { 'pein' } \\ \text { dywe } & \text { 'drip, of rain' } & \text { biskwa } & \text { 'be removed' } \\ \text { tandywa } & \text { 'be driven away' } & \text { skwera } & \text { 'spend the time' } \\ \text { kunrjwa } & \text { 'to drink' } & \text { izłwl } & \text { 'word' } \\ \text { munijwe } & \text { 'finger' } & & \end{array}$

Clearly $p k$ and $t \mathrm{kw}$ do not illustrate two distinct processes, viz. velarization as opposed to 'labiovelarization' but merely belong to different steps in the same velarization processes. Velarization affects labials first, hence they would be first to undergo a subsequent step, i.e. dropping of $W$. Doke gives very few examples ${ }^{3}$ of velarized labials in combination with $w$, whereas all his examples of 'velarization with semi-vowel' contain dental and alveolar segments.

2.1.2. Doke's statement of the process. "Velarization is brought about by an abnormal raising of the back of the tongue towards the soft palate ..., instead of the usual slight raising effected in pronouncing the velar semi-vowel $w$ "[Doke 1931:109]. A phonological explanation of this abnormal raising of the back of the tongue would necessarily entail assimilation to the preceding obstruent or nasal. This seems to be extremely plausible but conflicts with the conception of velarization as a regressive assimilatory process. The matter may be cleared up if Doke's definition is taken to apply to a later step in the process. First a consonant takes on the velarity of a following sonorant: $C \rightarrow C^{\text {pll }}$; then $C^{\text {II }} \rightarrow \mathrm{CW}$ by other rules and $\mathrm{CW} \rightarrow \mathrm{C} Q$ by Glide Harrowing.

On the surface Doke's Narrowing (= abnormal raising) analysis seems to handle the facts quite elegantly. This would derive the Tavara form -pea 'dry up' in the following way: -pwa 'dry up' $\rightarrow$-poa (by Narrow1ng). The glide $/ \mathrm{w} /$ is narrowed ultimately to a voiceless palatal fricative $\bullet$.

\footnotetext{
3 These examples 1nvolve nasals. Their significance is discussed below.
} 
This enalysis, however, does not predict the Korekore form -qwa, where the glide is retained; hence $\odot$ requires a different explanation. The derivation of this particular form $1 \mathrm{~s}$ given at the end of the section on velarization (sec. 4). It briefly amounts to the following: -pwa 'dry up' $\rightarrow$-powa (by Velarizstion, etc.) $\rightarrow$-qwa (Cluster Initial Deletion).

The velarization analysis proposed in this paper also accounts for forms such as the following (where nonlabial segments precede the glide) -batwa 'hold' $\rightarrow$-batowa, twana 'little children' $\rightarrow$ tkwana (cf. (6) for more examples). The Narrowing analysis cannot explain the 'extraneous' 6 and $k$.

2.2. Inftial domain and spread of velarization. Velarization in Shona is induced by $w$, arising from Proto Bantu *uV becoming $w V$ : *bua $>$ bwa. 4

$$
\begin{array}{ll}
\text {-pú- 'dry up'5 } & >\text {-poa, -pka } \\
\text {-búa- } & >\text {-bwa, -bła, -bga } \\
\text {-dúád- 'become ill' } & >\text {-rwara, -rłwara }
\end{array}
$$

2.2.1. The affected segments. The data allow only a few suggestions.

$$
\begin{aligned}
& \text { a. }\left[\begin{array}{l}
+ \text { ant } \\
- \text { cor }
\end{array}\right] \text { precedes }\left[\begin{array}{l}
+ \text { ant } \\
+ \text { cor }
\end{array}\right] \\
& \text { Labials precede alveolars. } \\
& \text { b. }[- \text { son] precedes [+ son] } \\
& {[p, b] \text { precede [m]. }} \\
& {[t, s, r, z] \text { precede [n]. }} \\
& \text { c. [- volce] precedes [+ volce] } \\
& \text { [p] precedes [b]. }
\end{aligned}
$$

\footnotetext{
${ }^{4}$ Proto Bantu $y$ induces lablalization, a rule that procedea velarization in time.

5The Bantu proto c1tations are taken from Guthrie [1967, 1970, 1971]. Guthrie 11sts his starred forms by C.S. (- Comparative Ser1es) number; these are not 1ndicated here since the 1 tems are arranged alphabetically and can be easily located.
} 
That labials precede alveolars has already been pointed out in sec. 2.2. above. It follows from an inventory such as Stevick's [1964:59] for Manyika :

$\begin{array}{lll}\text { by } & d w & g w \\ \text { px } & \text { tw } & \text { kw } \\ \text { mo } & \text { nw } & \end{array}$

The labial series has already reached an advanced stage of velarization, fricativization and closure, whereas the other series still have $w$.

The evidence for the primacy of obstruents $(8 \mathrm{~b})$ is rather scant and consists of two sets of free variants which have not undergone $\mathrm{W}-\mathrm{Ab}-$ sorption: Korekore: -yamwa -yamrjwa 'suck'; jwana mpwana 'child'. Doke notes furthermore that -yamnwa is "unique in its occurrence" [Doke 1931:113].

Closure $(8 c)$ seens to be lagging with the voiced labial $b$ so that there are more fricativized forms than with $p$ [Doke 1931:110-11]. Thi might indicate that velarization is initiated later in voiced segments.

2.2.2. The following vowel. Lanham [1955:46] points out that velarization (in Tonga) is favored before $a$, fluctuating before $e$ and nonexistent before $i$. Hence there is a clear preference for the lower vowel. Doke's data confirm this: the vast majority of velarized clusters occur before $a$. This state of affairs might be ascribed to the process of gliding preceding velarization: vowels become glldes first before low vowels.

2.3. The processes of velarization. The following rules are hypothesized: Velarization, Segmentation, Glide Narrowlng, Fricativization, Becklng, and Closure. Rules such as $w$-Absorption and cluster Initial Deletion interact with those in the Velarization block but do not form part of $1 t$.

Doke [1931:110] Bives the following steps, which are correct, minor details aside: 
(10)

$$
\begin{array}{lll}
\text { pwa bwa mwa } & \text { mâa } \\
\text { pqia bîa } & \text { mĩa } \\
\text { pqa bła } & \\
\text { pka bga moa }
\end{array}
$$

2.3.1. Velarization. Underlying the account in 2.2. 1s the concept of precedence central to implicational apread. The velarization rule below (cf. 11) reflects the spirit of Chomsky and Halle [1968]: It is static and discrete. The rule is static in the sense of merely giving a picture of the outcome Instead of the dynamics of the process (1.e. where it starts and in which direction it is heading). The discreteness of the formalized rule 1s above all a function of the way place of articulation is handled within the system of Chomsky and Halle. This might be remedied by the introduction of scslar features [Vennemann 1972] and a return to the traditional place of articulation continuum [Chen 1971:30-1].

Be that as it may the theory should allow for a precedence statement such as: Under velarization an obstruent with maximum (= maximally available) frontness takes on the color of the maximally back and high rowel following. Other precedence relations in this process include [- rolce]

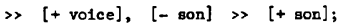

(11) Velarization

$$
\begin{aligned}
& {[+ \text { ant }] \rightarrow\left[\begin{array}{l}
+ \text { high } \\
+ \text { back }
\end{array}\right] /-\left[\begin{array}{l}
+ \text { son } \\
+ \text { high } \\
+ \text { back }
\end{array}\right]}
\end{aligned}
$$

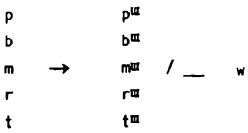

The vagarles of the velarization inducing glide $W$ will be left aside. The Justification for 1ts occurrence has been given in sec. 2.1. above. Compare 2.3.4. below for some remarks on w-Absorption. 
2.3.2. Segmentation. The non-simultaneity of $[+\mathrm{high},+$ back $], 1 . e$. the velarization, is abundantly clear from more advanced stages, where the velarization is manifested as a segment following the velarized segment, $c f$. forms such as tkwana, utkwu, etc. In (6) above, where $k$ is the reflex of earlier velarization. Doke [1931:111, fn. 13] remarks that bg may even be realized as $\left[b^{\circ} g\right]$. Evidently a rule such as (12) is necessary:

$$
\left[\begin{array}{l}
+ \text { ont } \\
+ \text { high } \\
+ \text { beck }
\end{array}\right] \rightarrow[+ \text { ant }]\left[\begin{array}{l}
+ \text { high } \\
+ \text { beck }
\end{array}\right]
$$

The forms Nambzya PQ⿱a 'dry up', Unyama mbwa 'dog', Zezuru mw̃ana 'child', and Njanja nwa 'drink', contain obstruent glides which are rounded. The change in rounding, i.e. if becoming $w$, is probably attributable to the same universal marking convention concerning Round in vowels that are $\left[+\mathrm{high},+\right.$ back]. In sum, then, cut becomes $\mathrm{CW}_{\mathrm{W}}$ by Segmentation and Rounding Adjustment.

2.3.3. Hardening. Glide Narrowing, Fricativization, Backing and Closure are all aspects of Hardening. 6 These rules are obviously well spaced in time, hence it is tempting to assume an 'inner teleology' or globel process within the development. Assimilation alone does not explain it all, since $w$ becomes $k$ even after $s$. Greenberg [1971:344] has noted that Saussure cannot account for the linguistic counterpart of the SiciIIan Defense in chess. This may be interpreted as an implicit plea for the introduction of teleological considerations. The elements of the Sic1lian Defense metaphor are to me the following: (a) It is not only states, but also processes that matter. (b) The Gestalt of a given process is not revealed in a specific state or even succession of states. A process is a dynamic entity. (c) Processes are not blind (like Neogrammarian sound laws) but operate in a specific way and in a specific direction (asymetrically, cf. Chen [1971]).

It $1 \mathrm{~s}$ not at all unreasonsble to assume that the problems concerning the functional unity of Hardening might be solved by a dimensional (and nondiscrete) interpretation of phonological categories. The matter will not be pursued any further here. 
Chomsky and Halle [1968:308] state that "...the degree of narrowlng is determinable from other features of a particular sound." This is correct, with the exception of the obstruent glides; cf. sec. 2.3.3.1. below. However, this atatement may also be taken to mean that the degree of narrowing is a high order feature determining the sound type. The fact that there is a change in sound class, then, follows from a change in stricture. There is no way to reflect this directly in the current formalism. Progression within a dimension (stricture/manner of articulation) rather than discrete change of category seens to be involved (cf. also sec. 2.3.3.1. below).

Another question is whether the degree of narrowing is predictable from the preceding segment (which induces the narrowing). There is no such regularity in the Shona data--suggesting that narrowing progresses on 1ts own along the stricture dimension-but Chonsky and Halle [1968: 310-11] discuss a few cases where narrowing is indeed predictable in this way.

2.3.3.1. Glide Narrowing. This is ostensibly a rule assimilating voleing and naselity:

(13) Glide Assimilation

$$
[+ \text { son }] \rightarrow\left[\begin{array}{ll}
\alpha & \text { voice } \\
\beta & \text { nesal }
\end{array}\right] /\left[\begin{array}{ll}
\alpha & \text { voice } \\
\beta & \text { nasal }
\end{array}\right]-
$$

However, the actual result is an extrenely narrow obstruent glide $\hat{w}$ or $\hat{\gamma}$. Within the current formalism the glides in question may be represented as follows:

$\begin{array}{lllllll} & \text { w } & \tilde{8} & \tilde{w} & \times & 0 \\ \text { high } & + & + & + & + & + & + \\ \text { back } & + & + & + & + & + & - \\ \text { son } & + & + & + & + & - & - \\ \text { nasel } & - & - & - & + & - & - \\ \text { volce } & + & + & - & + & - & -\end{array}$

Th1s 1s unsatisfactory on the following counts: (1) $w$ and $w$ are not distinguished. (11) It fails to bring out the relatedness of $\theta, \theta$, 
w as opposed to $w$.

Doke [1931:109] notes the narrowness of these segments on account of "an abnormal raising of the back of the tongue". It 1s not possible to express this in a rule such as the following:

(15) Gl1de Narrowing

$$
\left[\begin{array}{l}
+ \text { son } \\
+ \text { round }
\end{array}\right] \rightarrow[- \text { son }]
$$

This has the effect of changing $w$ to $x^{*}$ or $\gamma^{*}$ instead of ylelding the required outputs $\hat{w}, \hat{g}$ and $\tilde{w}$. It 18 not at all clear to me how the formalism could be modified to accommodate obstruent glides and capture the correct generalization.

2.3.3.2. Fricativization. This rule turns the volceless and volced obstruent glides $\hat{y}$ and $\hat{w}$ into fricatives, 1.e. $q$ and $\forall$ :

(16) Fricativization

$[\overline{\mathrm{W}}] \rightarrow[\mathrm{c}]$

[W] $\rightarrow[\nvdash]$

Notice that the resulting fricative is a palatal and not a velar. ${ }^{7} \mathrm{~A}$ possible explanation is fronting of $w$ under Narrowing.

2.3.3.3. Backing and Closure. These are necessary to account for $k, g$ $h, h<\varphi, \psi$; cf. Karanga paa : Zezuru ipka 'sweet reed'; Zezuru Imbła : Hera imbga 'dog'; Korekore lowa Ihwa 'sweet reed'; Korekore -hwa 'fight' < -rłwa. [h, $h]$ arise from the weakening of $[x, y]$. The rules for these processes are stated as (17) and (18) respectively:

(17) Backing

$$
\begin{aligned}
& {[- \text { back }] \rightarrow[+ \text { back }] /\left[\begin{array}{l}
+ \text { cont } \\
+ \text { high }
\end{array}\right]} \\
& \text { 1.e. } \& \rightarrow x, \psi \rightarrow y
\end{aligned}
$$

In Ladefoged [1968:32] a palatal fricative is attested under labial1zation. 
(18) closure

$$
\begin{aligned}
& {[+ \text { cont }] \rightarrow\left[\begin{array}{l}
- \text { cont } \\
- \text { round }
\end{array}\right]} \\
& \text { i.e. } \times \rightarrow k, \gamma \rightarrow g, \tilde{w} \rightarrow 0
\end{aligned}
$$

2.3.4. Other rules. There are a number of rules interacting with the velarization process, including w-Absorption, Stop Assimilation, Cluster Initial Deletion, Palatalization, and Weakening. These fall beyond our scope. W-Absorption has been mentioned in sec. 2.1. It depends on a number of factors, including the following:

(i) The nature of the cluster initial segment: w drops more readily (sooner) when this is a labial: Manyika powiza > pelza 'giraffe'; Zezuru miwara > mpara 'flint'. In this, the initiel form of $w$-Absorption, the labial glide is absorbed into the labiality of the cluster inttial, hence the name of the rule.

(ii) The operation of Cluster Initial Deletion hinders w-Absorption: Korekore i qwa < Ipwa 'sweet reed', cf. Zezuru ipka ; Korekore [-fiwara] < -rwara 'be ill', ce. Budye -rwara. In these cases $p$ and $r$ respectively have been deleted and the glide has been retained.

However, the folloving Chopl and Venda forms have undergone both w -Absorption and Cluster Initial Deletion: Chopi: -gela < *búéd- 'tell'; Vends: halwa < bwalwa 'beer', fiatsi < bwatsi 'gress', hana < bwana 'childhood'.

Further examples and derivations 1llustrating these processes are given in Appendix $I$.

\section{Labialization}

3.1. Introduction. Under velarization labial obstruents may become doubly articulated labiovelar and ultimately simple velars. It is hypothesized that labiovelar (and lablal) obstruents in a variety of languages may be explained by the complementary processes of labialization, $c r$. * kua , gua > kpa , gba in a number of nonBantu N1ger-Congo languages; $* k^{* a}, g^{* a}>$ pa, ba in scme Indo-European languages; and kua, gua 
etc. fa, va over an extensive part of the Bantu field.

3.2. The steps in labialization. The various steps in labialization are not instantiated as profusely as those in velarization. Analogous to velarization the following intermediate stages are assumed.

A $\quad B^{8}$

\begin{tabular}{|c|c|c|c|}
\hline gwa & gwa & & \\
\hline$g^{w}$ wa & $g \times$ wa & 1. & Labialization \\
\hline$g^{* a}$ & $g^{u a}$ & 2. & Glide Absorption \\
\hline gwa & gwa & 3. & Segmentation \\
\hline gîa & gพิa & 4. & Glide Narroving \\
\hline$g \beta a$ & $g \beta a$ & 5. & Fricativization \\
\hline- & gva & $5 a$. & Fricative Adjustment \\
\hline gba & - & 6. & Closure \\
\hline $\begin{array}{l}\text { 9ba } \\
\text { bo }\end{array}$ & $\begin{array}{l}\text { 9va, bva } \\
\text { va }\end{array}$ & $\begin{array}{l}7 . \\
8 .\end{array}$ & $\begin{array}{l}\text { Subordination of inner closure } \\
\text { Eliaination of inner closure }\end{array}$ \\
\hline
\end{tabular}

3.2.1. Step 1: Lablalization proper. The skeletal formalization of this process 18:

$$
\text { C } \rightarrow[+ \text { round }] /-\left[\begin{array}{l}
+ \text { son } \\
+ \text { round }
\end{array}\right]
$$

(a) The conditioning enviroment. Proto Niger-Congo 1tems with the canonical form cua are reflected as lablovelar stops in a number of deughter languages, whereas "Cu never is (cf. Hestermann [1927:197 ff.] and sec. 3.2.6. below). Hence I take it that gliding converts "Cua to Cwa before labialization sets in and that glides precede vovels in the hierarchy of this rule. In Bantu (cf. sec. 4. below) labialization operates before glides as vell as vovels but the reflexes give no indication of the early precedence relations.

(b) The domain affected. The prime focus of lablalization is on velars. Ladefoged [1968:5-13] alnost exclusively cites lablovelars such as $\mathrm{kp}$ and $\mathrm{gb}$. Westersann's reconstructions [1927] indicate that only

\footnotetext{
${ }^{8}$ Colum B represents the typical development in Bantu, cf. sec. 4. belou.
} 
* $k$ and $g$ are affected. The Incipient labialization documented in Doke [1931:124] is confined to the velar segment h (cr. Korekore hwunl < hunl 'firewood' and sec. 3.2.3. below). The development of the Proto Indo-European lablovelars in languages such as Greek, Old Irish and Old Cymric is so typical of the full labialization process that an early PRIE labialization rule can be hypothesized without too much wishful thinking, cf. "k'ok'- 'bake' > Proto Old Cymr1c "popl, and "g"en- 'wife'> Old Irish ben. The point is now that the PRIE lablovelars *k*, $g^{*}, g^{* h}$ are labialized velars: "Der 1dg. Phonentyp vird...allgemein als ein Velar mit gleichzeitiger Lippenrundung definiert..." [Szenerény1 1970:55].

Part of the Wichita stop systen [Hockett 1955:102] 1s:

t k

It appears that the labial hole in the stop pattern is on the verge of being filled by a labialized velar.

The comparative Bantu evidence indicates the full extent of the process, all points of articulation being affected, but allows no conclusions regarding the implicational spread due to the great age of the process (ce. sec. 4. below).

(c) The labialization. It is not easy to decide the precise status of the [+ round] feature in the structural change of the rule. The rounding presumably extends through the whole of the consonant. This is clearly demonstrable in Sotho, where all linguals are rounded before rounded sonorants. The lablalization is manifested as an extreme rounding affecting a given segment from beginning to end; cf. the following Northern Sotho forms where the rounding is signified by a raised $x$ :

$\begin{array}{lll}\text { [t'̌hxukYudXu] } & \text { tŠhukudu } & \text { 'rhinoceros' } \\ \text { [-rYoka] } & \text {-roka } & \text { 'sew' } \\ \text { [-IXoma] } & \text {-loma } & \text { 'bite' }\end{array}$

It seems, however, that the rounding may--and usuelly does--develop into an offglide. Hence: 


$$
\underset{[+ \text { round }]}{\mathrm{C}} \rightarrow\left[\mathrm{CW}^{\mathrm{w}}\right]
$$

[Cu] is a segmental polyphthong (cf. sec.3.2.6. for discussion). The PRIE labiovelars instantiate this stage. In Sotho original clusters of lingual consonant and $W$ are converted to $C^{W}$ via labiallzation:

$$
\begin{array}{llll}
\text { C } & w & a & \\
C^{w} & w & a & \text { Labialization } \\
C^{w} & & a & \text { Glide Absorption }
\end{array}
$$

The [U] offglide is not by any means a separate glide but a rounded transition to the following nonround vowel, cf. Northern Sotho [-క̌çu] - కweu 'white', [-rwala] -rwala 'carry'. Kunene [1961:120] notes the following:

The element $\underline{w}$, when occurring immediately after a consonant or consonant combination, is anticipated in the articulation of this sequence, imparting labial characteristics, in the form of lip-rounding, to this consonant or consonant combination, and 1tself persisting after the articulation of such consonent or consonant combination, and being released by the movement of the lips towards the position of the following vowel.

Kunene interprets the rounding as a glide following the rounded segment, a conclusion which does not necessarily follow, but we shall leave the matter at that.

3.2.2. Step 2: Glide Absorption. Nothing much need be said about this: the gllde is absorbed into the roundins of the labialized segment.

3.2.3. Step 3: Segmentation. Like Glide Absorption this is a prerequisite to later stages. No function is claimed for this rule other than the development of a rounded element following the consonant affected by labialization. In other words, this distinct element may be a full glide or even the rounded offelide mentioned above. The following Korekore forms attest to Segmentation [Doke 1931:124]) hunl > hwuni 'firewood', hope > hwope 'sleen', hono > hwono 'mole'.

3.2.4. Step 4: Glide Narroulng. Glide Narrowing 1s hypothesized but not instantiated. 
3.2.5. Step 5: Fricativization. In Bantu, Narrowing is terminated at this point. Step 5a: Fricative Adjustment is a 'natural segment' rule: the most natural labial fricatives are labiodental.

3.2.6. Step 6: Closure and double articulation. Compare the reflexes of the following "Western Sudanic" (i.e. Proto N1ger-Congo) forms [Westermann 1927:197 fe. ]:

$$
\begin{aligned}
& \text { "gud 'zerbrechen' : Ewe gbd, gbã; Ge gba } \\
& \text { "gual 'viel' : Eve gbàgbabà 'sehr viel'; Nupe } \\
& \text { *-guf- 'Leopard' : De gbf; Akassele -gbé; Bulom -gbe } \\
& \text { *-guò 'W1dder' : Evre -gbd; Nupe -gbo } \\
& \text { "-kua- 'Weg' : Beri -kpa; Nupe -kpa } \\
& \text {-kui 'gross, viel' : Eve kpl; Santrokofi kpi }
\end{aligned}
$$

Compare also Greenberg $[1966: 16,20,21]$ : no. 14 'd1e', no. 30 'leopard', and no. 40 'skin'. Westermann [1930:21] points out that Dahomey Eve has $\mathrm{gw}$ and $\mathrm{kw}$ in the place of Ewe $\mathrm{gb}$ and $\mathrm{kp}$.

Ladefoged [1968:5-13] has given detalled descriptions of Step 6 . The facts are complex and involve the timing of closures and relesses, the direction of the airflow and the airstream mechaniams used (cf. sec. 3.2.7. below). The phonological interpretation of double articulations in Chomsky and Halle [1968] is singled out for closer scrutiny.

SPE phonology equates segment with monophthong--especially in phonological representations. For example, diphthongs are analysed as real1zations of underlying tense vowels (cf. Chomsky and Halle [1968:183]). The rule there does not reveal the exsct nature of a diphthong, i.e. that it is a unitary rocalic segment with an acoustic structure that varies in time. The output of the SPE Diphthongization Rule is: [T] $[y],[\bar{u}][w]$, 1.e. sequences of two separate segments. Naturally this has the highly satisfying effect of constraining the theory in such a way as to preclude different (not to say contradictory) feature specifications within a single segment. In the cases above the opposite specifications $[+$ voc] and [- roc] are assigned to two distinct segments: 
(26)

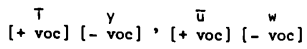

A monosegmental interpretation is forced to assign these opposite values to one and the same segment:

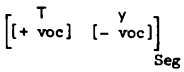

Evidently, the unconstrained use of opposite features within a single segment may so seriously weaken a phonetic theory as to neutralize every theoretical claim it has to make. I should, however, like to plead the case of the constrained use of non-homogeneous feature specifications in a swall range of cases, the segmental polyphthongs. Andersen [1972] has explicated the usefulness of such a concept in a wider context. His segmental diphthong is equivalent to segmental polyphthong as used in this study. Compare Andersen's definition [1972:18]: "...a single segment whose central phase is acoustically heterogeneous in its tenporal development, rather than presenting a steady state".

A diphthong is a kind of vocalic polyphthong. Other polyphthongs include secondary articulated consonants, i.e. consonants with offglides: $k^{\gamma}, k^{\nu}, p^{u}$; affricates: ts, $k x$; doubly articulated sounds such as $\hat{g} b, \widehat{k p}$, and clicks. Only secondary and doubly articulated obstruents fall within our purview.

Notice that the alphabetic phonetic notation used here represents the relevant segments as polyphthongs. This, the binary feature system does not do:

$$
\left[\begin{array}{c}
k^{\omega} \\
\text { - cont } \\
\text { - volce } \\
+ \text { h1gh } \\
+ \text { beck } \\
+ \text { round }
\end{array}\right] \quad\left[\begin{array}{l}
- \text { cont } \\
+ \text { volce } \\
+ \text { high } \\
+ \text { back } \\
+ \text { round }
\end{array}\right]
$$


This essentially timeless, monophthongal interpretation of all secments fails in the Nupe case reviewed in Chomsky and Halle [1968:311].

Historically, the Jupe labiovelars $\hat{k p}$ and $\hat{g b}$ are extremely lablalized velars developing from * $\mathrm{kwV}$ and ${ }^{*} \mathrm{gwV}$, $\mathrm{cf}$. the beginning of this subsection and Westermann [1927:197 ff.]. Being doubly articulated segments--and the only two in the Iupe system-they are phonologically opaque from a synchronic point of view and could be either extremely labialized velars or extrenely velarized labials.

Chomsky and Halle [1968] inroke the ilupe phonological system in order to decide the issue. They interpret $\hat{k p}$ and $\hat{g b}$ as extrenely velarized labials. Consider the following. The phonological system of Nupe contains segments such as $k$ and $\hat{k p}$ and rules such es exemplified in (29):

$$
/ k, \hat{k p} / \rightarrow\left[k^{*}, \hat{k p} *\right]
$$

and palatelization:

$$
/ k, \hat{k p} / \rightarrow[\hat{k r}, \hat{k p r}]
$$

cr. [Smith 1967; Hyman 1970].

Specifying $\hat{k p}$ as a velar with (extreme) rounding would fail to distinguish $\hat{k p}$ from $\widehat{k p} p^{\omega}$ (and $\left[k^{4}\right]$ ), since the only feature configuration avallable would be:

$$
\left[\begin{array}{l}
- \text { ant } \\
- \text { cor } \\
+ \text { high } \\
+ \text { back } \\
+ \text { round }
\end{array}\right]
$$

The $\hat{k p} \times \hat{p}^{w}$ distinction might be salvaged by rejecting the principle that "...the particular degree of rounding...can be determined by the phonological rules of the language..." [Chomsky and Halle 1968:311] and by spectfying degree of rounding: $p$ of $\hat{k p}$ being, say [th round] and $v$ of $\mathrm{kw}^{\mathrm{w}}$ and $\hat{\mathrm{kp}} \mathrm{w}[+1$ round]. Nevertheless, no amount of juggling will save the $\hat{k p} x \hat{k p}$ distinction since the feature [+ round] is reserved for the $p$ portion. 
By regarding $\hat{k p}$ as a labial with extreme velarization, 1.e.

$$
\left[\begin{array}{l}
+ \text { ant } \\
- \text { cor } \\
+ \text { high } \\
+ \text { back }
\end{array}\right]
$$

the $k^{W} \times \hat{k p} \times \hat{k p w}$ contrast is easily captured. However, the problem now is $\hat{k p} y$, the palatalized extremely velarized lablal, since, as Professor Hyman (personal communication) points out, the velarization [+ high, + back] is incompatible with the palatalization [+ high, - back] in the same segment.

I subnit that this particular dilemma is the result of an exaggerated insistence on the monophthongal nature of segments. Once this requirement is relexed to allow a polyphthongal interpretation of double articulation the whole problen concerning the phonological opacity (are the segments velarized labials or labiallzed velars?) and the phonological representation of $\hat{k p}$ and $\widehat{g b}$ in Nupe vanishes: synchronically they are neither labials with extreme velarization nor velars with extreme labialization but labiovelars: doubly articulated polyphthongs.

The processes of extreme labialization of $k$ and extreme velarization of $p$ may have precisely the same outcome: a labiovelar stop, written $\hat{\mathrm{kp}}$, which can only be:

$$
\left[\left[\begin{array}{l}
- \text { cont } \\
- \text { voice } \\
+ \text { high } \\
+ \text { back }
\end{array}\right]\left[\begin{array}{l}
- \text { cont } \\
- \text { voice } \\
+ \text { ant } \\
- \text { cor }
\end{array}\right]\right]_{\mathrm{Seg}}
$$

Furthermore, the exlstence of kpl forces the acceptance of a hierarchical arrangement of polyphthongs with $\hat{k p}$ as one unit and $y$ as another:

$$
\text { [ [ } \hat{k p}] \mathbf{y}]
$$


3.2.7. Step 7: Inner relesse and double articulation. In regard to the timing of releases in doubly articulated segments Chomsky and Halle [1968: 324] gtate:

The order of release of the different closures is governed by a simple rule. In sounds without supplementary motions, the releases are simultaneous. In sounds produced with supplerentary motions, closures are released in the order of incressing distance from the lips. The resson for this ordering is that only in this manner will clear auditory effects be produced, for acoustic effects produced inside the rocal tract will be effectively suppressed if the vocal trect is closed.

Compare the following remarks of Ladefoged on Kalabai go [1968:10]: "...the velar closure must have been completely released while the lips remsined closed for a further 50 msec...." [Mmphasis mine, FP].

This contravention of the Chomsky-Helle release principle accomplishes a subordination of one stricture to another: the g-stricture could eventually become a modification of $b$. The Chomsky-Helle principle could be extended in the following way to account for this: primary release of inner closures result in their subordinstion.

For Yorube $f$ the following development may be hypothesized: $g b$ > $9 b>6$.

(i) $\mathrm{gb}$ is a doubly articulated, extremely labialized $\mathrm{g}$.

(ii) $g_{b}$ is a b with velaric action: when the inner stricture is released first it becomes secondary in terms of the extended chomsky-Halle release principle.

(11i) B is an implosive. Velaric action induces lowering of pressure in the mouth so that air flows into the mouth on release of the lablal closure (cf. Ladefoged [1968:9]).

This conclusion is supported by the following considerations:

(1) Ladefoged [1968:6-7] has found that implosive 6 in Igbo is not alvays implosive, the stable mark distinguishing it from $b$ being velaric action (heightening of the back of the tongue). This may be a reault of the transition from step 2 to 3 above. 
(11) The large formant transitions of implosive B are similar to those of gb [Ladefoged 1968:13, and Plate 4B].

(11i) In Soso, Ladefoged informs us [1968:14] that "..there is also a rully voiced $\hat{g b}$ which verges on the implosive".

(iv) Igbo has $\hat{\mathrm{kp}}$ and $\hat{b}$ but no $\hat{g b}$ [Ladefoged 1968:59]. It seems plausible that $\hat{b}$ derives from $\hat{g b}$ if due consideration is taken of (i) above.

(v) If of occurs, so does $b$ but not vice versa. A possible explanation is that $B$ arises from labialization of $g$, which, being a velar, leads the labialization process.

Greenberg [1970] gives three ways in which Implosives arise, this being his second $(1970: 28-30)$.

The extended Chomsky-Halle release principle also accounts neatly for the development of the bilabial nasal click in Idoma [Ladefoged 1968:12] from an extremely labialized velar nasal:

$$
\begin{array}{ll}
\text { gW Labialization } \\
\mathrm{gm} \\
\mathrm{Im} \\
\text { no Subordination of inner closure }
\end{array}
$$

We may assume a similar development via double articulation and the subordination of inner closure for the Greek, Old Irish and Old Cymric labials from PRIE labiovelars, wheress Wichite $k^{w}$ is evidently on its way to [p] (cr. sec. 3.2.1(b)).

But a teleological explanation seens to be called for in view of the following symetry:

(1) Velarized labials may result in velars. Compare the Chopi and Venda examples in sec. 2.3.4, above.

(ii) Labialized velars may yleld labiala, as implosive $b$ in Igbo.

Such changes could be described in terms of normal and extended verstons of the Chomsky-Halle release principle, but in the end, the tining 
of releases itself requires explanation. Could it not be that the 'velar' part of a velarized segment and the 'labial' part of a lablalized segment bear some kind of 'focus'?

3.3. Labio-alveolar fricatives. These doubly articulated fricatives arise from combinations of labial (labiodental) fricatives and spirants. In Sotho (and Shona) the cluster itself arises from palatalization: f $>f S I>f \hat{i}$.

$$
\begin{array}{lllll}
\text { Shona } & & & \\
\text { *-pik- } & > & & -\hat{f s i k a} & \text { 'arrive' } \\
\text { *-plip- } & > & \text { Zez. } & -\hat{f s i p a} \text { 'become black' } \\
\text { "-biád- } & > & & -\hat{\beta} z a r a & \text { 'bear child' } \\
\text { "bi- Class } 8 \text { IP } & > & \hat{\beta} z i- &
\end{array}
$$

(37) Sotho

$$
\begin{array}{ll}
\text { lefifi } & >\text { lefsifsi }>\text { leswiswi 'darkness' } \\
\text { lefika }>\text { lefsika } & >\text { leswika 'stone, rock' }
\end{array}
$$

This is progressive assimilation induced by a consonant and does not fall within the scope of the present account. Notice that Sotho goeg one step further: the labio-alveolar fricative is changed to a rounded spirant: $f \hat{s}>s^{w}$ (cf. Ponelis [1973] for details).

4. Labialization in Bantu

4.1. Introduction. The earliness of this rule in Bantu is reflected by the following.

(i) Labialization is attested in a wide variety of Bantu langusges, including Rundi, Nkoya, Manyika, Pende, Sagala, Zulu and Bemba.

(ii) It functiong before the $7>5$ neutralization in the vovel systen, e.g. Zulu: *b $\rightarrow \vee / \_y ; b$ elsewhere: *bun- > -vun- 'harvest'; -bumba > -6umba 'clay for pottery'.

(iii) Labialization precedes velarization in the languages where both rules are operative (e.g. Rundi). The interaction between these rules polnts to the following: (a) Velarization and labialization take place 
before the highest back sonorant (vowel) available. (b) Stops take precedence over fricatives. Together, $(a)+(b)$ explain the fact that when lablalization changes $* P$ and $b$ to fricatives before * velarization attacks the stops before "u (and not the fricatives before $v$ ); $c f$. Rund1: -bụ́n-> Rund1 -vun- 'break'(tr.); "búfd-> Rundi -byir- 'tell'

(Iv) There is extensive neutralization of obstruents before $y$ which is evident from the nany cases of multivalence anong Guthrie's reflexes. Generally:

$$
\begin{aligned}
& \mathrm{p}, \mathrm{t}, \mathrm{k} \rightarrow \mathrm{f} / \mathrm{L} \\
& \mathrm{b}, \mathrm{d}, \mathrm{g} \rightarrow \mathrm{v} / \mathrm{u}_{-}
\end{aligned}
$$

(v) The process covers a large and continuous area in the central to southern heartland of the Bantu field (cf. Fopogram 14 in Guthrie [1967:79]).

4.2. Initial domain and spread of labialization. The assimilation determinant is the high beck "y, the highest back vowel in the Proto Bantu four helght system. Labialization Proper conceivably preceded Gliding, since no difference as to Labialization could be established between the environments $/{ }_{y}$ and $/ \ldots$, where $A$ developed from $y$ by Gliding. Note however, that the elide undergoes Absorption in a number of languages, cf. the reflexes of *-kứa 'die':

\begin{tabular}{|c|c|c|c|c|}
\hline \multicolumn{3}{|c|}{ No Glide Absorption } & \multicolumn{2}{|c|}{ Glide Absorption } \\
\hline (Bem) & ba, & Ile) & (Nyoro & , Zulu) \\
\hline k & 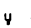 & a & k y & a \\
\hline$k^{w}$ & y & a & $k^{W} y$ & a \\
\hline$k^{w}$ & ด & a & $k^{*}$ ค & a \\
\hline & & & $k^{w}$ & a \\
\hline$p f$ & $w$ & a & pf & a \\
\hline$f$ & w & a & $f$ & a \\
\hline
\end{tabular}

Labialization Gliding Glide Absorption Narrowing, etc. cluster Simplification

The affected segnents are volced and volceless plosives, nasals remaining unaffected. All three primary Proto Bantu series--velars, alveolars and labials--participate in the process. 
4.3. The processes of labialization. Since it is an anclent rule the stages are poorly attested in Guthrle's data. The rules above generate derivations such as the following:

\begin{tabular}{|c|c|c|c|c|c|}
\hline \multirow[t]{8}{*}{ (40) } & py & ty & ky & dy & \\
\hline & $p \omega u$ & $t w$ & $k^{w} u$ & $d u$ & Lablalization \\
\hline & pwu & twu & kwu & dwu & Segmentation \\
\hline & pพ̣ิ & $t$ wิu & kพ̣̂u & dพิบ & Glide Nerrowling \\
\hline & pfu & tfu & $k f u$ & dvu & Fricativization \\
\hline & & pfu & $p f u$ & bvu & Stop Assimllation \\
\hline & $P f u$ & $P f u$ & Pfu & byu & Stop Subordination \\
\hline & fu & fu & fu & vu & Stop Elision \\
\hline
\end{tabular}

The change $p, t, k \rightarrow f$ and $b, d, g \rightarrow v$ is not mere fricativization. Pure fricativization would have resulted in $f \theta \times \beta$ б $\gamma$.

Hardening goes no further than the fricative stage, hence pfu tfu kfu bvu dvu gvu do not develop further into "ppu tpu kpu bbu dbu gbu.

The Stop Assimilation and Fricativization stages are exemplified in Appendix II with forms from Guthrie [1967, etc.].

4.4. Rule 1nteraction. Languages such as Nyekyosa [Guthrie 1971:56], Bembe [Guthrie 1971:57], Sagala [Guthrie 1971:47], Sango [Guthrie 1971: 51], and Zulu have reflex patterns such as the following:

$$
\begin{array}{rrr}
* & -i & -4^{9} \\
* t & > & f \\
* k & > & f
\end{array}
$$

The fact that $p \rightarrow+/ \ldots$ might be explained by the following assumptions :

(a) Lablalization and palatalization both spread from velars to labials, with palatalization trailing labialization (1.e. being initiated

\footnotetext{
9 Deta1ls such as Bemba 5 for $s$ are not reflected in (41).
} 
after it).

(b) Labialization reaches the labial series first and spreads to labials before i by phonetic analogy.

However, these assumptions are not borne out by Mambwe [Guthrie 1971: 56] :

(42)

$\begin{array}{lrr}* p> & -1 & -4 \\ t> & f \\ k & >s & s\end{array}$

The implicational spread explanation above might be salvaged in the following way. Palatalization is the earlier rule, which spreads first to the alveolar series. Labialization then juraps the alveolar series while palatalization is still 'busy' there to operate on the labial series.

However, the data seen to point to the existence of an intensity dimension vithin implicational spread to the effect that a given series is more susceptible to a given rule than another series. The processes in (42) illustrate that alveolars palatalize more readily, whereas $(4,1)$ and (42) together exemplify the greater susceptibility of labials to labialization. The assumption of an intensity scale explains why phonetic analogy takes place before i makinf it unnecessary to state phonetic unalogy as a separate principle.

4.4. Swazi labialization. In Swazi there is labialization of lax voiced and volceless, espirated alveolar stops: in both the release is slow. In (43) compare the following instances of this type of labialization, which occurs before back vowels and before the glide $w$.

\begin{tabular}{|c|c|c|c|}
\hline$-I t f u$ & 'ours' & Zulu & -ethu \\
\hline Iitfole & 'calf' & Zulu & ithole \\
\hline umt folo & 'acacta caffra' & Zulu & umtholo \\
\hline butfongo & 'slcepiness' & Zulu & ubuthongo \\
\hline -tfwala & 'carry' & Zulu & -thwala \\
\hline- tsatfu & 'three' & Zulu & -thathu \\
\hline
\end{tabular}


(143) b. d > dv:

$\begin{array}{llll}\text { indvodza } & \text { 'man' } & \text { Zulu } & \text { indoda } \\ \text { Ildvolo } & \text { 'knee' } & \text { Zulu } & \text { idolo } \\ \text {-dvuma } & \text { 'flavorless' } & \text { Zulu } & \text {-duma } \\ \text { indvuna } & \text { 'headman' } & \text { Zulu } & \text { induna } \\ \text {-dvwa } & \text { 'alone' } & \text { Zulu } & \text {-dwa }\end{array}$

What is different about this kind of labialization is that it affects only alveolars. 10

5. Conclusion

I have tried to put forward a unified explanation of a number of seemingly disparate phenomena in terms of processes of secondary articulation. It is argued that the secondarily articulated seguents arising via Velarization and Labialization Proper undergo Hardening, become doubly articulated and are eventually simplified to labial and velar obstruents, respectively. The possibility strongly presents itself that the rule hierarchies (imnlicational spread phenomena) and the dimensional progression of rules (as under Hardening) nay be accounted for adequately only within a nondiscrete phonology.

$10_{\text {Swazi and Lala }}$ (1.e. Tekela) palatalization before front vowels is constrained in exactly the same way.

\section{REFERENCES}

Abercrombie, David. 1967. Elements of General Phonetics. Edinburgh: Edinburgh University Press.

Andersen, Henning. 1972. "Diphthongization", Language 48.11-50.

Chomsky, Noam and Morris Halle. 1968. The Sound Pattern of English. Hew York: Harper and Row.

Chen, Matthew. 1971. "Metarules and universal constraints in phonological theory", Pepers on Linguistic Analysis 13.

Doke, Clement M. 1931. A Comparative Study in Shone Phonetics. Johannesburg: Witwatersrand University Press.

Greenberg, Joseph H. 1966. Languages of Africa (second revised edition). Bloomington: Indians University Press. 
Greenberg, Joseph H. 1970. "Some generalizations concerning glottalic consonants, especially implosives", Working Pepers on Lanquage Universels 2, Stanford University.

Greenberg, Joseph H. 1971. "Is language l1ke a chess game?" Language, Culture, and Compunication, ed. by Anwar S. Dil, 330-52. Stanford: Stanford University Press.

Guthrie, Malcolm. 1967, 1970, 1971. Comparative Bantu. London: Gregg. Hockett, C.F. 1955. Manual of Phonology. Bloomington: Indiane University Press.

Hyman, Larry M. 1970. "How concrete is phonology?" Language 46.58-76.

Kunene, D.P. 1961. The Sound Systern of Southern Sotho. Unpublished $\mathrm{Ph} . \mathrm{D}$. thesis, University of Cape Town.

Ladefoged, Peter. 1968. A Phonetic Study of West African Languages (second edition). Cambridge: Cambridge University Press.

Ladefoged, Peter. 1971. Preliminaries to Linguistic Phonetics. Chicago: University of Chicago Press.

Lanham, L.W. 1955. A Study of Gitonga of Inhambene. Johannesburg: Witwatersrand University Press.

Ponel1s, Fritz. 1973. "Studies in Northern Sotho phonological dynamics". Mimeo.

Reighard, John. 1972. "Labiality and velarity in consonants and vowels", Papers from the VIII Regional Meeting, University of Chicago: Chicago Linguistic Society.

Sm1th, N.V. 1967. "The phonology of Nupe", Journal of African Languages 6.153-69.

Stevick, Earl W. 1964. "Two Bantu consonant systems", Language 40.58-74.

Szemerény1, 0swald. 1970. Einführung in dle vergleichende Sprachwissenschaft. Darmstadt: Wissenscheftliche Buchgesellschaft.

Trubetzkoy, N.S. 1969. Principles of Phonoloky. Translated by Christiane A.M. Baltaxe. Berkeley: University of California Press.

Vennemann, Theo and Peter Ladefoged. 1971. "Phonetic features and phonological features", Working Papers in Phonetics 21.13-24. UCLA.

Vennemann, Theo. 1972. "Phonetic detail in assimilation: problems in Germenic phonology", Language 48.863-92.

Westermann, Diedrich. 1927. Die westlichen Sudansprachen und 1hre Beziehungen zum Bantu. Berlin: De Gruyter.

Westermann, Diedrich. 1930. A Study of the Fre Language. Translated by A.L. Bickford-Smith. I ondon: Oxford University Press.

Ziervogel, Dirk. 1951. A Gremar of Swaz1. Bentu Grammaticel Archives, No. 3. Johannesburg: Witwatersisnd University Press. 
Ziervogel, Dirk, P.J. Wentzel and T.H. Makuya. 1972. A Handbook of the Venda Lanquage. Manualla, vol. 10. Pretoria: University of South Africa.

\section{Appendix I}

A. Examples

$$
\begin{aligned}
& \text { *-tapwa 'be captured as spoll' } \\
& \text { *-pwa 'smesh' } \\
& \text { *-pwira > -phira 'ary up' } \\
& \text { *-bwe 'stone' } \\
& \text {-bwaira > -bgaira 'vink' } \\
& \text { *mwana > mnana, mw̃ana, miwana, jwana 'child' } \\
& \text { *-nwa > -njwa, -jwa 'drink' } \\
& \text { *-batwa > -batowa, -batkwa 'be hela' } \\
& \text { *-twa > -twa, -tha , -tcwa, -owa, -tskwa, -tsqwa 'pound' } \\
& \text { *-pindwa > -pindywa 'be entered' } \\
& \text { *-biswa > -blskwa 'be renoved' } \\
& \text { *-zuzwa >-zuzwwa 'be shaken' } \\
& \text { *-rwa > -rłwa, -gwa 'fight' }
\end{aligned}
$$

B. Derivations

In these derivations different dialect forms are generated.

*-dúád- 'be 111 '

Budya -rwara, Karange -rłwara, Korekore -fiwara, Menyike -gwara

rwara

$\begin{array}{ll}\text { rwwara } & \text { Velarization } \\ \text { rwwara } & \text { Segmentation } \\ \text { rwwara } & \text { Glide Narrowing } \\ \text { rywara } & \text { Fricativization } \\ \text { rywara } & \text { Backing } \\ \text { rgwara } & \text { Closure } \\ \text { gwara } & \text { Cluster Initial Deletion } \\ \text { Ywara } & \text { Cluster Initial Deletion } \\ \text { fwara } & \text { Weakening }\end{array}$


"-pú- 'dry ur'

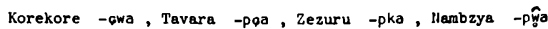

pwa

$p^{\boldsymbol{W}_{\text {wa }}} \quad$ Velarization

pwwa Segmentation

p్̧wwa Glide Narrowing

pqwa Fricativization

pxwa Backing

pkwa Closure

pka w-Absorption

Cluster Initial Deletion

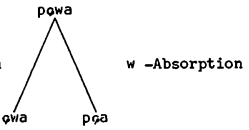

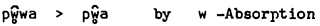

The precise derivation of poa is opaque since $w$-Absorption may either precede or follow Fricativization.

*-búa 'dog'

Korekore -mbwa, Urungwe -tjgwa , Budya -mbła, Hera -mbga, Unyama -mbwa

mbwa

$m b^{\text {III }}$ va Velarization

mbwwo Segmentation

mbwwa Glide Narrowing

rabłwa Fricativization

mbła $\quad w$-Absorption

mbyo Backing

mbga Closure

mbgwa 


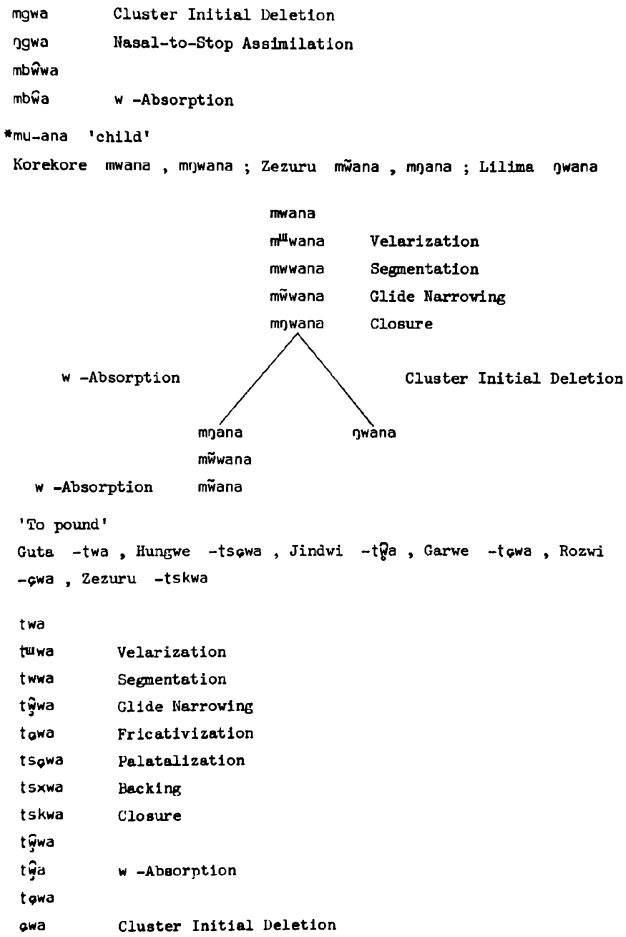


57

Append 1x II

A. Examples

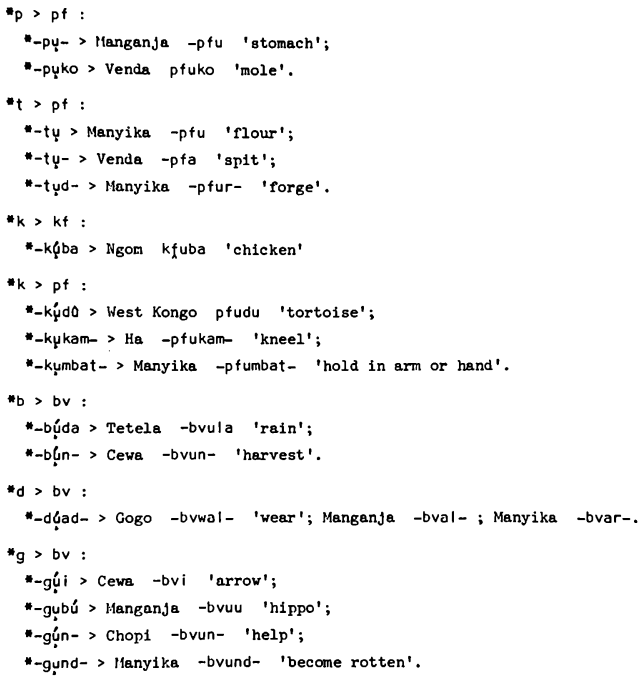

B. Further Exaraples

*b

"bụn- 'harvest' > Zulu, Tumbuka, Unguja -vun-; Cewa -bvun- 
-d

-dykut- 'blow bellows' > Unguja, Luba-Katanga -vukut-' ;Bemba

-fukut- ; Manganja -bvukut-

$\mathrm{g}$

-gynd- 'become rotten' > Unguja, Zulu -vund-; Manyika -bvund- ;

Lenje -fund-

*p

-puk- 'dig up, fling up (earth)' > Kele -fy-; Shambala, Lwena,

Bembe -fuk-

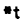

*-týd- 'forge' > Mvumbo -pfule-; Tiene -tful; Prokomo -fuy- ;

Unguja -fu- ; Central Kongo -ful-; Manylka -pfur-

$* \mathbf{k}$

-kykam- 'kneel' > Rund1, Central Kongo, Lwena, Luba-Katanga, Bemba,

Ils -fukam-; He -pfukam-

In some languages the volced-voiceless contrast is neutralized under labialization: [+ voice] $\rightarrow$ [ - voice]. This is a manifestation of $\mathrm{B}$ widespread strengthening rule functioning in the enviroment of bigh vowels and/or nasals. 
THE HISTORICAL DEVELOPMENT OF SOUTHWLSTERN MANDE CONSONANTS ${ }^{2}$

\author{
David Dryer \\ Michigan State Univeraity
}

1. Introduction

Southwestern Mande (SWM) constitutes a set of five closely related languages apoken in the republics of Guinea, Liberia, and Sierra Leone. The distribution of the five SWM languages: Mende, Loko, Band1, Loma and Kpelle is shown on the map in (1) below.

These languages are characterized by a well-developed system of morpheme-initial consonant alternation, a phenomenon which has long been recognized by lingulsts as an important area of research. Early investigations of SWM initial consonant alternation (Eberl-Elber 1937 and Hintze 1948] focused on the grammatical enviroments in which these alternations took place, while later investigations [Manessy 1964, Meeussen 1965, and Bird 1971a] sought a phonological explanation for this phenomenon.

Th1s paper reconstructs the historical developent of SWM Initial consonant alternation by demonstrating how the consonant system of each of the modern SWM languages developed from the consonant system of ProtoSouthwestern Mande as the result of simple, natural phonological changes. 2

\footnotetext{
$I_{\text {Th1 }}$ paper was originally presented to the Fourth Annual Conference on African Linguistics, Queens College, Flushing, New York, April 4-6, 1973. It has greatly profited from discussions which I have had with a number of scholars. I am particularly Indebted to William $E$. Welmers for the insight, wisdom, and information he so gratlously offered. And while he does not agree with all the conclusions presented here, this in no way diminishes the importance of his contribution.

Also at this conference, Larry Hyman presented a complementary paper dealing with the same subject, later published as "Notes on the history of Southvestern Mande"[Hyman 1973]. While Hyman did not at that time have access to the additional SWM data gathered during my field investigation of 1971-2, many of his conclusions are in accord with my own. Since the time of the or 1 ginal presentations, each of us has had the opportunity to reed and comment on the other's paper. Consequently, thin version of my paper has benefited from and incorporated many of Hyman's suggestions as will be noted. This version also contains a discussion of some of the more important diacrepancies between the two papers.

The rules provided in this paper are diachronic. The question of the types of eynchronic phonological rules used in the treatment of this phenomenon has not fully been answered. For a more complete discusaion of th1s problem, see Dryer [1973].
} 
(1) The distribution of the Southwestern Mande languages

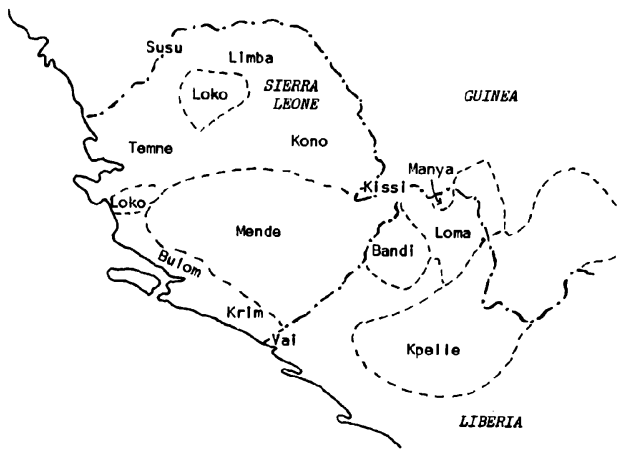

Section 2 of this paper describes the consonant alternations of each of the modern SWM languages and the conditions under which they occur. Sect1on 3 describes the historical development of these alternations, and section 4 discusses some alternative proposals concerning the historical development of SWM consonants.

\section{The Alternations}

The oppositions strong - yeak and heavy - 11ght - nasel are userw in the deacription of SWM consonant mutation. Each alternating consonant hes a otrong and a veak variant. The strong variant is usually the more fort1s member of the two, either volced, geminnte, or prenaselized consonant. The terms: 11ght, heavy, and nagal, describe the three series of strong - veak alternations. The underlying consonants of the 
light series are volceless obstruents: $p, f, t, s, k$, and $k p$. The underlying consonants of the nasal series are: $m, n, n y, 3$ and $D$ - No obvious class, hovever, describes the heavy series which includes the liquid $I$, the glides: $y, W$, and $Y$, and the implosive $B$. The important characteristics of this series are that the members are volced, non-nasal, and not true vowels (1.e., not [- consonantal, + vocal1c]). The Initial consonant alternations of the five Southweatern Mande languages are listed in Table I. ${ }^{4}$

In SWM, strong surface consonants are generally derived from an underlying sequence of a nasal followed by a consonant. 5 Correspondingly, when the underlying consonant is not preceded by a nasal, 1ts surface realization is weak. A phonological alternation between strong and reak initial consonants can occur because in some grammatical environments, the given initial consonant is preceded by a morpheme bearing a final nasal consonant, and in other gramatical environments the given consonant is not preceded by a morpheme bearing a final nasal consonant. Thus, the conditioning enviroments of these alternations can be established by identifying those morphemes which bear final nasals and by identifying the enviroments in which they occur.

The morphemes include three syllabic nasals and a number of (CV)CV( $(\mathrm{g})$ nouns and verbs. The three syllabic nasals as reconstructed for Proto-

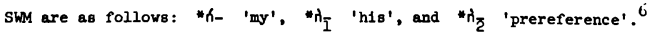

While it is not clear whether " $H_{I}$ ' $h 1 s$ ' and ${ }_{2}$ 'prereference' consist of one morpheme or two in Proto-SWM, there is no doubt that

${ }^{3}$ Pollowing traditional orthography, SWM palatel nasals are transcribed wh the digraph ny.

4 The SWM languages also contain morphemes with strong initial consonants which do not mutate. These morphemes can, for the most part, be identified as borrowings which have been acquired since the establishment of consonant mutation in SWM.

5 Due to the uncertainty of the synchronic status of the phonological rules (see footnote 2), the term underlying can only be taken tentatively.

6 see section 3.4. for a brlef description of the varlous reflexes of these possessive pronouns. 
Table I: Southwestern Mande 1nitiel consonant alternation

The Light Series

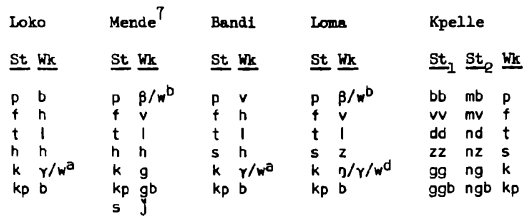

The Heavy Series

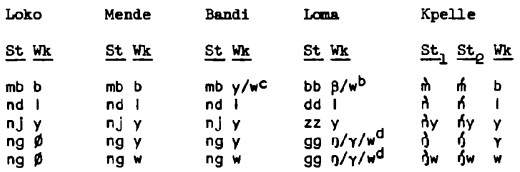

The Nossl Series

Loko Mende Bandi Loms Kpelle

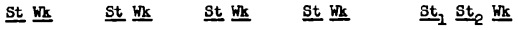

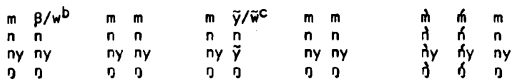
(a) $\quad \mathrm{W} / \underset{[+\mathrm{rd}]}{\mathrm{V}} \quad \mathrm{Y} /{ }_{[-\mathrm{rd}]}^{\mathrm{v}}$
(d) $\quad \mathrm{g} / \mathrm{v} \quad \mathrm{w}-\underset{[+\mathrm{rd}]}{\mathrm{v}} \mathrm{r} / \underset{[-\mathrm{rd}]}{\mathrm{v}}$
(b) $\quad W / \underset{[+b k]}{V} \quad B / \tau-\underset{-b k]}{v}$
(e) vowels following underlying nasals are nasalized on the surface

(c) $\quad w / \underset{\tau+b k]}{v} \quad \mathrm{y} /-\underset{[-b k]}{v}$

\footnotetext{
$7_{\text {The }} \mathrm{s}-\mathrm{j}$ alternation in Mende represents a recent development. The Mende FerIex of Proto-SWM "s is $h$ (Proto SWM: "sua 'animal" Mende: hua 'animal').
} 
historically these two prefixes are cognate. They are distingulahed here primarily to facilitate the presentation. The Kpelle version of this morpheme also carries the meaning 'prereference', 1ndicating that the noun to which it 18 affixed has previously been mentioned in a given dia-

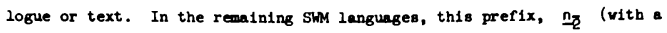
non-high tone) in Bandi, Loko, and Mende and $\hat{f}_{\S}$ in Loma, 18 prefixed to almost all noun phrases and with no spparent chsinge in meaning. Examples of the SWM noun phrases both with the "ind prefix and without the prefix are given in (2) below:

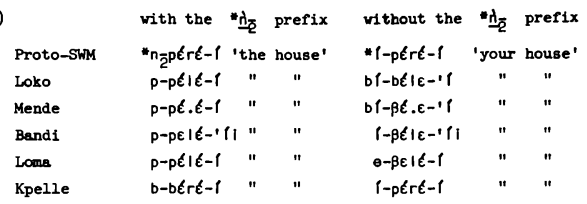

In addition to these syllabic nasals, SWM has numerous morphemes, both monosyllabic and bisyllabic, which bear final nasal consonants. These morphemes all conform to the formula (CV)CVn. Except for Mende, where all morpheme-final nasals have been lost, and for Kpelle, these morpheme-final nasals also interact with follouing initial consonants to produce strong surface consonants. Examples of these derived strong consonants are given in ( 3 ) below in the column glossed 'the old bee'. Corresponding weak consonents are given in the column glossed 'the old house' The base for of the adjective 'old' is either wóvo or pofis'; the base form of 'bee' Is kómín; and the base form of 'house' is either péré, péle or pé. $\varepsilon$, depending on the language. 9

8 For a more detalled statement concerning the distribution and meaning of the prefix of prereference and the definite suffix in Kpelle, see Welmers [1970].

9The use of a period (.), as in pe.E 'house', indicates that a sequence of two vowels separated by the period should be interpreted as long. A sequence of two vowels not separated by a perfod may then be used to represent short contour tones as a sequence of two tones (e.g., if and (I). For more deta1ls, see Dwyer [1973]. 
64

(3)

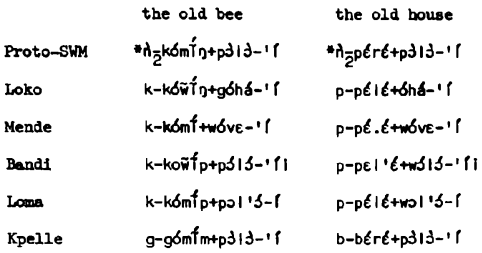

The same morphemes which strengthen following consonants, (CV) $\mathrm{CV}_{2}$. also take a strong definite suffix allomorph ( $n g f,-g g)$, or $\phi$, depending on the language); while those followed by weak consonants, (CV )CV, take a weak suffix allomorph $(-f$, or $-i$, depending on the language). These allomorphs are exemplified in (4) below:

(4)

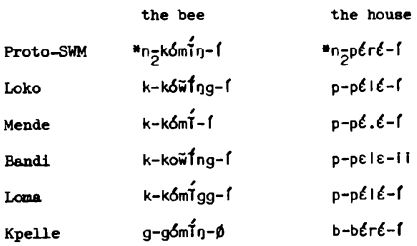

Additional examples showing the correspondence of Kpelle morpheme-final nasals to the strong suffixes of the other SWM languages appear in (5) below:

(5)

Proto-SWM

Loo

Mande

Band the shadow

*no $2^{-n T n E ั \jmath-1 ~}$

กอ̃ก'ย์́ng-।

nе̃ก $\tilde{\varepsilon}-1$ ?

nẽnêng-' ! the (his) hand the thorn

-

ngúng-1

ngu-'1

ngungi-'l

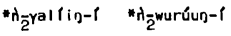

ngal'ing-'f ngul'úng-'f

ngalifie ngul'i-if

ngaling-'f ngulung-'f 


\begin{tabular}{|c|c|c|c|c|}
\hline $\begin{array}{c}\text { (5) (cont.) } \\
\text { Loma }\end{array}$ & $\begin{array}{l}\text { the shadow } \\
\text { nfnfgg-i }\end{array}$ & $\begin{array}{l}\text { the (his)hand } \\
\text { ggúgg-1 }\end{array}$ & $\begin{array}{l}\text { the thorn } \\
\text { gấl fgg-l }\end{array}$ & $\begin{array}{l}\text { the cobre } \\
\text { ggúl ugg-'f }\end{array}$ \\
\hline Kpelle & HYnTo & dwus & dalfin & dwurúun \\
\hline & the sun & the leaf & the mortar & the cov \\
\hline Proto-SWM & ${ }^{*} H_{2}+616-1$ & ${ }^{*} H_{2}$ láyó-1 & *i-konláa-1 & $n n_{2}^{n T n k a-1}$ \\
\hline Loko & $t-f \delta . \delta-1$ & ndárá-1 & $k$-kond's-' f & nTkk'b-1 \\
\hline Mende & $t-t \delta \mid \delta-1$ & ndówê-f & $k$-kond ' $\varepsilon-1$ ' & nTkka-' ' \\
\hline Band 1 & $t-f o l \delta-1 i$ & nday'á-fi & $k-k o n d \varepsilon-1 / i$ & nikka-fi \\
\hline Loms & $t-t \delta \mid \delta-t$ & ddáró-l & k-kбddá-1 & níkks-f \\
\hline Kpelle & $v-v \delta \mid \delta-1$ & na.a-1 & $k$-koná-i & nTna-1 \\
\hline
\end{tabular}

3. The Development of the Alternations

Th1s section contains a summary of the major consonant developments which have taken place in SWM including those which have led to the establishment of the initial consonant alternations in SWM. In this presentation, I have assumed the existence of four hypothetical languages: Proto-SWM, the ancestor of all the modern SWM languages; Proto-Central SWM, the ancestor of all of the SWM languages but Kpelle; Proto-Northern SWM, the ancestor of Loko and Mende; and Proto-Bandi-Loma, the ancestor of Bandi and Loma. With the use of these reconstructed languages, the diachronic development of SWM consonants can be presented as a series of natural phonological developnents. Furthermore, these hypothetical stages of SWM also permit the description of the diachronic development of the SWM tonal systems in a like manner. The relationship between the modern SWM languages and their reconstructed ancestors is shown in (6) belov: 
(6)

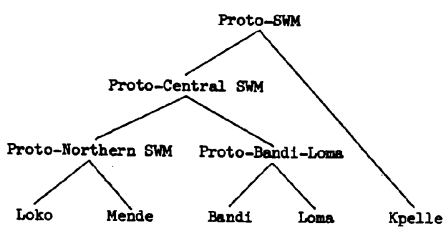

3.1. Proto-Southwestern Mande. Proto-STM has been reconstructed with three serles of underlying consonants. These are given in (7) below.

$$
\begin{aligned}
& \text { light " } p, * f, * t, * s, * k, * k p \\
& \text { heavy * } w, \quad y, * \frac{1}{*}
\end{aligned}
$$

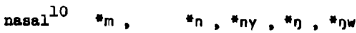

The reconstructed consonant alternations of Proto-SWM are given in ( 8 ) below. 11

$$
\text { 11ght heavy }
$$

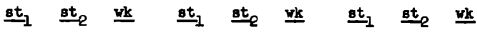

PP in $P$ iो in $B$ it if $m$

$f f$ inf $f$

tt hit $t$ iो $h \quad 1 \quad h \quad h \quad n$

$s$ tis $s$ ily hy $y$ hy hy $y$

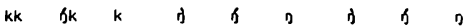

kkp hkp kp jw bw $w$ jw

The above alternations (8) are the resuit of three phonological rules: Nasal Point Assinilation, Nasal Absorption, and Gemination. Each of

\footnotetext{
10 Vowels following underlying nasels are [+ nasal]. This condition must prevail prior to the application of the dlachronic rules presented here.

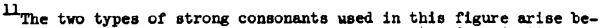
cause of the selective nature of the Genination rule (see (12)).
} 
these rules involves the Interaction of a nasal and a following consonant. The nasals involved in these processes are as follows: 'f- 'my', * ${ }_{\overline{1}}$ ' $\mathrm{hls}$ ' and " $\mathrm{H}_{\overline{2}}$ 'prereference'.

The first rule states that all nasal consonants assinilate to the point of articulation of the following consonant. This rule is comonly found throughout the world's languages and requires no further discussion.

Nasal Absorption can be thought of as two rules, Nasal Manner Assimilation (9) and Nasal Simplification (10). The first of these rules states that a heavy consonant assimilates fully to the manner of articulation of the preceding nasal consonant.

(9) Nasal Manner Assimilation (Proto-SWM) 12

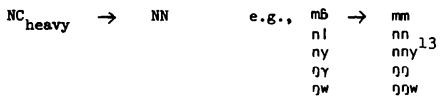

Nasal Simplification immediately follows Nasal Manner Assimilation. This rule applies to sequences of two identical nasals, cither those which are the result of the nasal being followed by another nasal or as the result of Nasal Manner Assimilation rule. Nasal Simplification reduces a sequence of two ldentical nasals to a single nasal segment. W1thout this rule, surface geminate nasals, for which there is no accoustical evidence, vould be derived.

(10) Nasal Simplification (Proto-SWM)

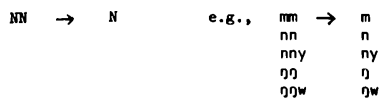

\footnotetext{
12 Nasal Manner Assimilation is essentially the same as the Akan rule known as "Progressive Non-Vowel Assimllation" [Schachter and Framkin 1968].

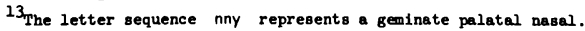


Nasal Manner Assimilation and Nasal Reduction can be written as a single process, Nasal Absorption (1I), and is done so in the remainder of this paper because of the lack of evidence to support the independent existence of each rule. 14

(11) Nasal Absorption (Proto-SWM) ${ }^{15}$

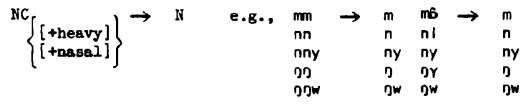

Gemination (12), the remaining Proto-SWM consonant rule, states that when an unstressed low-toned nasal prefix, $t_{1}$ or $*_{\overline{2}}$, is followed by a voiceless consonant, the feature values of this nasal prefix lose their distinctiveness and assimilate to those of the following consonant producing a fortis or geminate consonant.

(12) Gemination (Proto-SWM)

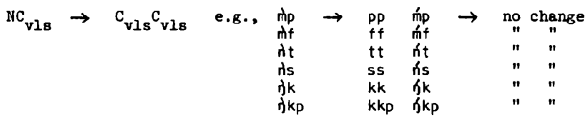

14 Hyman (personal communication) has pointed out that Nasal Absorption can be viewed as an example of Jacobsonian rephonologization. The only distinctive characterfstic of the preconsonantal nasal is its nasality. The reinterpretation of this nasality as a feature of nasality on the following non-nassl segment does not affect the distinctiveness of the two representations:

$$
\begin{aligned}
& n+C_{h} V>N V \quad\left(C_{h}=\text { heavy consonant }\right) \\
& n+N V>N \tilde{V}
\end{aligned}
$$

The rephonologization argument supports the view that Nasal Absorption is a single historical process.

15 The natural class of nasals and heavy consonants can be defined as being volced and not including true ([+vocalfc, -consonantal]) vowels. 
In Proto-SWM, as in most modern SWM languages, stress 18 generally assigned to the first high tone in the nominal phrase. 16 Consequently, phrase-initial low-toned nasals are never stressed while phrase-initial high-toned nosals are always stressed. As a result, Gemination applies to low-toned nasals and not to high-toned nasals because of the location of the stress. The reduction of marked features in an unstressed segment 18 a very common event. Therefore, the fact that low-toned (unstressed) nasals geminate through the reduction of marked features while high-toned (stressed) nasals do not can be considered a natural phonological process.

3.2. The development of modern Kpelle from Proto-SwM. The system of Kpelle initial consonant alternation can be derived by adding one rule, Post-Nasal Voicing (13), to the Proto-SWM list of rules. This rule states that a voiceless obstruent becomes voiced when freceded by a nasal prefix (and in some dialects of Kpelle by any nasal).

(13) Post-Nasal Voicing (Kpelle)

$$
\mathrm{N}-\mathrm{C}_{\mathbf{v l s}} \rightarrow \mathrm{N}-\mathrm{C}_{\mathrm{vd}}
$$

This rule, when coupled with the Proto-SWM gemination rule, produces a three-way surface alternation in the Kpelle light series (between $\mathrm{C}_{\mathrm{vls}}$. $\mathrm{H}_{-} \mathrm{C}_{\mathrm{vd}}$, and $\left.\mathrm{C}_{\mathrm{vd}} \mathrm{C}_{\mathrm{vd}}\right)$. The development of this three-alternation is demonstrated in the following Kpelle derivations (14):

(14) Gloss your back my beck his back

ваве 1-pólo h-poli

Nasal Absorption

Post-Nas Voice m-bolo m-bold

Gemination b-bold

Surface $\quad 1-p \delta|d \quad m-b \delta| d \quad b-b 61 d$ 
In order to derive volced geminate consonants from underlying $\dot{N}-C_{v i s}$ sequences, the Post-Nasal Volcing rule must apply before the Gemination rule. Were the ordering reversed, the Gemination rule would destroy the potential input for the Post-Nasal Volcing rule. ${ }^{17}$

Volced geminate consonants in Kpelle have been described by Welmers [1962] as having "heavy roicing." Heavy volcing means that the period of duration of voleing is longer than that used for a normally volced obstruent, The use of a geninate consonant adequately expresses this fact. Furthermore, the use of geminate consonants permits a fairly natural derivation of surface consonants with extra heavy roicing.

3.3. The development of Proto-Central SWM. In Proto-Central SWM, a very important lexical change took place: the Proto-SWM prefix of prereference, $t_{\overline{2}}$, was reinterpreted as a nominal prefix, and, as such, was added to virtually all phrese-initial (non-possessed) naninals in Proto-Central SWM. Because this prefix is a nasal, the inftial consonant of all nominals in Central SWM to which it is attached is strong. The distribution of this prefix in Proto-Central SwM sharply contrasts with that of Proto-SWM and Kpelle where, as a prefix of prereference, $H_{\overline{2}}$ generally appears only before noun phrases which are definite.

The development of Proto-Central SWM further involved the broadening of the Gemination rule to include all nasals and the establishment of the Weak Consonant Voicing rule, the Nasal Expansion rule and the veakening

17 Operating on the hypothesis that new rules usually appear at the end of the ordered list of rules, one would have expected Post-Nasal Volcing to have followed Gemination in Kpelle. Quite possibly this situation exlsted in an earlier stage or Kpelle (1.e., Pre-Kpelle). Were Genination to precede Post-Nasel Volcing in Pre-Kpelle, the Initial consonant of phrses such es 'his back' would remain volceless (e.g. "p-pulu ' $h$ l s back') because the Genination rule would eliminate the preconsonantal nasal. Since the sequence: Gemination - Post-Nasal Volcing, is a bleeding order, the reordering of these rules in modern Kpelle can be viewed es a simplification and natural dischronic development. 
rules. The surface alternations produced by these innovations are given in (15) below:

(15)

11ght

base weak strong

$\begin{array}{lll}p & b & p p \\ f & v & f f \\ t & d(1) & t t \\ s & z & s s \\ k & g(\gamma) & k k \\ k p & g b(6) & k k p\end{array}$

heavy

base weak strong

6 B mb

nd

$n j$

ng

ng nesal

base weak strong

$\begin{array}{lll}m & m & m \\ n & n & n \\ \text { ny } & \text { ny } & \text { ny } \\ n & \eta & \eta \\ \text { gw } & \text { gw } & \text { nw }\end{array}$

(the consonants in brackets are the results of the veakening rules)

In Central SWM, the structural description of the Gemination rule restructured to include all sequences of a nasal followed by a volceless obstruent. This includes both high and non-high-toned nasals as in (16) below. 18

Bandi

underlying

surface

gloss n-ko.o-r i-ko.o-i

k-kó.o-1fi 1-wó.o-'1i

my belly your
Kpelle

n-ko.o f-ko.o n-ko.o

r-go.o l-ko.0 g-go.o

my belly your _ his

18 Proto-Central SWM differa tonally from Proto-SWM in that ProtoCentrel SWM has only a two-way tonel contrast (high and non-high), this being the result of the merger of the Proto-SWM "low and "mid levels.

This view differs from that of Hyman [1973] who assumes that ProtoSWM has only four tonal classes with only a two-way tone contrast. I claim that this is an accurate description of Pre-Proto-SWM. The difference between these two positions is the point in the history of SWM when the fifth tonal class (*low-low) appeared. Hyman, citing arguments from Welmers ([1961] "Internal evidence of borrowing in Kpelle") concludes that the fifth tonal class must have been acquired through borrowlng in Pre-Kpelle. However, these class 5 nouns have demonstratable cognates in the other four SWM languages which cannot be attributed to borrowing (Me: bolo 'hat', Kp: bòls' 'hat'; Me: tondo 'chisel', Kp: tJ̀n' 'chisel'). Thus, one must conclude that these morphemes must have existed 1n Proto-SWM. Now, the arguments provided by Welmers for Kpelle can be applied to Proto-SWM with the conclusion that the fifth tonal class was acquired through borrowing in Pre-Proto SWM (for more deta1ls, see Dryer [1973]). 
Unlike Kpelle and Proto-SWM, the Central SWM gemination rule also includes morpheme-final nasals as in (17) below:

underlying

surface

gloss

$$
\begin{aligned}
& \text { Kpelle } \\
& \text { kómín+kómín } \\
& \text { kómín+kòmìn } \\
& \text { beethoney }
\end{aligned}
$$

Virtually all the Central SWM consonents not strengthened by the Genination rule are found in an intervocalic position. This is due to both a broadened application of the Gemination rule and the above mentioned reinterpretation of the PSWM ${ }^{*} \mathrm{H}_{2}$ prefix. These unstrengthened intervocalic consonants become voiced in Central SWM by a rule called Weak Consonant Voicing (18).

(18) Weak Consonant Voicing (Proto-Centrel SWM)

$$
\mathrm{c}_{\mathrm{vls}} \rightarrow \mathrm{C}_{\mathrm{vd}} / \mathrm{v}
$$

The Central SWM Weak Consonant Voicing rule and the Kpelle Postliasal Volcing rule apply in mutually exclusive enviroments. This gives the impression that half of the Kpelle consonants are mutating the wrong way (see Table I above).

Despite the Weak Consonant Voicing rule, voiceless obstruents do appear in the surfece structure of all of the Central SWM Ianguages as evidenced by the following Bandi examples (19):

(19) Bandi (tones onitted) 19

$\begin{array}{ll}\text { Iappi } & \text { fight } \\ \text { kottu } & \text { stone } \\ \text { massa } & \text { chief } \\ \text { nikka } & \text { cow } \\ \text { tukkps } & \text { valking stick (staff) }\end{array}$

19 AB in Loma, Bandi geminate consonenta are traditionally written as non-geminate (e.g., nika 'cov' instead of nTkka) because of the counterparts. 
These volceless obstruents do not volce because they are geninate and, therefore, do not fit the structural description of the Weak Consonant Voicing rule. These geminate consonants are derived from Proto-sw sequences of a nasal followed by a volceless consonant and the broadened Central SWM genination rule as follows (20):

(20) Proto-SWM ${ }^{20}$

Proto-Central SWM Gloss

\begin{tabular}{|c|c|c|}
\hline - | amp | & Gem1nat1on $\rightarrow$ & *lappl \\
\hline kontu & & "kottu \\
\hline t tiokpo & & "t I kkpo \\
\hline "ninka & & *nikka \\
\hline
\end{tabular}

Additional support for the reconstructions in (20) 18 given in section 3.3.

The last major development in Central SWM is the expansion of nasal consonents into a sequence of a nasal consonant followed by a voiced stop. This rule applies only when the vowel following the nasal consonant 18 non-nasal. It will be recalled (see Table I above) that vovels which follow underlying nasals are nasalized while those derived from sequences of a nasal followed by a heavy consonant are not. Th1s Nasal Expansion rule (21) has also been observed in Mstakali [Gudshinsky, Popovitch, and Popovitch 1970].

(21) Nasel Expension (Proto-Central SWM)

$$
\begin{aligned}
& N \rightarrow N_{\text {vd }} / \text { [-nasal] e.g., } \frac{m}{n} \rightarrow \text { mb } \\
& \text { ny } \quad n j \\
& \text { ong } \\
& \text { nw ng }
\end{aligned}
$$

20 The Kpelle reflexes of these forms are as follows: namu 'fight'. konu 'stone', tunwo 'staff', and nTga 'cow'. No Kpelle reflex has been found for PSWM "mãnsa 'ch1ef'. 
Like the other Central SWM nasal rules, Nasal Expansion applies to all nasals (not followed by a nasalized rowel). This includes phrase-inttial nasal prefixes as in (22):

$$
\text { Bend1 }
$$

$$
\text { Kpelle }
$$

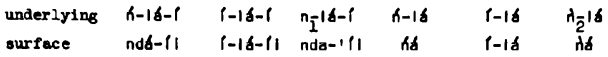

gloss my mouth your his my mouth your his

and morpheme-final nasals as in (23):

underlying

surface

gloss

\section{Band1}

n-kớ̛́n+wúlú-

$$
k-k \delta \tilde{T} T+n g u ́ l u ́-1 \text { 'l }
$$

bee+tree-the
Kpelle

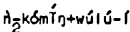
k-kómín+wulù-1

Pref-bee+tree-the

and morpheme medial nasals as in (24):

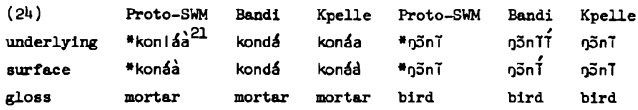

Furthermore, the ngf - 1 alternation of the definite suffix in Loko and Bandi and the gi - i alternation in Lome are also consequences of the Nasal Expansion rule. In Proto-SWM, the definite suffix is * $f$ es it is in modern Kpelle. ${ }^{22}$ In Central SWM, this suffix is said to have two allomorphs. The -ngf allomorph follows nouns which historically end in a nasal consonant. In fact, these nouns generally have cognates in modern Kpelle which atill have morpheme-final nasals (see (5) above). This observation was first reported by Heydorn [1940]

21 The reconstructed form "konla 'mortar' is proposed instead of *konda on the basis of the argument presented in 3.1. that Proto-SiM has no underlying $d$. However, either of these forms would produce the observed SWM ourface roflexes.

22 The definite suffix in Kpelle 1 B deloted following a nasal consonant:

Kpelle underlying $n_{2}^{-k o m i n g} f$ 'preref-bee-the' surface $\quad g-g b m i f f$ 
and has been relterated by B1rd [1971a] and by Welmers [1971].

With the introduction of the Nasal kxpansion morpheme-final velar nasals vere converted to $\mathrm{ng}$. This development when coupled with the definite suffix $-f$ produced the $-n g f$ definite suffix allomorph (1.e., ...n-f > ...ng+1 = ...ngl). The derivation of Proto-Central SWM 'the bee' and 'the tree' in (25) below further demonstrates the development of the ngf -1 definite suffix alternation.

\begin{tabular}{|c|c|c|}
\hline $\begin{array}{l}\text { Proto-Central SWM } \\
\text { Base }\end{array}$ & $\begin{array}{l}\text { the bee } \\
n_{\overline{2}} k^{\prime} \delta_{m} \tilde{i} j-1\end{array}$ & $\begin{array}{l}\text { the tree } \\
n_{2}-w u ́ l u ́-1\end{array}$ \\
\hline Homorganic Nasals & n-kómî́n-1 & D-wúlú-1 \\
\hline Nasal Absorption & & Dwúlú-P \\
\hline Genation & k-kómín-1 & \\
\hline Nasal Expansion & $k-k \delta m f n g-1$ & ngúlú-f \\
\hline Reinterpretation ${ }^{23}$ & $k-k \delta m^{\prime} \tilde{i}-n g f$ & \\
\hline Surface & k-kómí-ngI & ngúlú-f \\
\hline
\end{tabular}

The Nasal Expansion rule and the morpheme-final velar nasal are also useful In explaining the dcvelopment of the plural suffix alternation, nga - a (e.g., ...nta > ...ngta $=\ldots$.nga $)$.

Many of the members of the heavy consonant serles of Proto-SWM are the result of the weakening of voiced stops. These weakenings (26) have also been observed in Northern Mande [B1rd 1971b, and Welmers 1958].

Velar weakening Alveolar Weakening Labial Weakening

$$
\begin{array}{llll}
g & \rightarrow \gamma & d & \rightarrow
\end{array} \quad \text { b } \rightarrow \beta
$$

(Velar Weakening converts a volced velar stop into voiced velar continuant. Because labio-velars have a velar component, voiced labio-velar stops are also weakened by this rule)

23 Th1 s reinterpretation may be only one made by some lingulst $\mathrm{s}$ on the basis of the surface dats of these languages and not one that has been made by Central SWM speakers. 
In Proto-Central SWM, both Velar and Alveolar Weakening apply to the voiced obstruents which vere derived as a result of the Weak Consonant Rule. These veakenings resulted in the alternations: $k-Y$, $\underline{k p-b}$, and $\underline{t}-1$ (see (15)).

Mende weak consonants do not show the effects of the application of the Velar Weakening rule. The rejection of this weakening rule appears to be a Mende linguiatic simplification. The fossilized Mende compound nje+wúlo 'aunt' (11terally mother+small) provides ample evidence that these weakenings used to exist. Normally an initial $k$ in Mende, such as the $k$ in Mende kulo 'small' ought to become a $g$ rather than $w$ when occurring in a weak enviroment as in (27):

(27) Mende underlying $n_{2}-f^{\prime l a+k u ́ l \delta-1 ~}$

$$
\begin{array}{ll}
\text { surface } & \text { ngfla+gule-'f } \\
\text { gloss } & \text { dog+small-the }
\end{array}
$$

Thus Mende apparently discarded the Proto-Central SWM weakening rules in all cases save for a fer fossilized compounds.

Labial Weakening does not occur in Loko and is apparently a development which took place in Loma, Band, and Mende independently. 3.4. The development of Loma. The final major consonant rule development in Southwestern Mande involved the reordering of the Nasal ExpanBion rule. In Proto-Central SWM and in all of the descendants of ProtoCentral SWM but Loms, this rule is ordered following the Gemination rule. In Loms, the Nasal rule is ordered preceding the Gemination rule. The reordering in Loma produces a feeding ordering beceuse the Nasal Expansion rule provides additional input for the Gemination rule. And such a reordering is a oimplification in the Kiparskian sense and can be regarded as a natural, anticlpated development. As a result of this development, Loma has both volced and voiceless surface geminate consonants. These are derived in $(28)$ below: 
(28) Lome

Bese

Homorganic Nasal

Nasal Absorption

Nasal Expansion

Gemination

Surface underlying volceless

$n-t$ underlying heavy

$$
n-1
$$

The voiced geminate consonants, like the volceless geminate consonants in Loma, are usually transcribed in the linguistic literature as a single segment. This is because the corresponding single segment consonants have undergone weakenings (26) and consequently no longer contrast with the geminates only with respect to gemination.

The reordering of the Nasal Expansion rule has resulted in the gemination of all underlying sequences of a nasal followed by a heavy consonant. This includes the strong suffixes (29), morpheme-final nasals (30), morpheme-medial nasals (31), and all nasal prefixes (32):

\begin{tabular}{|c|c|c|c|}
\hline & Proto-SWM & Band1 & Loma \\
\hline underlying & ${ }^{*} n_{2}-k \delta m T ́ n-1$ & $n-k \delta \tilde{m}^{\prime} \tilde{n}-1$ & $\hat{h}_{2}$ komTn-1 \\
\hline surface & *k-kómín-1 & $k-k o \tilde{w}$ ' Tng-1 & $k-k \delta$ mígg-1 \\
\hline gloss & bee-the & bee-the & bee-the \\
\hline
\end{tabular}

Band1

underlying
surface
gloss

underlying

$$
\mathrm{n}_{2} \mathrm{k} \delta \text { w̃T́n+wúlú-i }
$$$$
\text { k-kow'ítngúlá-'pl }
$$

bee+tree-tho
Lome

$$
\mathrm{h}_{2}{ }^{\mathrm{kom} T \mathrm{n}+\mathrm{wul} u-1}
$$$$
k-k \delta \tilde{m} \tilde{T}+g g u l u-1 f
$$

beettree-the 
(31) Proto-SWM Band1 Lome

\begin{tabular}{|c|c|c|c|}
\hline underlying & " & $n_{2} \mid$ ámbán-1 & $\hat{n}_{2}$ labban-1 \\
\hline surface & *iámán-1 & ndamb 'óng-f & ddábbágg-1 \\
\hline gloss & crocodile & crocodile & crocodile \\
\hline underlying & ${ }^{*} n-k$ kon 1 ád-1 & $n \overline{2}^{\text {kondá-1 }}$ & $\hat{n}_{2}^{\prime}$ kodda-i \\
\hline surface & k-konáa-f & $k-k o n d a-1 f i$ & $k-k \delta d d \delta-1$ \\
\hline gloss & mortar-the & mortar-the & mortar-the \\
\hline
\end{tabular}

(32) Bandi

\begin{tabular}{|c|c|c|c|}
\hline underlying & h-lá-f & $p-1 a-1$ & $n_{1}-1 a-1$ \\
\hline surface & ndá- $f i$ & $|-| a-||$ & nda- $f i$ \\
\hline gloss & my mouth & your mouth & his mouth \\
\hline \multicolumn{4}{|l|}{$\operatorname{LomB}^{24}$} \\
\hline underlying & $n-1 a-i$ & $0-1 a-1$ & $n_{1}-a-i$ \\
\hline surface $^{25}$ & $d d a-1$ & $e-1 a-i$ & ddá-f \\
\hline gloss & my mouth & your mouth & his mouth \\
\hline
\end{tabular}

The major consonantal rule developments are summarized in Table II below:

${ }^{24}$ Loma has also undergone a tonal inversion, an historical development which reversed the values of the underlyins Lams tones (see Dwyer [1973]).

25 Because both underlying high tones and non-high tones produce surface volced geninate consonants, the resultant gemination can no longer be uniquely attributed to low tonedness. 
Table II:

$$
\text { Proto-SWM (P) }
$$

1. Homorganic Nasals-P

2. Nesal Absorption-P

3. Gemination-P

Proto-Central SWM (c)

Kpelle (KP)

1. Homorganic Nesels-P

1. Homorganic Nasel 8-P

2. Nasel Absorption-P

2. Nasal Absorption-P

3. Broadened Gemination-C

4. Weak Consonant Voleing-C

5. Nasel Expansion-C

6. Velar Weakening-C

7. Alveolar Weakening-C

Proto-Northern SWM

4. Post-Nasel Voicing-KP

3. Gemination-P

(no major consonantal developments)

Loko (LK) Mende (Me)

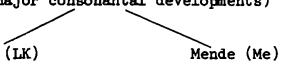

1. Homorganic Nas-P

2. Nasal Absorb-P

3. Broadened Gem-C

4. Weak Cons Voice-C

1. Homorganic Nasals-P

1. Homorganic Nas-P

5. Nasal Expan-C

2. Nesel Absorption-P

2. Nasal Absorb-P 7. Alveolar Weak-C

3. Broadened Gem-C

4. Weak Cons Voice-C

5. Nasal Expansion-C

6. Velar Weakening-C

7. Alveolar Weakening-C

8. $B>b-L K$

10. $\gamma>\emptyset-\mathrm{LK}$

3. Broadened Gem-C 8. B > b -PBL

4. Weak Cons Voice-C 9. Labial Weak-PBL

5. Nagal Expan-C

7. Alveolar Weak-C

9. Labial Weak-Me

8. $\mathrm{B}>\mathrm{b}-\mathrm{Me}$

Bandi ( $\mathrm{Ba})$

1. Homorganic Nas-P

2. Nasel Absorb-P

3. Broadened Gem-C

4. Weak Cons Voice-C

5. Nasal Expansion-C

6. Velar Weakening-C

7. Alveolar Weakening-C

8. $B>b-P B L$

9. Labial Weakening-PBL
Loma (Im)

1. Homorganic Nas-P

2. Nesal Absorb-P

5. Nesal Expengion-Im

3. Broadened Gem-C

4. Weak Cons Volce-C

6. Velar Weakening-C

7. Alveolar Weakening $-C$

8. $B>b-P B L$

9. Labial Weakening-PBL 


\section{Alternative Analyges}

In this section, four 1ssues are discussed: a) the possibility that all the underlying consonants of the heavy serles could have been stops, b) the possibility that heavy volcing and low tone are manifestations of the same distinctive feature, c) the possibility that what I have clajmed to be low-toned nasals, $\lambda_{\bar{l}}$ and $\lambda_{\overline{2}}$, are not nasals at all, but low-toned vowels, and d) that the underlying Proto-SwM pronouns * $k$ - and $i_{\overline{1}}$ are "is and "jo respectively. 4.1. Underlying stops. Before resolving the issue of whether all underlying Proto-SWM heavy consonants are stops or not, it is necessary to establish that there is only one series of heavy consonents in SWM. The development of the heavy series in SWM appears to be the result of a number of mergings of voiced stops with liquids and glides. This can be seen in the following comparison (33) of Proto-SWM and Northern Mande cognates. $^{26}$

(33) 1. Proto-SWM *w corresponds to Northern Mande $b$ or $w$.

PSWM: *wuru 'tree' $\begin{aligned} & \text { Bambara: yiri 'tree' } \\ & \text { Sugu: }\end{aligned}$
PSWM: 'wa? 'big'
Wambara: ba 'big'

2. Proto-SWM $*$ corresponds to Northern Mande $d$ or $I$.

$$
\begin{array}{llll}
\text { PSWM: * la 'mouth' } & \begin{array}{l}
\text { Bambara: da 'mouth' } \\
\text { Susu: }
\end{array} & \begin{array}{l}
\text { de 'mouth' } \\
\text { PSWM: \#a 'place' Bambara: Ia 'place, in' }
\end{array}
\end{array}
$$

3. Proto-SWM *y corresponds to Northern Mande $d j$ or $y$.

$$
\begin{aligned}
& \text { PSWM: 'ya 'water' Bambara: dja 'water' } \\
& \text { Susu: }
\end{aligned}
$$

4. Proto-SWM $y$ corresponds to Northern Mande $x$ or $k$.

$$
\text { PSWM: 'ralo 'moon' Bambara: kalo 'moon' }
$$

\footnotetext{
26 The Bambara data 18 from Travele [1913] and the Suau data is from Houla [1963].
} 
(33) 5. No correspondences involving Proto-5WM 6 have yet been established with Northern Mande. Possibly, the reconstruction of 'big' In Proto-SWM is "Ban rather than wa (see 33-1). Th1s assumption $1 \mathrm{~s}$ based on the barely possible interpretation of 'crocodile' as a compound meaning 'blg mouth' (Bandi ndamb'áng-f 'the crocodile' < PSWM (la-n-ban 'mouth-1t-big').

These mergings could have been the result of a veakening of the stop series or a strengthening of the heavy serles. The strengthening hypothesis is less likely for the following ressons:

(a) Merging through strengthening would result in a language with no 11 quids and no glides, an infrequent situation in language. 27

(b) Even if the underlying consonants in Proto-SWM are all stops, It is st1ll necessary to postulate weakening rules to account for the reak allophones of the heavy series in SWM (B, $I, Y, Y$, and $W$ ). As long as both hypotheses require weakening rules, it is at least more economical on a sychronic plane to claim that both these mergings and these weak allophones are the result of the same weakening rules.

(c) Except for the implosive 6 , these is no evidence to support the existence of underlying voiced stops in any of the SWM languages. 28 All of the surface volced stops in SWM can be derived from the underlying $B, I, Y, Y$, and $w$ through the application of the Nesal Absorption, Nasel Expansion and Genination rules.

(d) Moreover, volced velar stops have not been observed in Northern Mande efther. SWM's volced velar, $\gamma$, corresponds elther to Northern Mande's $X$, as in Susu, or $k$, as in Bambara. Thus no concrete evidence exists to support an underlyling voiced velar stop in either branch of Western Mande. Welmers [1958], assuming that SWM heavy consonants

27 Hyman has pointed out (personal communication) that it is his understanding that Proto-Bantu has been reconstructed without underlying glides 28 dialects of Kpelle [Welmers 1962] in place of an Initial I, Hyman argues (personal communication), suggests the possibllity of a second noncont1nuant *d in the Proto-SWM heavy series. 
were stops, postulated a voiced velar stop *g for Proto-Western Mande, the Immediate ancestor of Northern and Southwestern Mande. Welmers then concluded Proto-Western Mande " $g$ weakened to "x (as in Susu) and then " $X>k$ (as in Bambara). However, if the Proto-SWM heavy velar consonant is " $\gamma$ rather than $" g$, the Proto-Western Mande equivalent can also be given as " $\gamma$. This permits the description of the development of voiced velars in Western Mande as follows (34):

Proto-SWM

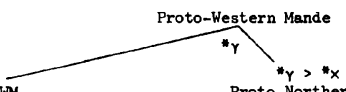

*r

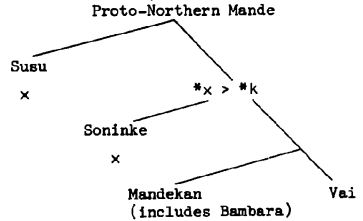

$k$

k

(e) The alternstions $n g-y$ and $n g-w$ can best be described if each alternation has a distinct underlying consonant. Were the two veak variants of these alternations, $y$ and $w$, in complenentary distribution, only one underlying consonant, say $\gamma$ would be necessary. Yet in Mende, for example, the weak allophones of these alternations are almost, but not completely, in complementary distribution: the allophone $y$ appears when followed by $, e, \varepsilon, a$, and $\partial$; the allophone $w$ appears when followed by $u, 0$, and 0 as in the folloving examples (35):

$\begin{array}{lllll}\text { (35) Mende } & \text { ngele-i } & \text { the sky } & \text { nyatyele-i } & \text { my sky } \\ & \text { ngombu-l } & \text { the fire } & \text { nyatyombu-i } & \text { my fire } \\ & n g u l i-i & \text { the tree } & \text { nya+wuli-i } & \text { my tree } \\ & n g o l \varepsilon-1 & \text { the sobbing } & \text { nyatwole-l } & \text { my sobbing }\end{array}$


If both $y$ and $w$ are derived from the same source, then it is difficult to show how both $Y$ and $w$ can occur before $J$. Ir, on the other hand, the ng-y alternation is derived fran an underlying $\gamma$ (later $\gamma>y$ ) and the $\underline{n g-w}$ alternation 18 derived from an underlying $w$, then this occurrence can be explained as follows: first the near complementary distribution of $\gamma$ and $w$ is the result of two phonological processes: one which states that a vowel which follows $w$ must be rounded (e.g., wi > wu, we> wo, we> wo, and wa > wo), and one which states that $\gamma$, when followed by $u$ or 0 must be rounded (e.g., ru > wu and $\gamma_{0}>$ wo). These two processes produce the near complementary distribution of $\gamma$ and $w$. Once $\gamma$ and $w$ developed near complementarity, $Y$ shifted to $y$ resulting in the present day Mende situation. These arguments weigh heavily in favor of *b, *1, *y, * $y$ and * being the underlying consonants of the heavy series in SWM.

4.2. Plus lowered. It has been proposed that extra heavy voicing is related to low tone by the feature [+lowered] [Bird 1971a]. This proposal makes it possible to state that the development of extra heavy voicing in Kpelle is an assimilation of the feature [+lowered] of the low tone of the nasal $i-$ by the following consonant.

Yet this approack does not explain why only low toned nasals in Kpelle cause extra heavy voicing and why other types of low tones in Kpelle do not. For example, in Kpelle there is a lowering rule which applies to certain nominal compounds and noun-sdjunctive adjective constructions. This rule lowers the tones of the vowels of the second constituent of these constructions, but does not cause extra heavy voicing in the consonants. Th1s is true of Southwestern Kpelle, the dialect described by Welmers [1962] and my own observations of Central Kpelle where a morpheme-final nasal causes the volcing of a following volceless obstruent as in the example in (36) below.

Southwestern Kpelle káldg chlef pśs old káldm+płlò old chief Central kpelle káldn chief pSIs old káldm+bjis old chief 
Were the feature [+lowered] to apply to the consonants of the second constituent as well as the vowels, extra heavy voicing would be anticipated (e.g., *kálòm+bbj̀ls̀ 'old chief'). If [lowered] is a feature of both sonorant and non-sonorant segments, then the Kpelle Lowering rule must be written so that it excludes non-sonorant sements. If, on the other hand, the feature used to mark low tones were not a characteristic of non-sonorant segments (such as the tone feature [low]), this awkward situation would not arise.

A second weakness of this approach arises with the existence of heavily voiced consonants which cannot be derived from a preceding low tone. In Loma, for example ( 37 below), heavily voiced consonants are derived from nasals which are high-toned as well as from nasals which are not.

(37) Loma surface underlying gloss

\begin{tabular}{|c|c|c|}
\hline ddE $ү \varepsilon$ & $n-\mid \varepsilon \gamma \varepsilon$ & my brother \\
\hline dd $\tilde{\varepsilon}_{\gamma} \boldsymbol{\varepsilon}$ & $n-1 \varepsilon \gamma \varepsilon$ & his brother \\
\hline
\end{tabular}

My investigations of heavily voiced consonants indicate that the difference between heavily and normally voiced consonants in Kpelle and Loma is not primarily one of quality, but one of the duration of the voicing of the segment. This fact is aptly rendered by representing heavily volced consonants as geminate.

4.3. The possibility of d. It has been suggested that what $I$ and others have called a low-toned nasal, $h-$, is actually a low-toned vovel, most likely if [Welmers 1971]. The basis of this argument is that the third person singular pronoun in Northern Mande is not a nasal, but a vowel, usually à. This argument would be stronger, were 1t not for the rather poor correspondence, as evidenced by (38) below, of the SWM and Northern Mande personal pronouns. 
(38)

\begin{tabular}{|c|c|c|c|}
\hline & Band1 & Kpelle & Bembara [Sauvant 1956] \\
\hline my & n- & i- & ne \\
\hline your & $1-$ & $1-$ & 1 \\
\hline his & $n-$ & $\lambda-$ & a \\
\hline our $_{1}$ & muú & kú & an \\
\hline our $_{2}$ & nif & & \\
\hline your & wú & ká & au \\
\hline their & $t+11$ & ddf & (PSWM: $n+1$ f) \\
\hline
\end{tabular}

Nevertheless, because there is same pronoun correspondence between Northern and Southwestern Mande, *d would be a likely candidate for this particle vere it not for a number of situations which require that this particle bear a nasal component. Nasality 18, after all, the crucial difference between these two proposals. Both *d and *it- are sonorant (tone-bearing) and low-toned; only $i \hat{h}-$, however, is [+nasal].

The first of these situations is the brosdening of the Gemination rule in Proto-Central SWM (see 3.3.) to include both the particle in question and the high-toned nasal *h- 'my', but not the high-toned non-nesel *f- 'your'. Th1s development can be seen as a simplification of the Gemination rule (the inclusion of all nasals) only given the $h$ - hypothesis. Given the "a proposal, the motivation behind this development is unclear at best.

The second of these situations concerns the process which has been termed Nasal Absorption (11). This process states that when the particle in question combines with a heavy consonant, the result is a nasal with the point of articulation of the heavy consonant. The resultant nasality is a natural consequence of the "it- proposal, but a apurious development given the "d proposel.

Thiraly, the Nesal Absorption process is necessary to describe the development of SWM medial consonants. If the proposel is followed, then the development of SWM Initial and medial consonants must be conaldered as the result of different processes, even though their result 
is the same. Again, given the H-hypothesis, the development of SWM initial and medial consonants can be seen as the result of the sane processes.

One of these processes, Nasal Absorption, 18 necessary to demonstrate why Kpelle medial nasals may correspond with elther Central SWM nasals, ${ }^{N C}$ dequences or voiceless stops. Some comparisons of Mende (a Central SWM language) and Kpelle are given in (39) below.

(39) 1. Kpelle medial nasal corresponds to Central SWM medial nasal:

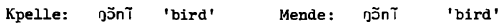

Kpelle: mẽnĩ 'hear' Mende: mẽni 'hear'

2. Kpelle medial nasal corresponds to Central SWM NC ${ }_{\mathrm{vd}}$ :

Kpelle: $\mathrm{kp} \mid \mathrm{nl}$ 'night' Mende: kpindi 'night'

Kpelle kona 'mortar' Mende: konda 'mortar'

3. Kpelle medial nasal corresponds to Central SWM voiceless stops:

$\begin{array}{lllll}\text { Kpelle: tunwo 'staff' } & \text { Mende: tikkpo 'staff' } \\ \text { Kpelle: fuga 'powder' } & \text { Mende: fukka 'powder' } \\ \text { Kpelle: nTga 'cow' } & \text { Mende: nikka 'cow' } \\ \text { Kpelle: mina 'spoon' } & \text { Mende: mitta 'spoon' }\end{array}$

The first set of correspondences represent reflexes of Proto-sim medial nasals (40):

(40)

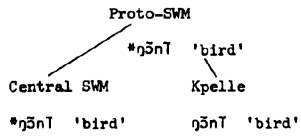

The second set of correspondences represent reflexes of Proto-SWM medial HC $_{\text {heary }}$ sequences and the effects or the Hasal Absorption and Nasal Expension rules (41): 
(41)

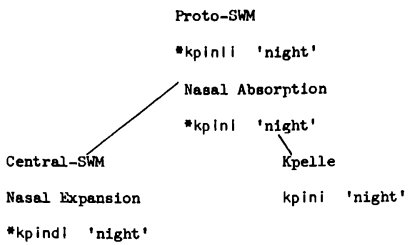

The third set of correspondences represent reflexes of Proto-SWM medial "NC $\mathrm{vls}_{\mathrm{s}}$ sequences and the effects of the Gemination rule, and a rule called Internal Post-Nasal Voicing (42), a Kpelle rule which applies before Nasal Absorption and voices medial consonents which are preceded by a nasal.

(42) Internal Post-Nasal Voicing (Kpelle)

$$
c_{\mathrm{vls}} \rightarrow \mathrm{c}_{\mathrm{vd}} /+\ldots \mathrm{N} \ldots . .+
$$

The third set of correspondences are derived as follows (43):

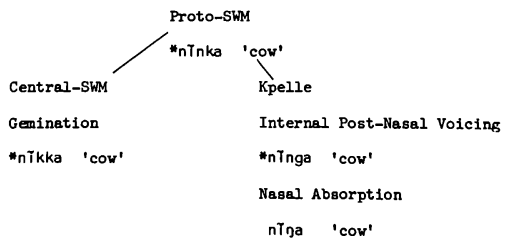

The Intermediate stage of the Kpelle development is supported by the following set of Vai (a Northern Mande language) cognates (44). Here, the Internal Post-Nasal Voicing rule applles in the absence of 
the Nasal Absorption rule: ${ }^{29}$

(44) Vai [Westermann 1927]

$$
\begin{aligned}
& \text { tungbe 'staff' } \\
& \text { fungu 'pouder' } \\
& \text { ninge 'cow' } \\
& \text { manja 'chlef' (c.f. Bandi: mässa 'chief') }
\end{aligned}
$$

Further evidence of nasality before volceless stops in Proto-SWM comes from the morphemes glossed 'bird' and 'spoon'. Each of these morphemes 1llustrates a SWM development akin to Meinhoff's law [Bennett 1967]. This variant states that morpheme-initial heavy consonants become nasal if the medial consonant is nasal. The development of ProtoWestern Mande "roni 'bird' is illustrated in (45) below: Proto-Western Mande

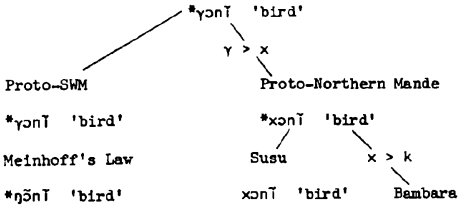

\section{koni 'bird'}

The Western Mande morpheme "binta 'spoon' also undergoes Meinhoff's law ("binta > *minta) indicating the presence of a medial nasal and the presence of medial $\mathrm{NC}_{\mathrm{vls}}$ sequences in Proto-SWM. The medial consonant developenent of Proto-SWM *minta 'spoon' (46) follows the sare medial consonant development as Proto-SWM *ninka 'cow' (43).

29 Because the Post-Nasal Voicing rule appears in only some of the Northern Mande languages and only one of the SWM languages, I feel that its presence in Kpelle and Vai must be due to some reason other than conmon genetic inheritance. 


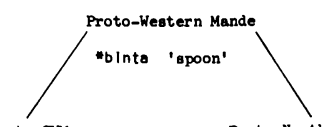

Proto-SWM

-binta 'spoon'

Melnhoff'g law

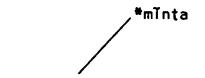

Proto-Central SWM

*minta 'spoon'

Gemination

mitta 'spoon' (Mende)
Proto-Northern Mande

-binta 'spoon'

Internal Post-Nasal Volcing

blnda 'spoon' (Susu)

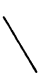

Kpelle

*minta 'spoon'

Internal Post-Nasal Volcing

-mTnda 'spoon'

Nesal Absorption

mTna 'spoon'

From the arguments and data presented here, one can see that the development of SWM medial consonants must be viewed in terms of nasalconsonant sequences and the Nasal Absorption, Nasal Expansion and Gemination rules, exactly those rules which were proposed for the development of SWM Initial consonants. Were the low-toned nasal wi- replaced by the non-nasal "d, this generalization would be lost.

4.4. The possibility of pg. The reconstruction of Proto-sWM 'my' and 'h1s' presented here differs from Hyman [1973] who reconstructs them as ins and "if respectively. We both belleve that the two sets of pronouns are related, but through different processes: Hyman believes that "f- 'my', for example, 1s derfved from "is through vowel deletion and tone transferral, while I claim that "os is morphemically complex, containing the pronoun $k-f$ and the particle of allenation wo. Because the development of the SWM pronouns 1s extrenely compl1cated and irregular, it could be the topic of a lengthy article itself. 
Table III: Southwestern Mande possessive pronouns

\begin{tabular}{|c|c|c|c|c|c|c|}
\hline Familial Possession & Mende & Loko & Bend1 & Lome & Kpelle & PSWM \\
\hline my & nyá & ni & nf & $n$ & $h$ & - \\
\hline your & bf & bf & $p$ & $\theta$ & i & $* 1$ \\
\hline h1s & ngif & ngif & ngtf & h & r & $n-$ \\
\hline$o u r_{1}^{30}$ & -- & nif & nil & dée & - & - \\
\hline our $_{2}$ & muú & muú & muú & gée & kú & $?$ \\
\hline your & wuá & wú & wú & wo & ká & $?$ \\
\hline their & tif & til & tit & téo & ddf & $* H-t$ \\
\hline
\end{tabular}

Corporal Possession

\begin{tabular}{|c|c|c|c|c|c|c|}
\hline my & nyá & nyá & A & $n$ & $h$ & H \\
\hline your & br & bi & f & e & i & 41 \\
\hline his & nglf & a láa & $n$ & $n$ & H & - \\
\hline our $_{1}$ & -- & nif & nif & dée & - & - \\
\hline our $_{2}$ & muú & muú & muú & gée & kú & $?$ \\
\hline your & wuú & wú & wó & wo & $\mathrm{k} \boldsymbol{f}$ & $?$ \\
\hline their & tif & $t 11$ & tif & tóe & ddf & $* \mathrm{H}-\mathrm{t}$ \\
\hline
\end{tabular}

Alienable Possession

\begin{tabular}{|c|c|c|c|c|c|}
\hline my & nyá & $n 1$ & nI & na-n & 6 \\
\hline your & bf & bl & 1 & ya & 1 \\
\hline his & nglf & ngif & ngif & $n a-\beta$ & त) \\
\hline our $_{1}$ & - & nif & nif & dáa & -- \\
\hline our $_{2}$ & muú & muú & muá & gáa & $\mathrm{kf}$ \\
\hline your & พuú & wuú & wú & wa & $k \mathfrak{d}$ \\
\hline their & tif & tif & $t 11$ & tóa & ddf \\
\hline
\end{tabular}

${ }^{30}$ Loma, Band1, and Loko draw a distinction between inclusive (our ${ }_{1}$ ) 
The sketchy outline of the SWM possessive pronouns (Table III) is offered In order to demonstrate why I differ with Hyman [1973] w1th respect to the Proto-SWM form of the above mentioned prnouns.

Southwestern Mande expresses three types of possession: familial, corporal, and aliensble. Famillal possession concerns one's relationship with his family (my father); corporal possession, with body parts (my foot); and allenable possession, with all other objects (my rice). These different types of possession not only correspond to different semantic cetegories, but to different morphological and phonological (including segmental and tonal) differences as well. The following discussion concerns only the morphological differences of the various SWM pronouns whose underlying representations are given in Table III above.

W1th the exception of the syllabic, tone-bearing nasals, which have alresdy been discussed, and the short rising tone (e.g., if , vú), which is reduced to either a simple high or non-high tone, the underlying representetions of (47) are virtually identical to their corresponding surface representations. Yet, in order to clearly demonstrate this relationship, the following corporal possessive paradigm is offered.

(47) Corporal possession in $\mathrm{SWM}^{31}$

\begin{tabular}{|c|c|c|c|c|c|}
\hline & Loko & Mende & Bandi & Lome & Kpelle \\
\hline my & nyś-wo.o-'s & nyá-go.e-’’ & $k-k \delta . \circ-1 / 1$ & k-ko.ogg-'p & $\delta-g 0.0$ \\
\hline your & bf-wo.o-1f & bl-go.e-'f. & f-wó.o-ł $i$ & e-wo.ogg-'f & i-ko.o \\
\hline his & ala-wo.o-if & $n g l-g \circ . \theta^{\prime}+f$ & k-ko.o-'îl & k-kó.ógg-1 & $9-90.0$ \\
\hline$o u r_{1}$ & nf-wo.o-'i & -- & nI-w'ó.o-' |l & of-wó.ogg-'f & -- \\
\hline $\operatorname{our}_{2}$ & mú-wo.o-11 & mú-go.e-'1 & mu-w'ó.o-' 1 l & gl-wó.ogg-'f & kú-ko.o \\
\hline your & wú-wo.o-'p & wú-go.e-'l & wú-wó.o-'fi & wo-wo.ogg-'i & ká-ko.o \\
\hline the1r & $t t f-w o .0-1 t$ & $t t /-g 0 . \theta-1\}$ & $t t 1-w \cdot 8.0-1 / 1$ & $t t f-w \delta . \circ g g-1\}$ & ddf-ko.o \\
\hline
\end{tabular}

and exclusive (our ${ }_{2}$ ) first person plurals. Eastern Kpelle, according to Lassort [1952] also has this distinction.

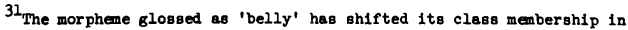
Loma, for here it behaves like those morphemes which historically end in a velar nasal. This suggests the possibility that in Loms this class distinction may be marked with a diacritic feature rather than phonetically. 
While the SWM pronoun development is not entirely regular, a few observations can be made. First, the Loma alienable pовsessive pronouns can be easily derived from the corporal possessive pronouns through the addition of a particle $-a$ and the elision of the pronoun vowel (note, hovever ya from (-a). Likewise, the Kpelle pronoun is' 'my' can be viewed as morphemically complex $(\mathfrak{f}+w 0)$. Furthermore, this situation can be seen even more clearly in an eastern dialect of Kpelle where in careful, deliberate speech, as reported by Lassort [1952:329] in (48) below, the entire paradigm of corporal pronoun plus wo is present.

$\begin{array}{llll}\text { (48) Aliensble } & \text { Alienable } & \text { Corporal } \\ & \text { Careful Speech } & \text { Normal Speech } & \text { Familial } \\ \text { my wo (high tone) } & \text { jo (high tone) } & \text { jo (high tone) } \\ \text { your } & \text { o wo } & \text { ye } & \text { e } \\ \text { his } & \text { wo (low tone) } & \text { ge (low tone) } & \text { go (low tone) } \\ \text { our } & \text { ku wo } & \text { kuo } & \mathrm{ku} \\ \text { your ka wo } & \text { ka } & \mathrm{ka} \\ \text { their di wo } & \text { die } & \mathrm{di}\end{array}$

(Lasgort uses the schwa in the above exemples to indicate a syllabic nasal. Thus no is equivalent to n.)

Lassort further mentions that po 'trace' and 'ye 'hand' can be used in place of w. This fact demonstrates that the sequence: pronoun particle of alienation - alienable noun, is quite common in Kpelle. In contrast to the eastern dialect of Kpelle described by Lassort [1952], the dialect described by Welmers [1962] has preserved the morphological distinction between alienable on one hand, and corporal and familial on the other in the first and third person singular only.

\section{Summary}

Th1s paper has outlined the major consonant developments of Southvestern Mande. It has shown that only one set of rules is necessary to describe the development of both medial and final consonants and initial consonant alternation. It hes show that initial consonant alternation has risen through the interaction of a low-toned nasal preflx with a 
following consonant. Subsequent consonantal developments vere shown to be natural developments which in most cases appesred to be simplificat1ons in the Kiparskian sense.

\section{REFERENCES}

Bennett, P. 1967. "Dahl's Law 1n Thagtcu", African Language Studieg 8.

B1rd, C. 1971a. "Observations on Initial consonant change in Southwestern Mande", in Papers in African Linguistic8, pp. 153-74. Ed1ted by C.W. KIm and H. Stahlke. Edmonton, Alberte and Champaign, Ill1nois: Linguistic Research, Inc.

B1rd, C. 1971b. "Scme observations on the phonology of Mandekan: Diachronic and synchronic regularity", Studies in African Linguist1c8, supplement 2 .

Dwyer, D. 1973. A Comparative Tonology of Southweatern Mande Nominals. Doctoral dissertation, Michlgan State University, Lansing.

Eberl-Elber, R. 1937. "Der Konsonantische Anlautwechsel am Hauptwort in der Sprachengruppe Gbande-Loma-Mende", Mitteilungen der Ausland Hochschule an der Universitat Berlin Jargang 15.

Gudshinshky, S., A. Popovitch and F. Popovitch. 1970. "Native reaction and phonetic similarity in Mexakal1 phonology", Language 46.1:77-88.

Heydorn, R. 1940. "Die Sprache der Bandi im nordwestlichen Liberia", Zeltschrift für Eingebornen Sprachen $31: 81-114,108-27$.

Hintze, F. 1948. "Zum konsonantischen Anlautwechsel in enigen vestafrikanischen Sprachen", Zeitschrift fïr eingebornen Sprachen 2:164$82,322-35$.

Houls, M. 1963. Etude descriptive de 18 langue Sugu. IFAN, Dakar.

Hyman, L. 1973. "Notes on the history of Southwestern Mande", Studies in Arrican Linguistics 4:183-96.

Lassort, R. 1952. Gramalre Guerzé. Mémolres de l'IFAN no. 20:303-423. Dakar.

Manessy, G. 1964. "L'alternance consonantique initiale in Manya, Kpelle, Loma, Bande, et Mende", Journal of Afr1can Languages 1.1:162-78.

Meeussen, A. 1965. "A note on permutation in Kpelle-Mende", African Language Studies 6.

Sauvant, M. 1965. Grammaire Bambars. Issy les Moulineaux.

Schachter, P. and V. Frank1n. 1968. A Phonology of Akan: Akuapen, Asante, and Fante. Working Papers in Phonet1cs 9. UCLA.

Travele, M. 1913. Petit dictionalre Francals-Bambara et BambaraFrancels. Paris. 
Welmers, W. 1958. "The Mande languages". Georgetown Series on Language and Linguistics 11.

Welmers, W. 1961. "Internal evidence of borrowing in Kpelle", Genersl Linguistics 4:1-9.

Welmers, W. 1962. "The phonology of Kpelle", Journal of African Lenguages 1:69-93.

Welmers, W. 1970. "The morphology of Kpelle nominels", (to appear in the Journal of African Languages].

Welmers, W. 1971. "Niger-Congo Mande", In Current Trends in Linguistics, Number 7, Linguistics in Sub-Sahara Africa, edited by T.A. Sebeok. Mouton, The Haque.

Westermann, D. 1927. Die wegtlichen Sudansprachen und Ihre Beziehumgen zum Bantu. Berlin: Reimer. 
A NOTE ON GLOBAL RULES IN BANGUBANGU TONE

\author{
A. E. Meeussen \\ University of Leiden \\ The Netherlands
}

\title{
1. Introduction
}

Recently McCawley [1973] has claimed that standard phonological theory, through its requirement that rules should be local, cannot account for some complicated cases, such as the tonal system of Bangubangu. (A local rule, when applying to a given string in a derivation, makes use of phonological information contained in the string itself, whereas a global rule in addition relies on phonological information contained in some previous string of the same derivation; in both cases, gramatical information can be used.) McCawley also submits two sets of rules for deriving Bangubangu tones; the first makes use of a "spurious" mid tone, the second contains global rules. The aim of the present paper is (1) to evaluate McCawley's arguments about the insufficiency of local rules, (2) to examine the validity of his global rules, and (3) to make some suggestions about other possibilities for an analysis of Bangubangu tone.

\section{Local Rules}

In the first case adduced by MtCawley two possible derivations are given for the phonetic string [...mulondó múyende] '(put) the jar into the house':

(a)

$$
\text { /mu Ióndo mu } \mathrm{ki} \text { endé/ }
$$

Ratsing

$$
\delta
$$

Spreading

ú

Lowering

○

$\theta$

Formalizing these rules, we obtain:

Raising:

$\mathrm{L} \rightarrow \mathrm{H} / \mathrm{H}$

Spreading:

$\mathrm{L} \rightarrow \mathrm{H} / \mathrm{H}$ \#

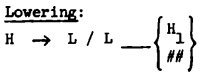


Here, McCawley's argument is: "lowering must be global, since it is the highs that were high before High Shift that get lowered, not the ones that it (or Terminal High Spreading) created." It is true that only nonderived highs must be lowered; but since every derived high is preced by high, any non-derived high can be identified at this stage through the fact that it is the first of a pair (or a sequence) of highs, or that it is preceded by low (or both conditions taken together). The environment given in the formalization, then, is doubly sufficient, and a global rule is superfluous. /mu lóndo mu $\mathrm{kl}$ endé/

Shift o ó

Spreading

ú

Lowering

$\boldsymbol{\theta}$

Formelized rules:

\section{Shift:}

$\mathrm{HL} \longrightarrow \mathrm{LH}$

Spreading:

$\mathrm{L} \longrightarrow \mathrm{H} / \mathrm{H} \#$

\section{Lowering:}

$\mathrm{H} \longrightarrow \mathrm{L} /$ \# \#

The difficulty about lowering does not arise here, and it can be observed that the lowering rule can be ordered before spreading or even before shift. The necessity of a global rule in this case is claimed by McCerley on the besis of a contrast with another atring: [mbeté namáfumú] 'knives and spears', with the following derivation:

$$
\begin{aligned}
& \text { /n péte ná ma fúmu/ } \\
& \text { Shift ó a de ú }
\end{aligned}
$$

The argument 1s: "In such an example, Terminal High Spreading would incorrectly make the rirst syllable of the second word high unless it were allowed to refer to the tone which that ayllable had before High 
Shift." That 1s, the rule should not apply to derived 10\%, but only to underlying lov. Now, derived lov is followed by bigh (as a result of $\mathrm{kIf} \rightarrow$ LH), wherese underlying low 1s followed by low. All that has to be done, then, is to add the mention of a following low to the enviroment of the spreading rule, thereby making 1 t non-applicable to mbeté namb́fumú:

\section{Spreading:}

$\mathrm{L} \rightarrow \mathrm{H} / \mathrm{H}$

It can be verifled that this addition has no undesirable results in (a) or (b). Again, a global rule appears not to be necessary.

The second case vhere according to McCavley a rule must be global 18 found in the examples [nlláciliná] 'I am afrald' and [Jilyégólí nódf nfluclind] 'I don't go (around) with it (because) I am arraid'. The first is stralghtforward if (final) lowering is ordered before andet:

$$
\text { /ni ló clín b/ }
$$

$\begin{array}{ll}\text { Lowering } & \text { a } \\ \text { Shlft } & \text { il }\end{array}$

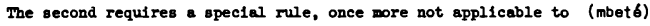
nambfumb. For this rule we can take advantage of a difference in environsent: namf́fumú is preceded by LH (:mbet $\delta$ ), whereas ...nllícilind 1s preceded by HII (:nádf); the same is true of the other known exaple: [gulávulá] 'you want' but [hfcá gúluvulf́] 'if you vant'. The rule--apparently a late rule--rill be:

\section{Reverbal:}

LH $\rightarrow$ HL / HH

Once more, the necessity of a global rule 1s not proved. But it must be adalted that the basis for the reversal rule is very narrov, and ve any assume that there are other dffeicult cases in the tonal system of Bangubangu. In order to deal with these, one of the following options will have to be adopted: (1) using "Interim" features, such as mid tone or extra high, which are absent both in depth and in surface; 
(2) using sone feature whlch 1s present in surface; (3) making use of global rules. It will be clear that (2), if at all posatble, is the most satisfactory cholce.

\section{Global Rules}

MeCavley's second rule set includes three global rules: 7,9 , and 10. Of these, 1t looks as if rule 9, as it stands, is not applicable to ang atring: 1t converts to high some syllables which were high before rule 4, but none of the rules 4-8 rewrites anjthing as low; in effect, then, rule 9 alvays applies vacuously.

Rule 10 converts all highs which were high before rule 4 into low (except in the first syllable of a verb); in so dolng, it yields wrong results in the following cases, taken from McCawley's derivations: *bónitagóna Instead of [bónitágána] 'they have called me', rrom

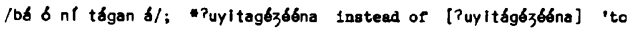
call each other', from /ku yl tágan izeen b/; "nilucliná Instead of [nilúclinf] 'I am arraid', from /nl lú clfn $f /$, as vell as all other cases of localization. It is not clear whether it vill be possible to restrict rule 10 in such a vay that these undesirable results are avolded.

\section{Suggestions}

4.1. Rising tones must be introduced by rules, perhaps by late rules, since they are present in surface. Noreover, every rising tone corresponds to an underlyling high. Therefore it is an attractive posalbility to convert most underlying highs into rising by a not too late rule, Instead of changing them into low by the shift rule. The result vould be that the desired distinction between derived high and non-derived bich 1s no longer a problem. Whether thls should be handled by a now feature [+ rising] or by the device of overspecified features, $\nabla z,[[-b][+h]]$, is a ignificant question in itself.

4.2. "Predeterninanta" could be treated by setting up the three formatives in question with an additional segment $[-$ vo, $-c o,+h 1]$, or $[+r o,-c 0,-6 y, 4 h 1]$, ll other features being either negative or unspec1fied: $n^{\prime}-$ '1t 1s', nda'- '1t is not', -a'-tense sige in 
relatives. Such "free high" would be an instance of underspeclfied features. Free high can be helprul also for tone paralleliam (tense sign - - ) and for subjunctive (tense alga -" - or -"-). Sinilarly, free low can be used to eccount for the exceptional behavior of prononinal prefixes: ' $y u ́-$, "bf-, etc., which are low in word initiel. 4.3. The possibility of a fairly early rule which makes all extension oyllables high before high final should be explored.

4.4. Much could be gained, expecially for the rules of doubling and for those concerning the verb, by giving a special status to the boundary between (last) preflx and oten.

\section{REFERENCES}

McCavley, James D. 1973. "Global rules and Bangubangu tone", in Issues in Phonological Theory, pp. 160-168. Edited by M.J. Kenstowicz and C.W. Kisseberth, The Hague: Mouton. 
r.t.

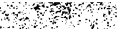

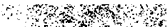

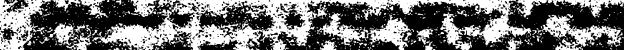

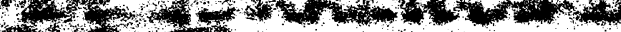
+

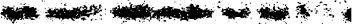

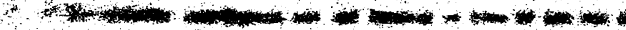

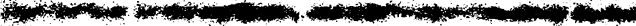

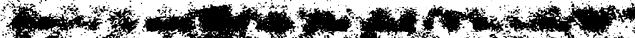

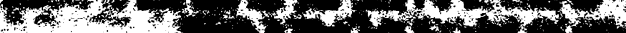

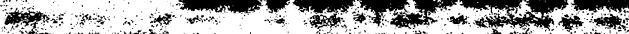

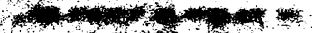
the

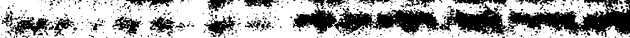

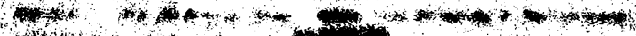

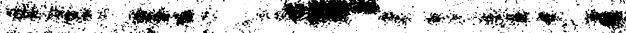

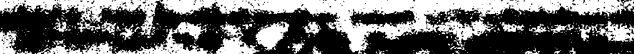

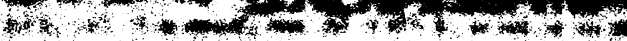

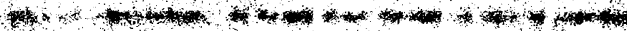

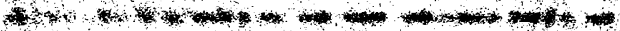
inotios

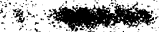

$+\infty$ A $\quad 20+\infty$

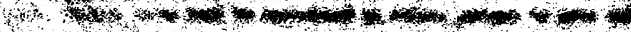

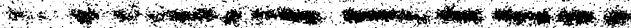

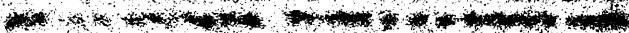

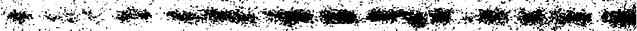

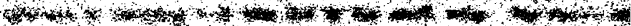

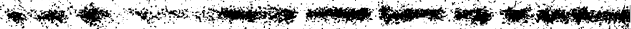

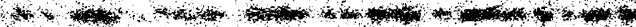

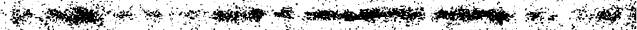

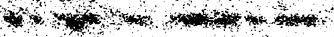

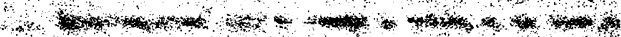

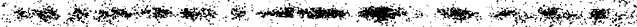

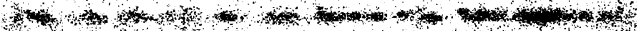

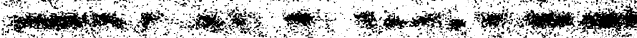


DERIVATION AND SIPPLIFICA'TION

BY ADOLESCENT DIOULA SPEAKERS

\author{
Gayle Partmann \\ Department of Linguistics \\ University of Southern Illinols, Carbondale
}

\title{
1. Introduction
}

This paper is based on part of the research for my dissertation, done in Ivory Cosst during the period of October 1970 through July 1972, and supported by grants from Stanford University. The research took place in Bouaflé, a medium sized town near the center of the country, with a mixed ethnic population. The general purpose of the research was to compare Dioula as it is spoken by primary speakers with the Dioula spoken as a second language in inter-ethnic communication. In this particular section, evidence was found of simplification comparable to that found in many pidgin languages. The Dloula language is part of Mandingue, of the Mande sub-group of Niger-Congo. Dioula is also called Malinké and Bambara, depending to some extent on soctal and geographic factors. The examples of derivation were elfcited with an oral questionnaire which was tape recorded. This particular section of the questionnaire consisted of sentences to be translated from French to Dloula. The other parts of the questionnalre, Including lexical items and free questions, were elicited in Diouls. Judging from the lack of French borrowings, either lexical or structural, the use of French did not seem to influence the derivation responses. All the speakers were first and second year pupils at a local secondary school, about 14 to 15 years old. The speakers were divided into two groups: The f1rst group, D-I, was comprised of pupils who spoke Dioula as their first language. They were chosen to create a balance in what are reported to be geographic dialect areas according to their respective regions of orig1n. The second group, D-II, were speakers from other ethnic groups who spoke Dioula as a second language. In this case the group was balanced according to the primary language of the epeaker. The D-I group had eleven speakers, the D-II thirteen.

2. Derivation in Dioula

The formstion of new words by affixation is a rich process in Dioula. 
Dumestre [1970] gives $81 x$ "derlved" or "Integrated" verbals and twentytwo nominals in his grammar of Dioula. In the present study I have considered both derived (derivation with no change in word class) and integrated (derivation with a change in word class) words together under the title of derivation. I chose to investigate fifteen derivations cited by Dumestre (see Appendix). These fifteen derivations appear to be fairly frequent. They are found not only in Dumestre's grammar, but also in the Delafosse [1955] dictionary. While Delafosse marked some derivations as rare in his dictionary, none of these fifteen were so marked. I have no other information, however, that indicates the frequency of these derivations in current Dioula speech. For this reason, the overall percenteges of use for any derivation in this research cannot be adequately evaluated. The interest lies in those derivations where the two groups differ in frequency of use, and especially in those derivations where the difference is a qualitative difference in formation.

One other problem deserves mention. The purpose of the test was to determine the speakers' ability to use certain derivational affixes. Real words in Dioula were used instead of nonce forms, as it was felt that the speakers would not respond to nonce forms. It was therefore possible for the speakers to produce a derived word as a vocsbulary item without knowing the derivational process. For meny items in the test, the responses were so varied that vocabulary learning did not seem to be influential. In other cases the base morpheme was sufficiently uncommon to minimize this effect also. In two cases, where one word of a derivation vas consistently given correctly and the other word not at all (/dumunl/ $11 . \mathrm{b}$. and /siglian( 15.8.), these two words vere considered to have been learned as vocabulary, and thereby ellminated from further considerstion.

In Dioula it 18 also posalble to derive new words by suffing lexemes. The lexemes / $\mathcal{C}_{\theta}$, muso/ 'man, voman' are often suffixed to animate lexemes: /oggo-ce/ 'little brother', /karo-muso/ 'elder sister', /somusol 'mare', /misl-muso/ 'cow'. The D-II group often used this process, though the lexemes they affixed vere not ones normally used by D1oulas. In addition to lexical derivation, there are other compound words which are unfque, such as /nege-so/ 'blcycle', from /nege/ 
'metal, Iron, and /so/ 'horse'.

Similar word formation is found in other languages of this sub-aroup. For Susu, a language from Guinea closely related to the Malinké group, Houls [1963] gives six derivations of lexical origin, of which two do not have corresponding free lexemes now, and seven other derivations created by affixation. One of the derivations of lexical origin (but without a current corresponding lexeme), /-ka/ 'locative of origin', is cognate with /-ka/ from Dioula. Another lexical derivative, /-di/ 'diminutive', is probably cognate with /dẽ/ 'child in Dioula, which is sometimes used as a diminutive, in the sense of 'offspring of', such as /misi-dẽ/ 'calf'.

\section{Results of the Tests of Derivation}

3.1. General results. An analysis of variance with unequal N's was done for each derivation separately; the sum of the means for all derivations was calculated and the two groups were compared on this basis also (see table I). Group D-I (N II) are the primary language speakers; Group D-II (N 13) are the vehicular language speakers. The speakers had from one to three attempts (depending on the derivation) to give the correct form. The percentage of correct responses for each speaker was noted, then converted by an arc sine value for the purpose of the analysis of variance.

Those derivations where the between group variance has a lesser probab1lity than $1 \%$ were derivations known fairly well to members of D-I, and almost not at all to those of D-II. The variance on the sum of derivations also had a less than $1 \%$ probability. Those derivations where the between group variance has a probability of between $1 \%$ and $5 \%$ were derivations known to members of group D-I to some extent, and almost not at all to those of D-II. The derivations having a greater than $5 \%$ probability of between group variance were known very little or not at all to elther group, although this last set of results is mixed. It should be noted that all significant (less than $5 \%$ ) variances favor the D-I group.

It should be remembered here that these results are based on a test of production and not of comprehension. It is possible that the speakers, especially those of D-I, understood more derivations than they ordinarily 
Table 1: Analysis of Variance--Tests of Derivations

$\begin{array}{llll}\text { Derivation } & \text { Number of } & \text { (1) group \% of } & \text { critical value } \\ \text { trials per } & \text { correct responses } & \text { of F } \\ \text { speaker } & \text { D-I } & \text { D-II } & \\ & & \text { (IN II) } & \text { (N 13) }\end{array}$

\begin{tabular}{|c|c|c|c|c|c|}
\hline 2. & Verb redup. (2) & 2 & 0 & $4 \%$ & \multirow{9}{*}{$\underset{5 \%}{\text { greater than }}$} \\
\hline 4. & Adj. /man/ & 1 & $0 \%$ & $0 \%$ & \\
\hline 5. & Augment. & 2 & $77 \%$ & $42 \%$ & \\
\hline 6. & Dimin. & 2 & $9 \%$ & $4 \%$ & \\
\hline 10. & Verb /man/ & 1 & $45 \%$ & $15 \%$ & \\
\hline 11. & Verb /Ii/ & 3 & $42 \%$ & $33 \%$ & \\
\hline 12. & Verb /bali/ & 2 & $0 \%$ & $0 \%$ & \\
\hline 13. & Verb /len/ & 2 & o\% & $0 \%$ & \\
\hline 15. & Instrunental & 2 & $36 \%$ & $23 \%$ & \\
\hline 3. & Adj /ya/ (verb) & 3 & $37 \%$ & $10 \%$ & \multirow[t]{2}{*}{$5 \%--1 \%$} \\
\hline 7. & origin & 1 & $36 \%$ & $0 \%$ & \\
\hline 1. & Trans. verb & 2 & $41 \%$ & $0 \%$ & \multirow{4}{*}{$\begin{array}{l}\text { less than } \\
1 \%\end{array}$} \\
\hline 8. & Ord. livm. & 1 & $91 \%$ & $8 \%$ & \\
\hline 9. & Adj /ya/ (nom) & 2 & $59 \%$ & $8 \%$ & \\
\hline 14. & Agentive & 2 & $50 \%$ & $1 \%$ & \\
\hline (1) & \multicolumn{5}{|c|}{$\begin{array}{l}\text { These percentages are of course not used in the analysis of variance. } \\
\text { They are given here only to provide the reader with a more precise } \\
\text { indication of the direction of the variance than would be provided } \\
\text { by "low use, high, etc." }\end{array}$} \\
\hline (2) & \multicolumn{5}{|c|}{$\begin{array}{l}\text { See Appendix for a fuller description of the derivations. Num- } \\
\text { bers refer to the number of the derivation in the Appendix. }\end{array}$} \\
\hline
\end{tabular}


produced. Also, the expression asked for can often be rendered in other ways than by a derivation. Sometimes the so-called "wrong answers' denote lack of response; the speaker simply said he didn't know. Hovever, many of the "wrong answers" were paraphrases expressing, some better than others, the requested 1dea. These alternate angwers will be discussed further below. The more interesting results of the present research having to do with simplification were found in these alternate answers.

\subsection{Results by derivation}

3.2.1. Derivations with no significant between group variance. Derivations 2, 4, 6, 12, and 13 had very low scores for both groups. Derivation 2 , reduplication of the verb to express a repeated action, was not used, but reduplication of other forms was quite frequent. The two sentences should have been:

(2a) /a ka sogo t Ige tige/

'he cut the meat into little pieces' (/tlge/ 'cut')

(2b) /a ka a sen ko ko/

'he kept washing his feet again and again' (/ko/ 'wash')

For the first sentence, most speakers added the word 'little' /fitini/ and repeated it without repeating the verb, i.e.:

$$
\text { /a ka sogo tlge fitini fitini/ }
$$

For the second sentence, there was more varlety in the answers, but often the speaker repeated the whole predicate, also adding other words, 1.e.:

$$
\text { /a ka a sen ko... ka a sen ko/ }
$$

Only one speaker, from Group D-II, repeated the verb alone.

Derivation 4, adjectival plus /-man/ to form a nominal, was not used. The speakers, especially those of D-I, often changed vocabulary to contrast the sentences. The sentences ellcited were:

(4a) /a gbã no/ 'it is hot'

(4b) /gbã-man lo/ '1t's the heat'

The speakers used the adjectival /gbã/ for the first, then made a 
sentence with the noun $/$ tIle/ 'Bun' for the second.

Derivation 6 was the diminutive $/-n i n /$. To express the diminutive the speakers used elther /fit|nl/ 'little' or /denl/ 'chlld'. The final syllable of these words resembles the diminutive, but the two words are autonomous morphemes. Group D-I used the two words appropriately. That is, /deni/ was always used for 'puppy' (1.e./wulu-deni/), and sometimes for 'little bird', interpreting 'little' to mean 'baby'. /fltini/ was sometimes used with bird, interpreting 'little' as size, but was never used for 'puppy'. Menbers of D-II, however, generalized /fitini/ as a diminutive marker, using it for 'puppy' and 'little bird' indiscriminately. There was very little use of /deni/ by group D-II. /fitini/ was probably generalized by group D-II simply because it IB a very frequent word in Dioula, and is well known by everyone. Even foreigners who know no more than ten words in Dloula know /fitini/. This word is also used as a brend name of infants' wear sold by the Chaine Avion stores throughout the country. In the lexicon section of the research, two D-I speakers used the diminutive /-nin/ for 'path', but no D-II speaker did so.

Derivation 12, a verbel plus /-bali/ meaning 'deprived of, lacking', was not used at all, nor was Derivation 13, a verbal plus $/-\mid$ en/ to form a nominal. Derivation 13 will be further discussed with Derivation 11.

Derivations 10, 11 , and 15 were used somewhat by the two groups. That Derivation 10, a nominal formed from an integrated verbal plus /-man/ was used at all is remarkable, because no speaker used a very similar derivation, that of nominal from adjectival plus /-man/ (4). One case of an 'Integrated verbal' given by Dumestre [1970:49] was an 'adjectival plus Ø', so It 1s not evident why the nominalization of an adjectival and that of an adjectival plus $\emptyset$ have given such different results. In the discussion of these two derivations in Dumestre [1970:52-53], two classes of adjectives were implied. This is so because the integrated verbal had two translations of 'it is black': /a ka fin/ adjectival, and /a fin na/ verbsl. "It is sweet' had only one, the edjectival /a ka dl/. One would like to know which adjectives can be verbels, which cannot, and if it was 
this difference that was significant in the results of the speakers.

In derivation 11, the nominal formed by the verb plus $/-11 /$ seened to replace the nominal formed by the verb plus /-len/ (Ver. 13), even though the nominal / $\mid$ i/ was not regularly employed. The derivation / I en/ was never used, but for the two gentences used to elfcite this derivation the speakers ofter gave $/-1 \mid /$. The sentence, 'The meal was yesterday', was eliminated from the analysis because the derived term, /dumūni/ (1lb), is well known as a vocabulary item. Almost all the speakers gave the form /dumũni/ and only one speaker gave /tagali/ in the preceding sentence ( $11 a$ ) 'leaving is painful'. Judging by these two sentences, /- $1 \mathrm{i} /$ did not seem to be known. But when the two sentences where /-len/ was expected were considered, /- $i \mathbf{l}$ did have a wider use, as it replaced $/-1 \mathrm{en} /$. The analysis of variance for Derivation 11 was based on sentences $11 \mathrm{a}, 13 \mathrm{a}, \mathrm{b}$.

Derivation 15 is the instrumental, a verbal plus /-lan/. Again, for one of the sentences (15a) it is likely that the derivation was learned as a vocabulary item. All the correct answers for D-II and most of those for D-I used this word, /siginan/. Since there were not all that many correct answers, however, the case is not as clear as that of /dumũni/, and the item was retained in the analysis of variance calculations. In the lexicon, D-I speskers used the affix for three words; the D-II speakers did not use it at all.

Derivation 5, the augmentative /-ba/, was the best known to both groups. In most instances where the speaker did not use the affix /-ba/, he used the independent morpheme /gbele/ 'big, fat', often with reduplication. In the lexicon, both goups used the affix also.

3.2.2. Derivations with a significant ( $5 \%$ or less) between-group variance. In all of the following derivations, the D-II score was always very low. Derivations 1, 3, and 7 were used somewhat by the D-I speakers. Derivation 1 changed an intransitive verb to a transitive. While the actual derivational affix /la-/ was not used often, the other verbal marker in the transitive sentence, /ka/, was widely used by both groups. Sentence (la) was the intransitive: 
(1a) /musa wuli la/ 'Moussa got up'

Its transitive pair should have been:

(1b) /musa ka taball la wuli/ 'Moussa lifted the table'

but was often given as:

/musa ka tabali wuli/

The marker /ka/ was given by Dumestre [1970] as the marker for the 'accomplished' in transitive verbs, active voice. The suffix $/-\mid a /$ was given as the marker for the accomplished for transitive verbs in passive voice and for intransitive verbs. These markers, with the addition of an object in the transitive sentences, sufficed for all the D-II speakers and for more than half the D I speakers to distinguish the transitive from the intransitive, without the prefix $/ \mathrm{a}-/$.

Derivation 3 was an adjective plus /-ya/ meaning 'to become $X$ '. Most of the incorrect answers could be translated by 'he is $X$ ', instead of 'he has become $X^{\prime}$. The word /sisan/ 'now, immediately', was used several times by D-I and D-II speakers, almost always without /-ya/, giving the impression that this word expressed the idea of 'become' for some speakers.

Derivation 7, nominal plus /-ka/ 'inhabitant of', had many alternate answers not using the derivational affix. $36 \%$ of the D-I respondants used the verb /bo/ 'to come', as in 'he comes from...'. 15\% of the D-II answers used $/ \mathrm{bo} /$ and another $23 \%$ of the D-II answers were with /sigi/ 'sit', which was not used by D-I at all.

Derivation 9 and 14 received moderate use by the D-I's. Derivation 3, the derivation of a verbal 'to become' from an adjectival, has already been discussed. This derivation cen also be used as a nominal (derivation 9). With the adjectival /jugu/ 'wicked' one can form the following sentences:
a. /a ka jugu/
'he is wicked'
b. /a jugu-ya-ra/
'he has become vicked'
c. /jugu-ya lo/
'1t's wlckedness'

It is the last sentence which is of interest now. D-I speakers used 
/Jugu-ya/ as a nominal in 59\% of the cases, while those of D-II used it in $8 \%$ of the cases (one case). Most of the D-II Groups simply said they didn't know how to say sentence (9c).

The agentive, Derivation 14,18 formed from a verbal (which can be a nominal plus / $\mathrm{ka} /$ 'do') plus / $/ \mathrm{la} /$. $50 \%$ of the D-I answers vere correct, as agsinst only $4 \%$ of the D-II answers. The speakers, more in D-II than in D-I, used the word /mogo/ 'person' instead of the derivational affix. Two D-I speakers used /mogo/, while six D-II speakers did so. In adaition, two other D-II speakers used other 'person' lexemes, /ce, denl/, in place of the derivation. The words for 'butcher' and 'vendor' in the lexicon showed similar results to the sentences. In the agentive, then, we again see the replacement of a derivational affix by independent lexical items.

The last derivation to be mentioned is Derivation 8 , the derivation of an ordinal number from the cardinal. Th1s was very well known by the D-I group, and almost not at all by the D-II group. Members of D-II used the cardinal form exclusively in most cses for both cardinal and ordinal. There vere two 1nstances of borrowing from French in D-II and one in D-I. Th1s was the only derivation for which speakers borrowed from French.

\section{Geogrephic Dialects in D-I}

The distribution of the number of derivations known by a speaker was parallel to that of the lexicon. That is, the group from the centernorth (Korhogo, Boundial1, S1kasso, Faraba) knew the most, with those from Odienne second. The following table gives the average number of derivations known by the speakers of each geographic group.

\begin{tabular}{lr} 
Table 2: Geographic Areas \\
\hline Center-North & 9.25 \\
Odienné & 7.30 \\
Séguéla & 6.50 \\
Toubs, Man & 5.00
\end{tabular}

\section{Primary Languages of D-II}

The apeakers of Akan and Krou languagea had about the same average knowledge of the derivations, 1.75 and 2.0 derivations per speaker respectively. The Western Kande group know the derivations better, with 
an average of 3.23 derivations per speaker. It would be helpful to know if some of the derivations tested are cognate with these speakers' first languages as Dioula is also a Mande (Eastern) language. The four Mande speakers did not all know the same derivations, but their three respective first languages could have retained different derivations from Proto-Mande. Considering the derivations which were known by the Mande speakers, two of these derivations were cognate in Dioula and Gouro (the only other Mande language in question for which a gramar was avallable).

$$
\begin{array}{ll}
\text { Gouro } & \frac{\text { Dioula }}{\text { /ne/ 'child, dim.' }} \\
\text { Verbal / / li / 'nominal' } & \text { Verbal / / } / i / / \text { 'noninal' }
\end{array}
$$

The instrumental in Gouro is $/-f \varepsilon /$. In Dioula the word / fen/ means 'thing', and was sometimes used to express the instrumental instead of the inflection $/-1 a n /$. One other derivation used by the Western-Mande group was the agent $/-\mid a /$, and for that the derivation in Gouro is /-za/.

\section{Simplification in the Derivational System and Pidginization}

The system of derivation, such as has been examined here on the level of every-day usage, was limited as measured against an ideal grammar for the primary speakers (D-I), and much more severely reduced for the secondary speakers (D-II). More Important than this difference in quantity of derivations correctly used, as demonstrated by the analysis of variance of the speakers' scores, was the rather widespread tendency to replace the affix of the derivation with a lexeme. Both groups did this, but the practice was more comon in the D-II group. Both groups frequently used a lexeme for the diminutive. For the aumentative and the agentive D-II speakers used lexemes considerably more than those of D-I. Another derivation, /sun/, to indicate the tree or plant bearing a particular fruit, was elicited in the vocabulary section. D-II speakers substituted the lexeme /ylri/ 'tree, plant' exclusively, whlle D-I speakers preferred /-sun/, the derivational affix. D-II speakers also used the lexene for 'thing', /fen/, Instead of the 1nstrumental derivation. The replacement of the affix by a separste lexeme constitutes a true simplificetion 
In the language, for no information has been lobt to complicate or conruse communication. The two terms (lexeme and derivational affix) in each case have the sane meaning, but now there 1s one term where there were two. The lexcme alone has the roles of a functional morpheme and of a word.

This development in the derivational system is paralleled by certain developments in pidgin languages and by the child learning his mother-tongue. To quote Traugott [1972]:

If a language is used in rather limited ways, in other words, has attached to it a narrow set of appropriateness conditions, we should expect a rather limited set of derivations (given a generative semantic point of view). We would therefore predict a relatively small number of surface possibilities, and that is of course exactly what we find. Compared to non-pidgin langueges, pidgina certainly have highly simplified surface structures....(p. 44)

And in referring to language acquisition:

It seems to me that a natural syntactic process gives distinct surface expression to grammatical categories such as tense, aspect, mood, confunction, negation, quantification, and so forth. Ideally they will be expressed analytically, that is periphrastically, though under the influence of the input, they may be expressed agglutinatively or even inflectionally. In the earliest stages of acquisition, however, they are nearly always periphrestic.....(p. 16)

In the present research on Dioula a reduced number of derivations was found, as predicted above. There was also a tendency to express the Idea of the derivation by an analytic expression, a free lexeme, instead of by an inflection. These tendencies were found in both groups, but they were more marked in the second language speakers.

In speaking of West African Pidgin English, Agheyisi [1971:54-55] also remarked that tense, number, aspect, etc, are expressed by lexemes instead of by inflection. She noted the lack of derivations and also the polyvalence of certain forms. This polyvalence was evident in D-II speakers, who used one form (the cardinal) for both the cardinal and 
ordinal numbers. Almost all the D-I speakers made the distinction between the two sets.

Traugott [1972:33] also pointed out the use of adverbs to replace the tense markers in pidgins. A similar substitution for a derivation was found in the Dloula speakers for Derivation 3 (adjectival plus /-ya/ meaning 'become'). Several speakers, this time more in D-I than in D-II, used the adverb /sisan/, 'now, immediately' Instead of the affix, to translate a sentence such as 'my father has become old'. One D-I speaker and one D-II speaker used both the adverb and the affix.

In the case of Dioule, then, one finds parallels to tendencles characteristic of pidgin languages, and to the acquisition of a first language by the child. The reduction of surface markers such as inflection, has also been noted in simplified registers (i.e. baby talk, foreigner talk) by Ferguson [1971]. The fact that these tendencies were found principally in the Dioula-as-second-language group (D-II) suggests that these tendencies may characterize language learning in general, whether first, second or pidgin ( $I$ am excluding here the acquisition of a foreign language in a classroom). The presence of these tendencies in telegraphic style, foreigner talk, etc. shows them to be part of the adult language potential as well. What evidence there was of these tendencies in the D-I group may be explained by the age of the speakers. As they were young adolescents, it is quite possible (though I do not have empirical evidence) that they had not completely learned their first language (Dioula) and that derivations are acquired late. These cases may then be considered under the category of a child's acquisition of his first language.

\section{RETLREICES}

Agheyisi, R. 1971. West African Pidgin English: Simplification and Simplicity. Stanford University. Ph.D. dissertation.

Benoist, J. 1968. Granma1re Gouro, Groupe Mandé-Cóte d'Iroire, Documents lo. 3, Afrique et Langage.

Delafosse, M. 1955. La Langue Mandingue et ses dialectes, $2^{e}$ Volume, Dictionnaire Mandingue-França1s, Librarie Orientaliste, Paris:

Paul Geuthner. 
Dumestre, G. 1970. Blénents de Grammaire Dioula. Doc. 11nguistique $X I I$, Institut de Linguistique Appliqué, Université d'Abidjan.

Ferguson, C. 1971. "Absence of copula and the notion of simplicity: a study of normal speech, baby talk, foreigner talk, and pidgins", in D. Hymes, Pidginization and Creolization of Language. Cambridge University. 141-150.

Houls, M. 1963. Etude Déscriptive de la langue Susu. Mémoires de I'IFAN \#67, Dakar.

Traugott, E. "Historical linguistics and its relation to studies of language acquisition and of pidgins and creoles", lecture given at Univeraity of California, Santa Cruz, August, 1972.

\section{APPENDIX: The Derivations}

The derivations were taken from Dumestre, Eléments de Grammaire Dioula, pp. 47-57. The English sentences are traublations of the Frencn sentences used to elicite the derivations.

1. Transitive verb derived from an intransitive verb:
(a) /musa wullla/
'Moussa got up'
(b) /musa ka tabali la-wuli/
'Moussa lifted the table'
(c) /musa bo $\mid \mathrm{la} /$
'Moussa went out'
(d) /musa ka a la-bo/
'Moussa made him go out'

2. Verbal reduplication:
(a) /a ka sogo tige-tige/
'He cut the meat into little pieces'
(b) /a ka a sen ko-ko/
'He washed his foot over and over'

3. Adjectival plus /-ya/, 'become':
(a) /wulu jugu-ya-ra/
'The dog has become mean'
(b) /mogo ca-ya-ra/
'The people have becone numerous'
(c) In face koro-ya-ra/
'My father has become old'

4. Nominel from an edjectivel plus /-man/:
(a) /a gba-na/
'It's hot'
(b) /gba-man-lo/
'It's the heat'

5. Augmentative:
(a) /bon-ba be yan/
'There is a big house over there'
(b) /a ka muru-ba san/
'He bought a big knife' 
6. Diminutive:
(a) /kono-nin do be sante/
'There's a little bird up there'
(b) /a ka wulu-nin san/
'He bought a puppy'

7. Region, origin:

(a) /ce nin ye bwake-ka ye/ 'Th1s man 18 from Souake'

8. Ordinal numbers:
(a) /saba-nan/
'third'

9. Nominal from a verbal (adj. -ya) plus $\emptyset$ :
(a) /a ka jugu/
'He is mean'
(b) /a jugu-ya-ra/
'He has become mean'
(c) / jugu-ya lo/
'It's meanness'
(d) /a ka kene/
'He's in good health'
(e) /a kene-ya-ra/
'He's gotten well'
(f) /kene-ya lo/
'It's health'

10. Nominal form an integrated verbel plus /-man/:
(a) /a ka tin/
'It's black'
(b) /fin-man lo/
'It's blackness'
(c) /a ka dl/
'It is sweet'
(d) /di-man lo/
'It's sweetness'

11. Nominal from a verbal plus $/-1 i /$ :
(a) /taga-11 ye fen gbeleman ye/
'Leaving is painful'
(b) /dumun-nI-kera kunu/
'The meal was yesterday'

12. Verbal plus /-ball/:
(a) /dugu nin mogoye malo-ball ye/
'The people of this village are shomeless'
(b) /sun don-ball/
'He who doesn't fast'

13. Hominal from a verbal plus $/-1$ en/:
(a) /sogo tige-len lo/
'It's cut neat'
(b) /mo-nin-men lo/
'It's souething cooked' 
14. Agent:
(a) /n face ye sene-ke-la ye/
'My father is a farner'
(b) /baara-ke-law be yan/ 'The workers are here'

15. Instrument:
(a) /a sigilen be sigi-lan kan/
'He is seated on the seat'
(b) /kulisija-lan/
'belt' 

Ha

\section{$+x+3$}

W

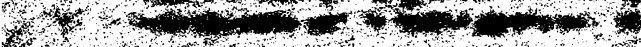

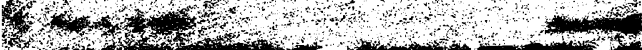

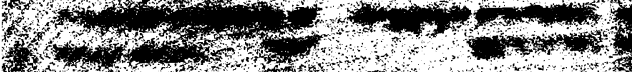

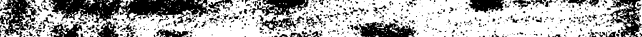

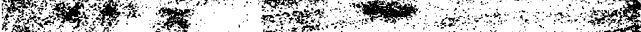

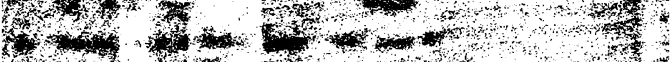

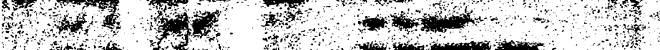

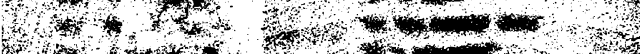

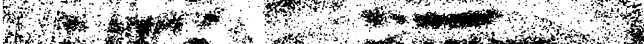

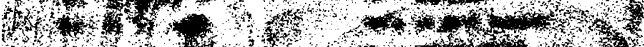

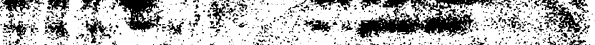

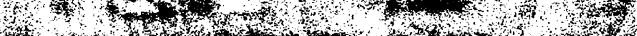

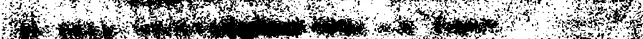

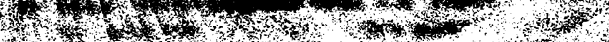

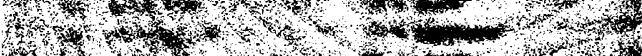

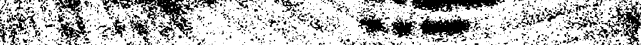

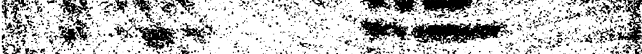

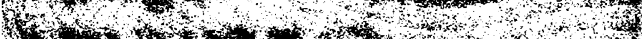

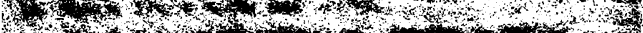

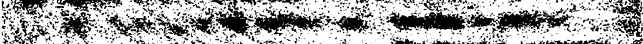

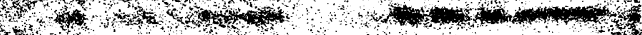

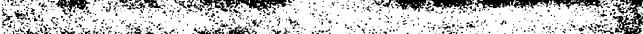

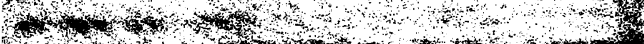

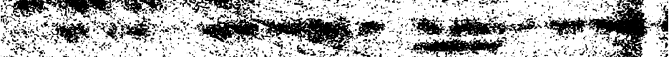

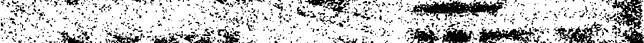

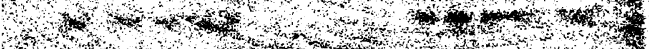

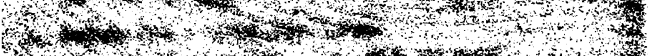

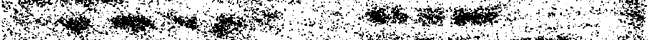

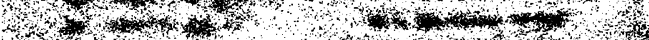

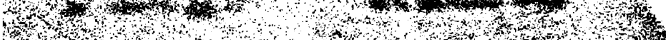

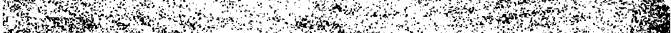

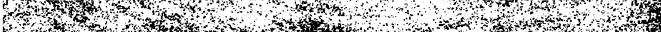


SYNTACTIC CHANGE IN LAKE-BANTU: A REJOINDER ${ }^{1}$

\author{
Talmy Givón \\ Department of Lingulatics \\ University of California, Los Angeles
}

1. Introduction

In the last issue of SAL Wald discussed a case of two converging syntactic changes in the lake area of Horth-East Bantu (Ganda, Hyankore, Luhya, Haya). The changes involve the complementary functional distribution of two morphemes in the gramar, the copula $\mathrm{ni}$ and the Pre-Prefix vowel (henceforth PP). Briefly stated, Wald suggests that in the LakeBantu area the copula $n l$ as a predicate marker represents a more recent innovation, while the use of the PP as an attributive (contrasting with predicative) marker is an older stage in the gramar of Lake-Bantu languages. In other words, Wald suggests that the contrast ATTRIBUTIVE/PREDICATIVE for adjectives, verbs, possessives or nouns, was initially marked by the prefix-morphology contrast VCV/CV, but was later replaced by the contrast $\mathrm{CV} / \mathrm{nl}-\mathrm{CV}$, respectively. In the course of his argument Weld makes a number of assumptions that, I believe, are open to questions. Some of those are not essential to the argument, and will not be discussed here in much detail. ${ }^{2}$ others, more germain to the argument, are:

${ }^{I}$ I am Indebted to Benji Wald, A.E. Meeussen, Frhard Voeltz and Martin Mould for helpful comments on an earlier version of the manuscript.

Wald also assumes that the $0-$ and $\theta-$ vowels in the PP in Luganda arise as a result of vowel-fusion with a preceding morpheme a-. This assumption has no shred of evidence to support it. The lowering of the initial vowels $u-/ 1$ - to $0-/ \theta-$ is currently in the middle of happening in KinyaRwanda. There are several ways one could view this process. First one may view it as a partially gremar-influenced dissimilation. One may also $v 1$ ew $1 t$ as a natural lowering rule in word-initial position. Finally, a suggestion for which I am indebted to Martin Mould, one may concede that the opirit of Wald's interpretation of this phenomenon was Indeed correct in the following way: Many words in the discourse preceding both object and subject nouns are verbs. And in Bantu in general many of those are 11kely to end with the neutral vowel -a. And as Weld [1973] points out, the fusion: $a+u>0$ and $a+1>0$ is a widespread rule in Bantu. Thus many PP's in Bantu tend to be pronounced, in rapid speech, as o-, e- due to this process. This may very well influence their form in isolation as well, or at the very least accelerate other natural processes. 
(a) That the copula $n i$ is an Innovation In the Eastern Bantu zones;

(b) That the PP was a pre-noun demonstrative in Proto-Bantu and later, (following de Blois [1970]), a definttizer.

In this paper I would like to show that there exist both factual and theoretical grounds for bellevelng that the replacement process described by Wald went on in exactly the opposite directionality. That is, the copula $n i$ is not an innovation in the Eastern Bantu zones but is rather reconstuctible to Proto-Bantu and most likely, in some form or other, also to Proto-Niger-Congo. And further, there exists an alternative--and perhaps more plausible--scenario for explaining the introduction of the PP into the morphology of noun modifiers, one which depicts this process as a natural outgrowth of the function of the PP in Proto-Bantu as a referentiality marker on nominals.

\section{The Copula ni in Bantu}

At the crux of Wald's argument lies the assumption that the copula $n i$ is an Bastern-Bantu innovation. This argument is supported by the fact that in languages west and north-west of the east Congo dividing line, i.e. languages chiefly of the Western and North-Western Bantu zones, the copula $\mathrm{nl}$ is not attested. Even disregarding the fact that Meeussen [1967] has reconstructed both $\mathrm{ni}$ and its negative counterpart $t]$ for for Proto-Bantu (as well as the inflected copulas $-1 i$ and -ba, to be discussed later on), I would like to suggest that the assumption of the loss of $\mathrm{nl}$ in the Western and North-Western zones is much more plausible than the assumption of 1 ts innovation in the Eastern zones. The argument for the $108 \mathrm{~s}$ hypothes1s rests first on a number of patterns observed in Bantu languages outside the North-Esst corner. It is further augented by a more careful re-examination of at leat one North-West Bantu language (Lamongo), and 1s further strengthened by considering related languages in N1ger-Congo. I will begin the discussion by citing the distributionsl pattern of $\mathrm{nl}$ in a number of languagea from Central, Fastern, Southern and North-Eestern Bantu. 
2.1. Bemba (Central Bantu). In this language in most predicate environments $\mathrm{ni}$ was deleted and replaced by a high-tone, long vowel cVV pref1x. Further (with names, pronouns and demonstratives standing as an exception), $\mathrm{ni}$ is used only before non-referential predicates, while -li (or -ba) are used for referential predicates. Thus:

(1) umu-ana ali umu-puupu 'The child is the thief' (ref.)

(2) umu-ana múu-puupu 'The child is ㅌ thief' (non-ref.)

(3) umu-ana ali umu-suma 'The child is the good one' (ref.)

(4) umu-ana múu-suma 'The child is good' (non-ref.)

For morphologically defective noun classes, i.e. $1 a / 2 a$ and $9 / 10$ in which the morphology makes it difficult to accomodate a vCV/Cŕv contrast, ni appears in non-referential predicates:

(5) umu-ana ali im-fumu 'The child is the chief' (ref.)

(6) umu-ana nii-m-fumu 'The child is a chief' (non-ref.)

(7) umu-ana ali kaleemba 'The child is the writer' (ref.)

(8) umu-ana ni-kaleemba 'The child is a writer' (non-ref.)

For pronouns, demonstratives and names, which naturally appear only as referential predicates, $n i$ is obligatory, but so is $-1 i$. This suggests to me that $n i$ here is a purely morphological-support device and had no significance in meaning. Thus:

(10) umu-ana ali ni-Mubanga 'The child is Mubanga'

(11) umu-ana all ni-iwe 'The child is you'

What is also of interest, for the eventual reconstruction of the semantics of $n I$ as against $-\mathrm{I} i$ and $-b a$, is that in past tenses (or future) - $\mathrm{i} /$ /-ba rather than $n \mathrm{l}$ are used-and the prefix of non-referential predicates is CV without the extra-high tone: 
(12) umu-ana $\delta$-d-11 umu-puupu 'The child was the thief' (ref.)

(13) umu-ana ó-ò-11 mu-puupu 'The child was a thief' (non-ref.)

(14) umu-ana of-d-11 umu-suma 'The child was the good one' (ref.)

(15) umu-ana á-d-11 mu-suma 'The child was good' (non-ref.)

The use of $\mathrm{nl}$ as 'morphological-support' for defective noun classes, pronouns, names and demonstratives has been extended to non-present tenses too--but there again it appears together w1th -11/-ba :

(16) umu-ana $a-d-11$ kaleemba 'The child was the writer (ref.)

(17) umu-ana $\mathfrak{a}-\mathfrak{d}-\underline{i}$ ni-kaleemba 'The child was a writer' (non-ref.)

(18) umu-ana $\delta-d-\underline{1 i}$ ni-uyu 'The child was this one'

(19) umu-ana á-à-li ni-iwe 'The child was you'

(20) umu-ana á-à-li ni-Mubanga 'The child was Mubenga'

Given the data above, one may reconstruct the senantics/syntax of $\mathrm{ni}$ in bemba as such:

(a) Third person (noun class) subjects

(b) Present-habitual tense

(c) Jon-referential (i.e. attributive) predicates

of these three, (a) and (b) are attested in Swahili (Eastern Bantu), Siluyana (Lunda-type Central Bantu) and KinyaRwanda (North-Eastern Bantu), where the use of $\mathrm{ni}$ is not reduced as in Benba. In all three languages, further, there is a tendency to dispense with $n i$ optionally. In two of ther, Siluyana and KinyaRwanda, locative predicates require $-1 i$ in the present tense, as is also the case in Benba:

(21) umu-ana a-11 ku-no 'The child is here'

(22) umu-ana ku-no

Finally, while these three languages do not have the referential/nonreferential contrast in predicates as does Benba, in all three $\mathrm{nl}$ may not appear when the subject is f1rst or second person. It thus seens that at the very least conditions (a) and (b) above governed the use of 
nl In Proto-Bantu, with the possible addition of (c). The copulas -11 and ba functioned in the predicate-copulative paradion in other env1roments, and where $\mathrm{ni}$ is lost they may invade 1 ts end of the paradigm and replace it.

What is also of 1nterest in van Spanndonck's [1971] auggestion that in Lube and perhaps in other Bantu languages, the loss of $\mathrm{nl}$ resulted In the absorption of 1ts high-tone on the CV prefix of the predicate noun.

Another area of great Interest, in Bembe 8 s well as in other languages where $n i$ has largely disappeared from simple copular-predicate sentences, is its survival in two apecial envirorments which are semantically and diachronically related to predicate-copular structures: Cleft sentences and WH-questions. In cleft sentences in Benbs one gets exactly the same distribution of $n i$ as in copular-predicate sentences:

(24) múu-puupu nda-mweene 'It's a thief that I saw' (non-ref.)

And $n l$ survives in non-referential nouns of the defective noun classes, as in:

(25) ni-uyu-kalulu ndd-mweene 'It's this hare that I saw' (ref.)
(26) ni-kalulu nad-mweene 'It's a hare that I saw' (non-ref.)

The semantic-syntactic relation between cleft sentences and wh-questions has been discussed extensively in the literature, and for recent Bantu references see Takizala [1972] and Heny [1971]. In Berba there are three WH-question patterns: cleft, pseudo-cleft and 'umarked order'. In the cleft pattern (as well as in the pseudo-cleft, which represents the 'regular copular-predicate' construction here), one finds oblifatory reflexes of ni. Thus:

\section{Subject:}

(27) n-ani dd-boombele 'Who (1s It who) worked?'

(28) ni-banl bdd-boombele 'Who (are they who) worked?' 
Accusative:

(29) n-anl wadd-mweene 'Who (was it that) you saw?'

(30) ni-banl wadd-mweene 'Who (were they that) you saw?'

Dative/prepositional:

(31) ni-kuli-ani wad-seendele icltabo 'It's from whom that you received the book?'

Locative:

(32) ni-kwi dà-ile 'It's where-to that he vent?'

Temporal:

(33) ni-lilali da-ishile 'It's when that he came?'

This pattern of survival of $\mathrm{nl}$ in Bemba is important for the following reason: Further below I will show that in other languages of the Eastern zones the copula $n \mathrm{l}$ is lost in the simple copular-predicate construction, but its reflexes are still attested in two grammatical environments: Cleft sentences and Wh-question words. One may thus consider these two environemtns as relic environments for the copula $n i$.

2.2. Nyanje (Esstern Bantu). My data from Nyanja are derived from Price [1966]. In this language one finds a number of areas where $\mathrm{ni}$ has survived (provided one accepts the survival hypothesis). To begin with, the reflex $n$ - rather than $n_{n l}$ is attested before consonsnts, conforming to the universal reduction of $n l$ morphemes in most bantu languages (e.g. in class $9 / 10$ and for the lst person singular pronoun). Further, one still finds $n$ - in Nyanja in a small number of predicate-adjectives, as in:

(34) ku-namo n-ko'lpa 'Lying 1s bad', 'Lying is of badness'

(35) cl-manga cl n-c'a-nga 'This maize is mine'

(36) ma-laya wa n-ga-c'abe 'Th1s garment 19 no good'

One further finds the survival of $n i / n-$ in non-cleft (or pseudo-cleft) Wh-quest1ons, as in: 


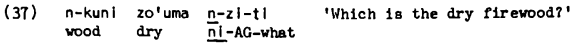

(38) mu-dzl wo $n-z \mid-t I$ 'Which 18 that village?' villege that $\frac{n !}{-A G-w h a t}$

(39) ml-nda ya-bwlro $n-j i-t l$ 'Which are the good gardens?' gardens of-goodness $\bar{n} \mid-A G-$ what

The more common copula in Nyanja is a fusion of $n i>n$ with $-1 i$, yielding the expected ndi, as in:

(40) ny-alugwe ndi ci-lombo c'a-ukat $i$

leopard is animal of-fierceness

'The leopard is a fierce animal'

(41) eenl ma-sitolo ndl Amwenye

owners stores are Baheis

'The store-keepers are Bahais'

(42) Dr. Livingstone ndi m-zungu wo'yamba kudza kuno

$\mathrm{Dr}$. Livingstone $\bar{i}_{8}$ white-man of-first to-come here

'Dr. Livingstone is the first white man to come here'

Much like in Bemba, Swahili and Siluyana, $n l$ is not used in Nyanja in the pest tense, but is replaced by -11 , as in:

(43) Cldyaonga a-na-11 mfumu ya-ki-kulu ya-Angoni

C1dyaonge AG-FAST-be chief of-bigness of-Ngont

'Cidyronga was the great chief of the Ngoni'

Next one sees $n I>n$ surviving in the use of the fused ndi in cleft sentences, as in:

(44) n-di-ne.... 'It's I (who)....'

$\begin{array}{lll}\text { (45) } \frac{n-d i-y e}{\text { be-he }} & \text { PRO-PAST-them-call }\end{array}$ 'It's he who called them'

One finds a simflar use of ndl in pseudo-clefts, as in:

(46) w-a-ku-clta $\mid c i$ si-n-dl-ne 'Whoever did this is not $I^{\prime}$ PRO-PAST-do this NEG-be-I

Finally, one finds reflexes of $n i>n$ in WH-question pronouns, whether or not in cleft constructions: 
(47) n-d(i)-anl mzungu yo 'Who is that European?' (cleft)

(48) n-na-|l-po n-d(1)-an| 'Who was here?' (pseudo-cleft)

(49) antu a-na-blsala bwa-n-jl 'Jlow did the people hide?'(preudo-cleft)

(50) cl-lombo cy-a-n-Jl cy-a-pha nkuku 'What animel killed the chicken?

(51) kodl mu-funa $n-d(I)$-ani 'Whom are you looking for?'(pseudo-cleft)

To sum up the situation in Nyanja, I think one could see how $-1 i$ has invaded the paradien and fused with $n i$ in simple copular constructions, cleft and pseudo-cleft. But a reflex of $n l$ survives in some adjectives and, in particular, in WH-interrogative pronouns.

2.3. SeSwati (Southern Bantu). My data on this language are derived from Ziervogel [1952]. One doesn't find $n i$ here at all in simple predicatecopular constructions. However, one finds its reflex $n-$ in cleft constructions, where it is augmented by (and thus preserves!) old reflexes of the PP as well as, perhaps, old reflexes of the secondary-concord of nasal-prefix noun classes. Thus:

(52) um-fati 'woman' n-gu-m-fati 'it's a woman'

(53) ema-kuba 'hoes' n-ge-na-kuba 'it's hoes'

(54) eba-fati 'wonen' n-ge-ba-fati '1t's women'

In most cleft constructions, the morphene $n$-gu has been generalized, as in:

(55) ngu-phans I 'It's below'

(56) ngu-kuphi 'Where is 1t?'

(57) ngu-loyl 'it's this one'(cl. 1)

(58) ngu-labo '1t's those ones'(cl. 2)

(59) ngu-|e|l 'it's this one'(cl. 5)

(60) ngu lo-wanti '1t's the broad one'(cl. 1)

(61) ngu la-bangekho '1t's the absent ones'(cl. 2)

(62) ngu le-|i-ngakhall '1t's the one wh1ch doesn't cry'(cl. 5) 
One also finds ngV in cleft-forms of pronouns, as in:

(63) ngl-mi '1t's I'

(64) ngu-we 'it's you'

(65) ngi-10 'it's it'(cl. 5)

(66) ngu-10 'it's 1t'(cl. 11)

(67) nga-bo 'it's them'(cl. 2)

(68) nga-wo 'It's then'(cl. 6)

One finds similar reflexes of $n i>n$ in various WH-interrogatives, as In:

(69) ngu-muphi umtfana 'Which boy?'

(70) ngu-mt fana muphi 'Which boy?'

(71) ngu-bani loyi 'Who is this one?'

(72) u-khuluma nga-ban! 'Who are you talking about?'

(73) Iu-swane Iu-nje nga-bani 'The child looks like who?'

(74) ngu-kuph I lapha a-khona 'Where is it that he is?'

(75) u-sebenta $n-J a n l$ 'How does he work?'

(76) u-ta-ku-ya $n i-n i$ 'When will you go? 3

(77) u-sebenta nga-ni 'Why does he work?'

Thus, 1 one accepts the identity of $n$ with *ni, then the survival of $n l$ in cleft and WH-1nterrogative patterns conforms well to what has been shown in Bembe and Nyanja.

2.4. The copula ni outside the East-Bantu zones.

2.4.1. Lomongo (North-Western). My data for this language are derived from Hulstaert [1966]. Lomongo 1s presumably one of the languages in the

3 This is perhaps a case of non-reduction of $n I>n$ due to a prohibition, in most Bantu languages, on 1dentical CC or Ni clusters. 
zones where the copula $\mathrm{nl}$ is not attested. However, here one finds the the reflex $n$ - of $n l$ in precisely the same environments as is to be expected from the discussion above. Thus in Wh-1nterrogatives, one finds:

(78) $\quad \underline{n-b}$

'What?', 'Which?'

(79) n-ko

'Where?'

(80) $\mid \boldsymbol{\varepsilon}-\underline{n}-k \delta$

'which ones?'

(81) bá-ñ-gá

'how nany?'

(82) èkéké ólé-n-kó 'what time?'

Simllarly, in cleft constructions one finds:

(83) $\hat{A}$-k-oninga 'it's only the friend'

(84) đ̆ki-m-osángáká ̣́k-endé 'who I said is already here' (pseudo-cleft)

(85) ole wóká nd-ónko 'the one who accused him is this one'(ps.-cleft)

One also finds a reflex of $n i>n$ in the comparative preposition 'be like', as in:

(86) bonóng'ésé n-gá bofaya 'The locals are l1ke the foreigners'

(87) elongi đ̌káó ñ-gá saányi 'His face is like a basin'

To sum up, then, while the data here represent only one lorth-Western language, it nevertheless shows that ni could not have been an Eastern-Bantu innovation.

2.4.2. Kihung'an (Western). For the data on this language I am indebted to Alexis Takizala (in private communication). While this language replaced "ni with an inflected copula on the paradigm of CV-e (with the CV- standing for the noun-class agreenent morpheme), two potential survivals of * $n i$ are found in WH-question pronouns. Thus the morphene for 'who' is na. The morpheme for 'what', which also figures in many other Wh-questions, $18 \mathrm{khi}$ synchronically. But one could argue that the aspiration is directly related to a lost $n$. To support this consider the following: 
(87a) verb stem

$$
\begin{array}{ll}
\text { ku-beet 'hit' } & \\
\text { ku-tal } & \text { 'look at' }
\end{array}
$$

with lst nergon Eingular (II-)

$$
\begin{aligned}
& \text { m-beet 'hit me' } \\
& \text { thal 'look at ne' }
\end{aligned}
$$

The form of PB mu-ntu 'person' in Kihung'an is muu-t, with the long vowel presumably arisine from the original presence of the now-lost $n$. The loss of $/ \mathrm{n} /$ before voiceless stops in bantu is a rather widespread process, and it is often coupled with the espiretion of those stops. The data in (87a) above stongly suggest that the aspiration in $k^{\text {h }} \mathbf{i}$ 'what' in Kihung'an is a result of the loss of an underlying $/ n /$.

2.4.3. Others. Heeussen (in private communication) has suggested to me that there exist tonological evidence, in the form of a 'ghost' high tone (or 'tonal raising') in predicate environments in a number of Western Eantu languages, such as Tsio, Kongo-litandu, Yaka, Suku and Mhale. This certainly corresponds to the tonal raising ouserved in Bemba (see section 2.1. above) in identical enviroments, as vell as to what van Spaandonck [1971] has suggested for CiLuba. Alexandre [1966] also notes the presence of $n(i)$ in Bulu.

To sum up, then, the contention that the copula ni was restricted to the Eastern zones of Bantu cannot be supported. Further below I will also show that comparative Bantoid and Niger-Congo evidence suggests that $n i$ goes back much further than Proto-Bantu.

2.5. Luganda and the Lake-Bantu area. It is certainly true that in Luganda one finds no use of $\mathrm{ni}$ in simple copular-predicate constructions. The more baffling fact about Luganda, however, is that it shows no traces of $n l$ or $n$ - in either cleft, pseudo-cleft or WH-interrofatives. This by Itself certainly requires an eventual explanation. However, the copula $\mathrm{nl}$ is attested marginally in llaya and more than marginally in RuNyankore. It $1 \mathrm{~s}$ fully productive (i.e. used in simple copular-predicate constructions) in Luhya (Martin Mould, in private conmunication). It is fully productive in much the same way in KinyaRwands, where it appears in 
clefts, pseudo-clefts and Wh-1nterrogatives, as in: 4

$$
\text { ni-nde wà-glye 'It's who who came?' (cleft) }
$$

(89) Inzu ni n-nIni 'The house is big'

(90) uwd-giye nl-nde 'The one who came 1s who?' (pseudo-cleft)

(91) nl-iki kyd-menetse 'What got spilled?' (cleft)

(92) ni-mu-gitondo yd-glye 'It's in the morning that he left' (cleft)

(93) ni-ku-išuli yd-giye 'It's to school that he went' (cleft)

(94) ni-he yà-giye 'Where did he go?' (cleft)

(95) ni gute yal-giye 'How did he go?' (cleft)

(96) umwaka ušize ni wo yd-je-mo 'Last yeer is when he came'

It seems that in the lake area only in Luganda, Lusoga and Lunyoro, which represent a close dialect cluster, the copula $\mathrm{ni}$ is not attested (for this observation I an indebted to Martin Mould, in private communication). 2.5. Summary. I have shown that in many languages where $\mathrm{ni}$ does not function in simple predicate constructions, its reflexes may nevertheless be found in cleft and WI constructions. One may argue that perhaps those constructions represent the locus of innovation, rather than the locus of survival as I have been claiming all along. It seems to me that there are strong reasons for suspecting that the pattern is indeed a relic/survival--rather than an innovative pattern:

(a) Both cleft and $\mathrm{WH}$-interrogative environments, which are diachronically as well as semantically related, are hiphly-marked special constructions. It is highly unlikely for a lanruage to introudce a copula there, rather than in the unmarked predicate constructions. In particular, cleft constructions are likely to be of lover frequency than simple predicate constructions, and thus an unlikely enviroment for innovation, but a typical relic environnent.

\footnotetext{
For the KinyaHwanda data in this paper I an much indebted to Charles Uwimena and Alexandre Kimeny 1.
} 
(b) Wh-1nterrogative pronouns usually fuse into oingle words. And this is precisely a situation where one finds relics of older syntex.

(c) In Bemba in simple predicates one finds $\mathrm{nl}$ only in morpholopicallyirregular noun classes, pronouns, demonstratives and names. This is again a typical relic environment rather than an innovation pattern.

(d) When one considers languages in which $\mathrm{nl}$ is at all attested, one comes up with an implicational pattern: All the languages that have $n i$ in simple predicates, also have it in cleft and cleft-Wh constructions, but not vice versa. That is:

$$
\text { [simple] } \supset \text { [cleft, WH] }
$$

This is a strong suggestion of a dependency. That is, while the existence of $n i$ in cleft and Wh can be predicted from its existence in simple predicates, the existence of $\mathrm{ni}$ in simple predicates cannot be predicted from its existence in cleft and Wh constructions.

It seems to me that the weight of the evidence, as well as the theoretical considerations presented above, militate much more strongly against the innovation hypothesis and for the survival hypothesis.

3. The Pre-prefix Vowel in Bantu

3.1. Reference and definiteness. While de Blois [1970] suggests that the PP was a definitizer in Proto-Bantu, I think there are grounds for believing that it was either a referentiality marker or both a referentiality marker and definitizer. These two semantic functions form a natural class, where [+ definite] is a discourse feature relevant mostly to nominals which have been marked already as [+ referential]. A situation of the VCV/CV contrast functioning only for referentiality (but not for defin1teness) may be seen in Bemba (for a detailed discussion see Givón [1972]), where in non-opaque enviroments, 1.e. in enviroments where nouns are obligatorily referential, one finds only vCV prefixes:

(97) umuana aa-somene lcl-tabo 'The child read a/the book' (ref.)

(98) *umuana aa-somene cl-tabo 
In non-negative enviroments one finds a VCV/CV contrast:

umuana aa-fwaaylle uku-soma $|c|-t a b o$ (ref.)

(a) 'The child wanted to read the book' (def.)

(b) 'The child wanted to read a book' (Indef.)

(100) umuana aa-fwaaylle uku-soma cl-tabo (non-ref,)

'The child wanted to read some book'

Finally, in negative opaque enviroments the [+ ref.,- def.] interpretation is ruled out, so that the referential (VCV) noun is automatically interpreted as definite. This particular 'change' is apparently a senantic universal (see the discussion of Dzamba, KinyaRwanda and Luganda below; see also Givón [1974 (forthcoming)]). Thus:

(101) umuana taa-somene lci-tabo (ref.)

(a) 'The child didn't read the book'

(b) 'The child didn't read an Indefinite book' ("indef.)

(102) umuana taa-somene cl-tabo (non-ref.)

'The child didn't read e/any book'

It is thus not unreasonable to assume that the identification of [+ referential] with [+ definite] in the scope of negation is perhaps responsible for the extension of the $\mathrm{VCV} / \mathrm{CV}$ contrast in Bantu from referentiality to definiteness. A situation of this extended type may be observed in Dzamba (see Bokamba [1971]), where in non-opeque envirorments --1.e. where a nominal is obligatorily referential--the VCV/CV contrast functions for definiteness, as in:

(103) oSaloml aenekl omu-ana 'Salome saw the ch1ld' (def.)

(104) oSalomi aoneki mu-ana 'Salone saw a child' (indef.)

In a negative opaque environment, where referential nouns universally must be definite, the VCV/CV contrest functions for referentiality, ss In:

(105) oSaloml teenekl omu-ana emba (ref., der.)

'Salome didn't see the child' 
(106) oSalomi teeneki mu-ana omba (non-rer.)

'Salome didn't see a/any child'

In non-negative opaque environments in Dzamba, the VCV/CV contrast still signals referentiality. However, while in Bemba it is the VCV (referential) prefix which is ambiguous between (referential) definite and inderinite, in Dzamba it is the CV prefix which is ambiguous between non-referential and referential-indefinite. Thus:

(107) oSalomi a-zingaki na-ene omu-ana (ref., def.)

'Selome wanted to see the child'

(108) oSalomi a-zIngaki na-ene mu-ana

(a) 'Salome wanted to see a child' (ref., indef.)

(b) 'Salome wanted to see some child' (non-ref.)

The extension of the REF/NON-REF distinction to DEF/INDEF thus seens to be a natural process.

In the Lake-Bantu area, specifically in Luganda and KinyaRwanda, one finds traces of the REF/NON-REF VCV/CV contrast at lesst in two environments. One of those is in objects of necated verbs, a situation comparable to the one discussed above for Bemba and Dzamba, For example, in KinyaRwanda ${ }^{4}$ the mornhological VCV/CV contrast is lost here, but the semantic contrast REF/NON-REF is intact. Thus, the VCV prefix is obligatorily interpreted as non-referential:

(109) nhi-ya-bonye umu-nhu 'He didn't see any man'

In order to obtain a referential (and thus automatically definite) Interpretation, the object NP must be pre-posed, i.e. it must undergo a topicfronting movement (and the obligatory pronominalization associated with 1t):

(110) umu-nhu nhl-ya-mu-bonye $\left\{\begin{array}{l}\text { 'He didn't see the man' } \\ \text { 'As to the man, he didn't see him' }\end{array}\right\}$

The semantic connection between definite, pronominal and topic need not be belabored here. It seems reasonable to assume that when the language lost the VCV/CV contrast in this environment, it capitalized on the 
universal redundancy rule:

(111) [+ referential] $\rightarrow$ [+ definite] / iNEG-verb [----] object and then also on the existing toplc-movement rule (which obviously applies only to definite objects), and thus maintained the contrast intact.

In Luganda (see Mould [1972]) the situation is virtually the same, except that the non-referential object noun, which remeins behind the negated verb, receives a CV prefix, while the pre-posed referential/definite noun receives the expected VCV prefix: ${ }^{5}$

(112) ya-gula eki-tabo 'You bought a/the book'

(113) ta-ya-gula kl-tabo 'He didn't buy any book' (non-ref.)

(114) eki-tabo, ta-ya-ki-gula $\left\{\begin{array}{l}\text { 'He didn't buy the book' } \\ \text { 'As to the book, he didn't buy it'' }\end{array}\right\}$

3.2. Feference and non-restrictive modifiers. There is another area of natural extension of the VCV/CV referentiality contrast in Bantu, and this area is particularly relevant for understanding how the vCV prefix, i.e. the PP, invaded the noun-modifiers paradipr and in due course becane a marker for attributives, as in Luganda.

In Bemba (for details see Givón [1972]), the VCV/CV contrast a]so functions to differentiate non-restrictive from restrictive embedded modifiers (relative clauses, adjectives, nouns, possessives). Thus, for exanple:

(215) abantu abà-à-ishile 'rine people, who (all) came,...' (IR)

(116) abantu bà-d-ishllo 'The people who cane...'(not those who didn't)(R)

(117) abantu aba-suma $\left\{\begin{array}{l}\text { 'The people, who were (all) good...' (IIR) } \\ \text { 'The people, the good ones,...' (NR) }\end{array}\right\}$

(118) abantu ba-sum 'The cood people...' (R)

5 For these data I andebted to various manuscripts of $L$. Walusimbi [1971]. 
(119) abaana aba-a-nul 'The children, those that are mine,...' (NR)

(120) abaana ba-a-ndi 'My children...' (R)

In Givón [1972] I argued that this is a natural semantic extension of the REF/iNON-REF contrast. Briefly, one notes that only referential nouns, quite universally, may be nodified by non-restrictive modifiers. Thus:

(121) nshla-mweene aba-ana bd-à-lshile (R)

'I didn't see the children who came'

(122) nshia-mweene aba-ana abd̀-d-ishile (NR)

'I didn't see the children, who (all) came'

(123) nshia-mweene ba-ana bd-d-ishile (R)

'I didn't see any children who came'

(124) *nshia-mweene ba-ana abd-d-ishile ("NR)

* 'I didn't see any children, who (all) came'

Thus, since the deleted equi-noun within the non-restrictive ('parenthetic') relative clause must have been referential, it is predictable in Beruba-where an anaphoric pronoun must show the same vcV/CV type prefix as Its co-referent deleted noun--that a VCV prefix will mark the IR modifier. This is provided that one accepts the assumption that ansphora is indeed involved in NR relative clauses. That is, that the underlying structure of a sentence such as (122) above is scmething like:

(125) 'I didn't see the children, (I mean) those children who came'

'I didn't see the children, those who came'

'I didn't see the children, who came'

For the regular assumption of the deleted noun's prefix by an anaphoric pronoun in Bemba, consider the following:

(126) nshia-mweene aba-ana ba-suma

'I didn't see the good children'

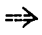

nshla-mweene aba-suma

'I didn't see the good ones' 
(127) nshla-mweene ba-ana ba-suma

'I didn't see any good children'

nsh la-mweene ba-suma

'I didn't see any good ones'

(128) nshi-mweene aba-ana bd-d-ishlle 'I didn't see the children who came'

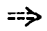

nshia-mweene abà-à-ishile

'I didn't see the ones who came'

(129) nshia-mweene ba-ana ba-d-ishlle 'I didn't see any children who came'

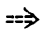

nshia-mweene bda-d-ishile

'I didn't see any (ones) who came'

In the Lake-Bantu area it is of interest to note that at least in a number of languages the VCV/CV contrast functions here much the same way as it does in Bemba, 1.e. to differentiate between $i R / R$ modifiers, respectively. Thus, in a number of KinyaRwanda dialects, ${ }^{4}$ one finds this contrast to be quite regular (tho the optionality with some morphenes nay suggest that it is still spreading):

(130) abaana bat-ryamye ubu 'The children who're now asleep'(R)

(131) abaana abd-ryamye ubu 'The children, who are (all) now asleep'(IR)

The pattern has been partially extended to object relatives (where it does not exist in Bemba):

(132) umusozl (wo) du-tuye-ho 'The village where we live' ( $R$ )

(133) umusozl uwo du-tuye-ho 'The village, where we live' (NR)

Similarly, with adjectives:

(134) abagabo bof-n|n| 'The big men' (R)

(135) abagabo abf-n|n| 'The men, who are (all) big' (IVR)

According to Martin Mould (in private communication), a situation similar 
to KinyaRvands and Bemba is observed in a number of other Lake-Bantu languages.

In Luganda 1tself, where as Vald [1973] has shown the vCV/CV contrast distinguishes attributives (modifiers) from predicatives, non-restrictive modifiers are not embedded, but are rather post-posed to the end of the sentence. Thus, in object relative clauses one finds: ${ }^{5}$

omu-wala gwe njagala ye atalil-wo (R)

'The girl that I like is not here'

(137) omu-gala ye atalii-wo gwo njagala (IJR)

'The girl is not here, the one I like'

Then, for adjectives, similarly:

(138) omusajja omu-rungi a-genze 'The good man left' (R)

(139) omosajja a-genze omu-rungi 'The man left, the good one' (IIR)

Finally, for subject relative clauses, one finds:

(140) abasajja aba-a-genda ba-rungi (R)

'The men who left are good'

(141) abasajja ba-rungi aba-a-genda (INR)

'The men are good, the ones who left'

T'o sum up, then, it seems that in the Lake-Bantu area the sane natural extension of the VCV/CV morphology from signalling the RiF/NON-RET distinction to signaliing the NR/R distinction, as seen in Hemba, is well attested. One may further suggest that Luganda (and its close cluster of Lufoga, LuToro, Lullyoro) probably had that extension at some earlier date, and this can explain how the VCV prefix invaded the noun-modification paradigm. Finally, when Luganda stopped embedding NR modifiers and started post-posing then, there was no more need for a VCV/CV contrast in the attributive position, and the VCV prefix became generalized--especlally that these languages had also lost the copula $\mathrm{nl}$. The CV form of the prefix thus remained the form for the predicative. 
4. Discusaion

Following the data presented in the preceding sections, one could now propose an alternative scenario to the syntactic development in the LakeBantu area and re-interpret the Luganda oftuation as such:

(a) Luganda has the VCV/CV contrast for referentlality, a contrast which probably goes back to Proto-Bantu;

(b) Like Bemba, Rwanda and Luhya, Luganda also extended that contrast to mark the NR/R contrast for embedded modiflers;

(c) At a certain point, for reasons yet to be clarifled, Luganda lost the copula ni ; 6

(d) The loss of $\mathrm{ni}$ created a situation whereby $\mathrm{cV}$ prefixes marked both predicatives and attributives (modifiers);

(e) Since the enbedding of IR modifiers 18 much less universal, being that they are parenthetic statenents and are senantically conjoined rather than subordinated, ${ }^{7}$ it was relatively eesy for Lugande to move NR modifiers out of the noun phrase altogether and post-pose them--together with their original vCV prefix;

(f) As a result of this movement, the VCV prefix was not needed any more to mark IR modifiers, which were now marked by their post-posed syntactic position;

(g) The VCV prefix was freed to be used for all attributives (embedded noun modifiers), contrasting them with the CV prefix or predicatives.

Two other points should be also mentioned here. The first concerns ressons for the $108 \mathrm{~s}$ of $\mathrm{ni}$ in many Bantu languages. In general all over the Bantu area $\mathrm{nl}$ segments (1.e. clsss $9 / 10$ prefix, first person singular pronoun and the copula $\mathrm{nl}$ ) tend to get assimilated and reduced before consonents--first to $n$ and then, in many languages (this is particularly

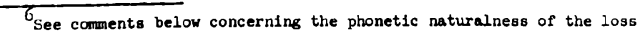
of $n \mathrm{l}$ segents in Bantu.

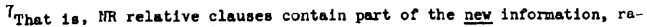
ther than old (presupposed) Infornation.
} 
true for class $9 / 10$ prefixes), on to complete zero. The reflex $n$ - tends to lose 1ts articulatory position, tends to get devoiced before volceless consonants, tends to fuse with the following volced consonant (Meinhoff's law) or with the following volceless consonant (cf. S1luyana). In other words, the loss of $n$--once it became $a$ bound morpheme--1s a highly predictable outcome of natural assimilation rules in Bentu.

The second point involves the following conslderations: There are strong grounds for believeing that cognates of $\mathrm{ni}$ exist in other BenueKwa and Niger-Congo languages. Thus, for example, in Yoruba the morpheme $\mathrm{nl}$ is used both as a locative copula and as a focus-cleft morpheme, as the following data from Stahlke [1974] attest:

(142) Qmiq nâ ni ibi ajá kpa adlę adię nI ajá kpa ajá nI $6 \mathrm{kpa}$ adię
'The child 18 here'

'The dog killed the chicken' 'It's the chicken that the dog killed' 'It's the dog that killed the chicken'

As Lord [1973] has recently shown, there is a natural development in Benue-Kwa by which a copulative verb meaning 'be at' or 'be with' becomes elther a locative preposition/post-position or a comitative/associative/ instrumentel one. With this in mind, one finds an instrumental $n i$ preposition in Yatye [Stehlke 1970]; $n i$ 'be at' or 'at' in Yoruba [Lord 1973]: ní 'be at' in Igbo [Lord 1973]; na 'at', 'in', 'on' in Igbo [Lord 1973]. One finds nin 'with' in Bambars (Mande); ne 'with' in Mooré [Peterson 1971](Gur); ni 'with' in Sup'ide [Welmers 1950](Gur); nl 'be at' in Wara [Prost 1968](Gur); ne as an instrumental post-position in Kru [Givón 1974b](Kwa); one also finds a copulative/predicative morpheme $n-$ in Tiv [Abraham 1940](Bantoid). Now, the universal relat1onship between locat1ve and existential (be-pred) expressions has also been noted by Clark [1970] and Lyons [1967]. It 1s thus reasonably safe to assume that the Bantu existential copula nl is a natural semantic extension of the locative copula/verb $n l$ 'be at', 'be with' in NigerCongo. Th1s makes Wald's contention that $\mathrm{nl}$ ls an innovation of EasternBantu all the less plausible.

For the data I am indebted to Karen Courtensy and Ibrahima Coulibaly. 
REFERENCES

Abraham, R.C. 1940. The Principles of Tiv. London: Crown Agents.

Alexandre, P. 1966. "Syateme verbal at predicat1f du Bulu", Langugge日 et Litteratures de l'Afrigue Noire I, Paris.

Bokamba, G. 1971. "Specificity and definiteness in Dzamba", Studies in African Linquistics 2.3:217-238.

Clark, E.v. 1970. "Locationals: A study of the relation between 'existential', 'locative' and 'possessive' constructions", Stanford Working Papers on Language Universals \#3.

de Blo1s, K. 1970. "The augment in the Bantu language", Africana Linguistica IV, Tervuren: Musée Royal de l'Afrique Centrale.

Givón, T. 1972. Studies in ChiBembe and Bantu Grammar, Studies in African Linguistics, supplement \#3.

Givón, T. 1974, forthcoming. "The presuppositions of negation".

G1vón, T. 1974b. "Serlal verbs and syntactic change: Niger-Congo", to appear in C. Li (ed.), Proceedings of Conference on Vord-order and Word-order Change, Santa Barbara, January 26-28, Amsterdam: Reidel.

Heny, F. 1971. "Focus and interrrogatives in Bali", paper read to the 2nd Conference on African Linguistics, UCLA (Us.).

Hulstaert, G. 1966. Grammaire du Lomongo, 3ien Prt, Syntaxe, Tervuren: Musée Royal de I'Afrique Centrale, serie IN-8, \#58.

Lord, C. 1973. "Serial verbs in transition", Studies in African Linguistics 4.3:269-96.

Lyons, J. 1967. "A note on possessive, existential and locative sentences", Foundations of Ianguage 3:390-396.

Meeussen, A.E. 1967. "Bantu gramatical reconstructions", Africana Linguistica III, Tervuren: Musée Royal de I'Afrique Centrale.

Mould, M.J. 1971. "The syntax and semantics of the initial vowel in Luganda", in E. Voeltz (ed.), Proceedings of the 3 rd Conference on African Linguistics, Bloomington: Indiana University Press.

Peterson, T. 1971. Mooré structure: A generative analysis of the tonal structure and aspects of the syntax, Ph.D. dissertation, UCLA.

Price, T. 1966. The Elements of Hyanja. Blantyre, Malawi.

Prost, R.P.A. 1968. Deux langues Voltalques en vole de disparition: Le Wara et le Natioro, Université de Dakar, Documents Linguistiques.

Stahlke, H. 1970. "Serial verbs", Studies in African Linguistics 1.1: 60-99.

Stahlke, H. 1974. "Ross' constraints and related problems in Yoruba", Studies in African Lingulatics vol. 5 (to appear). 
Takizala, A. 1972. "Focus and relativization: The case of K1hung'an", Studies in Africen Linguistics 3.2:259-287.

van Spaandonck, M. 1971. "On the so-called reversing tonal system of Chiluba: a case for re-structuring", Studies in African Linguistics 2.2:131-144.

Wald, B. 1973. "Syntactic change in the lake area of Northeast Bantu", Studies in Africen Linguistics 4.3:237-268.

Welmers, W. 1950. "Notes on two languages of the Senufo group", Language 26.4:495-531.

Walusimbi, L. 1971. A number of unpublished manuscripts on Luganda grammar, UCLA.

Ziervogel, D. 1952. The Grammar of Swaz1. Johannesburg: Witwatersrand University Press. 



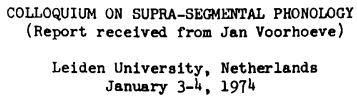

\section{Progrem:}

F. Heny (Dept. of Linguistics, University of Massachusetts, Amherst)

"Ganda tone as pitch-accent"

A. E. Meeussen (Musée Royal de l'Afrique Centrale, Tervuren, Belgium)

"Notes on tone in Gands"

W. Leben (Committee on Linguistics, Stanford University, Stanford, Calfornie)

"Introduction to suprasegmentel phonology"

J. Voorhoeve (Dept. of African Languages, Leiden University, Leiden, Netherlands)

"Tone in Mende"

A. E. Meeussen (Musée Royal de l'Afrique Centrale, Tervuren, Belgium)

"Tone in Tiv"

J. L. Donewx (C.L.A.D., University of Dakar, Dakar, Sénégal)

"Contreproposition pour le Tiv"

J. Voorhoeve (Dept, of African Languages, Leiden University, Lelden, Netherlands)

"Note on unspecifled vowels in Bamileke"

T. Schadeberg (Dept. of African Languages, Leiden Univergity, Leiden, Netherlands)

"Supresegmental h1story"

"On the segmental reality of flosting tones in Eve" 


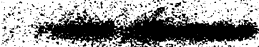
How

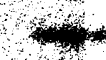

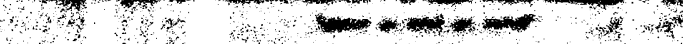

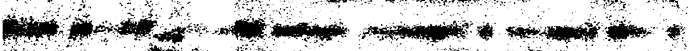

An

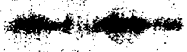

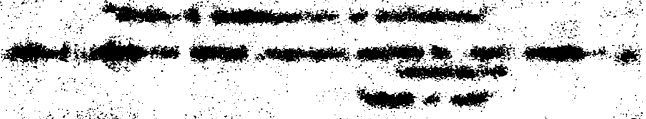

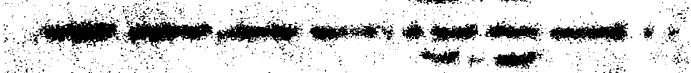

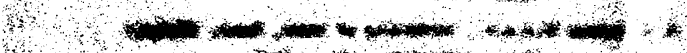

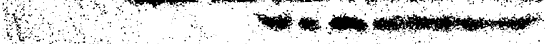

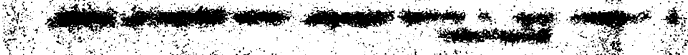

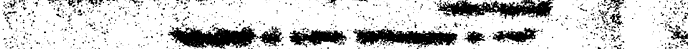
17 .

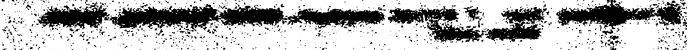
(1) 
FIFTH ANNUAL CONFERENCE

ON AFRICAN LINGUISTICS

Stanford University

March 29-31, 1974

Fridsy, March 29

Symposium on Linguistics and Africen Languages:

Contributions of Mutual Interest.

1. Joseph H. GREENBERG, "Language as culture history: the Bantu example"

Discussant: A. E. MEEUSSEN

2. Eric Ofoe APRONTI, "Sociolinguistics and the question of a national language: the case in Ghana"

3. Paul SCHACHTER, "A non-transformational account of serial verbs".

Discussant: Herbert STAHIKE

4. Peter LADEFOGED, "Contributions of African linguistics to phonetic theory"

5. Larry M. HMAN, "Contributions of African linguistics to phonological theory"

Discussant: Chin-W. KMM

Seturday, March 30

\section{Syntax}

1. Isaac GEORGE (U. of Ibadan), "Verb serialization in Nupe:

lexicalization and higher predicates"

2. Whn Bryson EULENBERG (Michigan State U.), "Towards a general copula theory"

3. Carol LORD (UCLA), "On causatives in some Kwa languages"

4. Erhard F. K. VOKUlZ (Indiena U.), "Inalienable possession in Sotho"

5. David 0. OKE (U. of Ife), "Syntactic correlates of notionally defined adverbial phrase types in Yoruba" 
6. Frank R. BRANDON (U. of Texas, Aust1n), "Structure of the finite verb in Swahili"

7. Talmy GIVóN and Alexander KIMENYI (UCLA), "Truth, bellef and doubt in KinysRwands"

\section{Phonology}

1. Peter GINGISS (U. of Houston), "Phonological process in Worodugukan"

2. Paul AOKI (U. of Washington), "An observation of vowel contraction in Xhose"

3. Robert K. HERBERT (Ohio State U.), "Seven will get you five: Luganda vowels"

4. Karen H. HUERT, "Partial vowel harmony in Kera"

5. Jilali SAIB (UCLA), "Schwa insertion in Berber and the problem of multiple application of phonological rules"

6. George N. CLEMENTS (MIT), "Vowel harmony in Ewe"

7. Martin MOULD (UCLA), "On the origin of consonant gemination in Lugganda"

8. Thomas HINNEBUSCH (UCLA), "Restructuring and Natural Generative phonolopy in Kamba"

Sunday, March 31

Language Relatedness and Contact Phenomena

1. Harold C. FLEMING (Boston U.), "Omotic as a branch of Afroasiatic"

2. Clifford HILL (Columbia U.), "Variability of reference in relational terms in West African languages"

3. Gayle PAITTHALIN (Southern Illinois U.), "A preliminary report on a sociolinguistic project for educational evaluation in Ivory Coast"

4. Philip A. S. SEDLAK (Stanford U.), "Generational language shift and linguistic diversity measures: a Kenye case"

5. Anthony LEWIS (UCLA), "Possible African linguistic survivals in the Palenquero Creole dialect"

6. Charles DE BOSE (Stanford U.), "Papiamento plurals" 
7. Colgton R. WESTBROOK (Contra Costa College), "D1sguised tonal retentions in Afro-American speech"

\section{Syntax}

1. Patrick R. BENHETT (U. of W1sconsin), "Focus, temporal 'downstep' and embedding in Kikuyu"

2. Olusola AJOLORE (U. of Lagos), "Learning Yoruba focus sentences"

3. Eyambe G. BOKAMA (Indiana U.), "A counterexample to Bech's "Quest Ions"."

4. El-Rashid ABU BAKR (U. Of Khartoum), "Syntactic emphasis in the spoken Arabic of the Sudan"

5. Claude HAGECE (U. de Poitiers), "The 'adjective' in some Central African languages"

6. Alexis TAKIZALA (UC San Diego), "On the similarity between nominal adjectives and possessive forms in Kihungan"

7. Sahnny JOHNSON (Indiana U.), "The Bambara postpositional system" Tonology

1. Laura F. MEYERS (UCLA), "Tone patterns in Hausa"

2. Carl R. LAVELLE (UCLA), "An experimental study of Yoruba tones"

3. Jean M. HOMBERT (UC Berkeley), "Universels of downdrift: their phonetic basis and significance for a theory of tone"

4. Maurice TADADJEU (Georgetown U.), "Floating tones, spreading, and downstep in Dschang-Bamileke"

5. Ian MADDIESON (UCLA), "A new cause of tone splitting: evidence from Yorube"

6. David DWYER (Michigan State U.), "Loma: a language with inverted tones"

7. Ivan R. DIHOFF (U. of Wisconsin), "The tonal intricacies of the verbal in Chori"

8. Cheryl AUSTEN (Indians U.), "Anatomy of the tonal syatem of a Bantu language" 
Business meeting, Sunday, March 31

The business meeting of the Fifth Annual Conference on African Linguistics was held on Sunday, March 31. The following resolutions were adopted:

1. The proceedings of future annual conferences on African Linguistics will be published by Studies in African Linguistics. The host institution will be responsible for selecting the papers for the conference, editing the proceedings and presenting SAL with a camera-ready copy. The editor(s) will receive full credit for editing the proceedings. 2. The Sixth Annual Conference on African Linguiatics will be held in the Spring of 1975 at Ohio State University, Columbus, Oh1o. Members of the Department of Linguistics of OSU will be responsible for orgenizing the conference. For inquiries please write: Robert Herbert, Department, Ohio State University, Columbus, Ohio.

3. The participants in the Fifth Annual Conference expressed their thanks to Will Leben and the Stanford Committee on Linguistics for organizing a beautiful conference. 